Rodrigo Afonso de Moraes

\title{
Análise das Estratégias Competitivas e do Desempenho na Indústria de Streaming Audiovisual
}

Dissertação de Mestrado

Dissertação apresentada como requisito parcial para obtenção do grau de Mestre pelo Programa de Pós-graduação de Empresas do Departamento de Administração da PUC-Rio.

Orientador: Prof. Fábio de Oliveira Paula 
Rodrigo Afonso de Moraes

\section{Análise das Estratégias Competitivas e do Desempenho na Indústria de Streaming Audiovisual}

Dissertação apresentada como requisito parcial para obtenção do grau de Mestre pelo Programa de Pós-graduação em Administração de Empresas da PUC-Rio. Aprovada pela Comissão Examinadora abaixo.

Prof. Fábio de Oliveira

Orientador

Departamento de Administração - PUC-Rio

Prof. Jorge Ferreira da Silva Departamento de Administração - PUC-Rio

Prof. Angilberto Freitas

Universidade do Grande Rio 
Todos os direitos reservados. É proibida a reprodução total ou parcial do trabalho sem autorização da universidade, do autor e do orientador.

\section{Rodrigo Afonso de Moraes}

Graduou-se em Engenharia de Produção pela Universidade Federal do Estado do Rio de Janeiro em 2019 e em Direito pela PUC-Rio em 2017.

Ficha Catalográfica

Moraes, Rodrigo Afonso de

Análise das estratégias competitivas e do desempenho na indústria de streaming audiovisual / Rodrigo Afonso de Moraes ; orientador: Fábio de Oliveira Paula. - 2021.

103 f. ; $30 \mathrm{~cm}$

Dissertação (mestrado)-Pontifícia Universidade Católica do Rio de Janeiro, Departamento de Administração, 2021.

Inclui bibliografia

1. Administração - Teses. 2. Streaming. 3. Streaming audiovisual. 4. Audiovisual. 5. Estratégia. 6. Grupos estratégicos. I. Paula, Fábio de Oliveira. II. Pontifícia Universidade Católica do Rio de Janeiro. Departamento de Administração. III. Título.

CDD: 658 


\section{Agradecimentos}

À minha família, em especial meu pai, George Eduardo de Moraes, minha mãe, Elza Afonso de Moraes e minha irmã, Rafaela Afonso de Moraes, pelo carinho e apoio incondicional.

Ao meu orientador, Fábio de Oliveira Paula, pelo auxílio, atenção e colaborações, imprescindíveis para a conclusão dessa pesquisa.

Ao Gabriel Barradas, pelas contribuições, sugestões e correções.

Aos meus colegas de trabalho, pela compreensão e apoio.

A todos que direta ou indiretamente fizeram arte da minha formação, minha gratidão.

O presente trabalho foi realizado com apoio da Coordenação de Aperfeiçoamento de Pessoal de Nível Superior - Brasil (CAPES) - Código de Financiamento 001. 


\section{Resumo}

de Moraes, Rodrigo Afonso; Paula, Fábio de Oliveira. Análise das Estratégias Competitivas e do Desempenho na Indústria de Streaming Audiovisual. Rio de Janeiro, 2021. 103p. Dissertação de Mestrado Departamento de Administração, Pontifícia Universidade Católica do Rio de Janeiro

No decorrer das últimas duas décadas, o mercado audiovisual sofreu uma mudança disruptiva em relação ao consumo, distribuição, e, até mesmo, produção do conteúdo. Com o advento do streaming, os clientes podem assistir seus filmes e séries de onde e quando quiserem, sem a limitação das grades de programação tão características da TV Aberta e TV Paga, ou de horários definidos pelas salas de cinema. O surgimento dessa tecnologia gerou uma onda de adoção por empresas da Indústria audiovisual, marcada pelo pioneirismo da Netflix e posterior entrada de incumbentes de outros setores audiovisuais. Diante desse movimento recente, capaz de destruir outros setores, como o do vídeo doméstico, faz-se relevante seu estudo. O presente trabalho tem por objetivo analisar quantitativamente e classificar 37 plataformas de streaming audiovisual com base na tipologia de Porter (1980) e identificar as estratégias competitivas dos grupos que apresentam melhor desempenho, no âmbito global. Para isso, foram revisados na literatura conceitos que tratam de grupos estratégicos, tipologia genérica de Porter e outros autores, avaliação de desempenho e estratégia competitiva. Os dados que tornam o presente trabalho possível são oriundos de demonstrativos de resultados das empresas, sites de pesquisa de mercado, periódicos especializados em audiovisual e os próprios sites das empresas. Com a base de dados consolidada e organizada, foram aplicados testes estatísticos como z score, Kolmogorov-Smirnov, Shapiro-Wilk, k-means cluster, Wilcoxon, MANOVA, ANOVA, entre outros. Como resultado, 14\% das plataformas estudadas foram alocadas no grupo estratégico Diferenciação, 30\% em Liderança em Custo, 19\% em Enfoque em Diferenciação, 8\% em Enfoque em Custo e 30\% no grupo sem posicionamento ou Stuck In the Middle.

\section{Palavras-chave}

Streaming; streaming audiovisual; audiovisual; estratégia; grupos estratégicos. 


\section{Abstract}

de Moraes, Rodrigo Afonso; Paula, Fábio de Oliveira (Advisor). Analysis of Competitive Strategy and Firm Performance in the Aduovisual Streaming Industry. Rio de Janeiro, 2021. 103p. Dissertação de Mestrado - Departamento de Administração, Pontifícia Universidade Católica do Rio de Janeiro

Over the last two decades, the audio-visual industry experienced a disruptive change in the consumption, distribution and production of content. The arrival of streaming technology, that distributes content through internet, without the need of a file download, created the flexibily of content consuption. Clients now can watch their movies and series without the limitation imposed by the very characteristic schedule of Pay TV and Open TV, or the fixed movies sessions of cinema theaters. This thecnology generated a wave of addoption by audio-visual Industry companies, first by Netflix, the pioneer on this choice, followed by incumbent companies from other audio-visual markets, such as Free TV and Pay TV. Facing this recent industry moviment, capable of distroing other sectors, such as the Home Video, this study becomes relevant. The present work has as an objetive to analyse and classify 37 streaming platforms, in a quantitative manner, using Porter's (1980) typology as a theorical framework, and to identify which strategic group shows the best strategic performance, globally. For doing so, literature concepts on strategic groups, strategic typologies, performance analysis and competitive strategy were reviewed. The data that makes the present work possible were colected from the companies financial results, market research websites, speciallized periodics and from their own websites. Once with the organized data base, statistics tests were used such as z score, Kolmogorov-Smirnov, Shapiro-Wilk, k-means cluster, Wilcoxon, MANOVA, ANOVA, between others. As a result, 14\% of the studied platforms were alocated in Differentiation strategic group, 30\% on Cost Leadership, $19 \%$ on Focus Differentiation, $8 \%$ on Focus Low Cost and 30\% on Stuck In The Middle.

\section{Keywords}

Streaming; audiovisual; strategy; strategy groups. 


\section{Sumário}

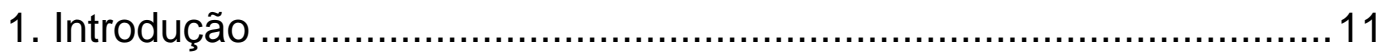

1.1. Objetivos da Pesquisa .............................................................

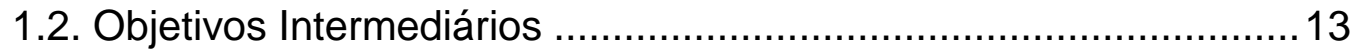

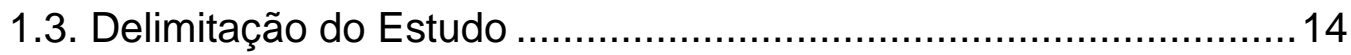

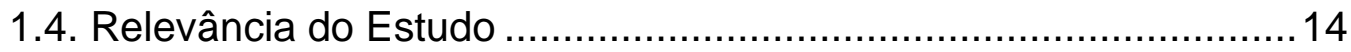

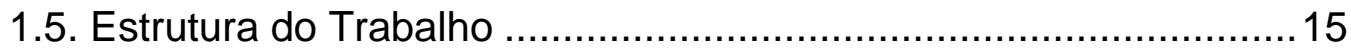

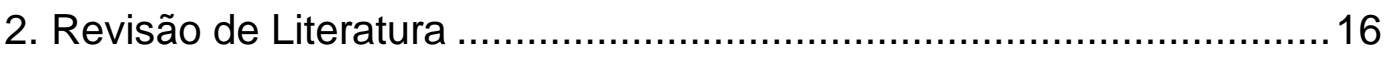

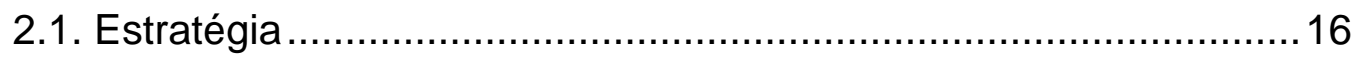

2.2. Vantagem Competitiva ........................................................... 18

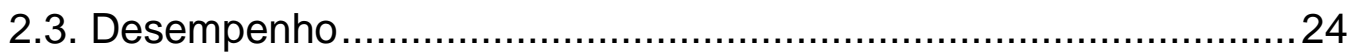

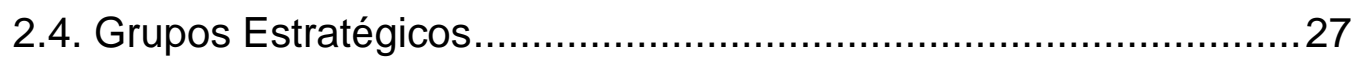

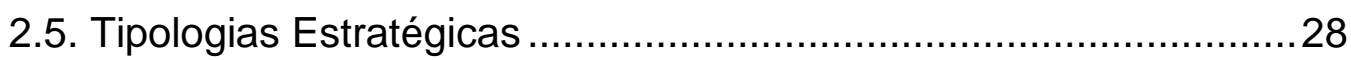

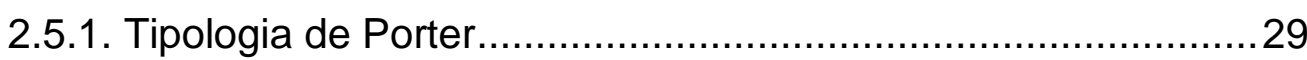

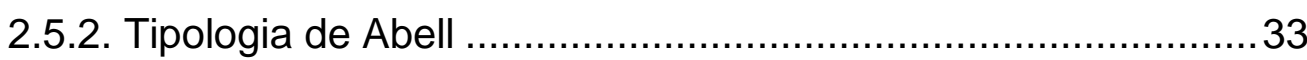

2.5.3. Contribuições de Chrisman à Tipologia de Abell ......................35

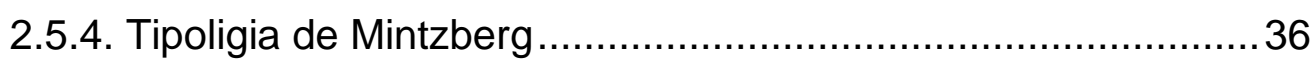

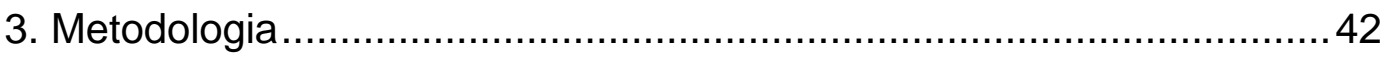

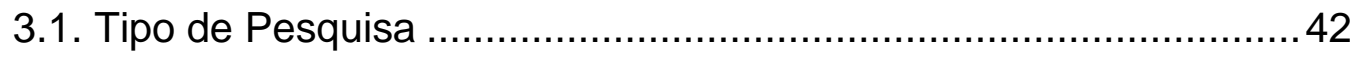

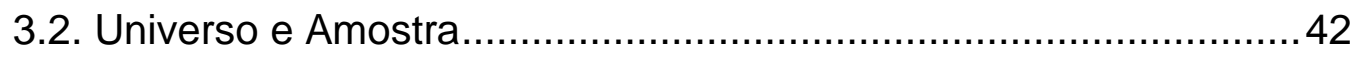

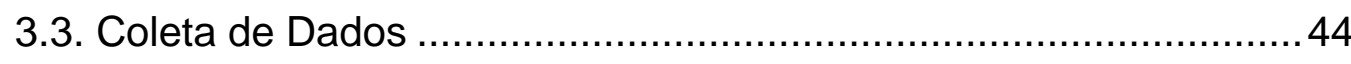

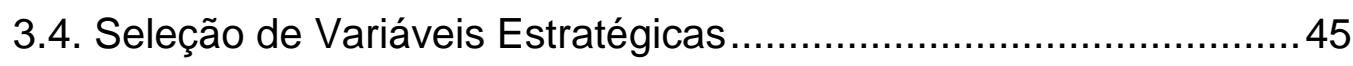

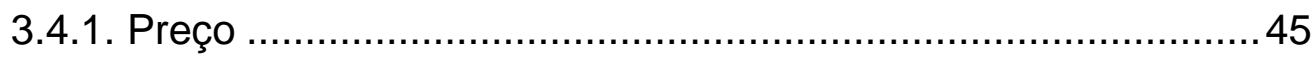

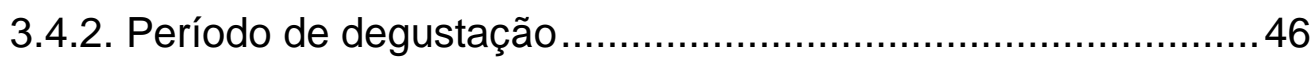

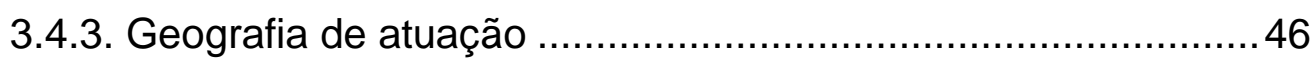

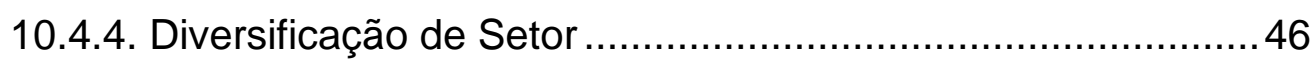

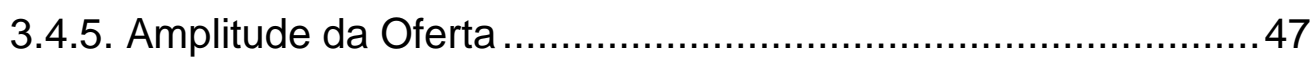

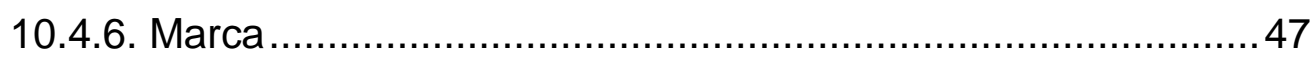

3.4.7. Diversificação de Modelo de Negócios .....................................48

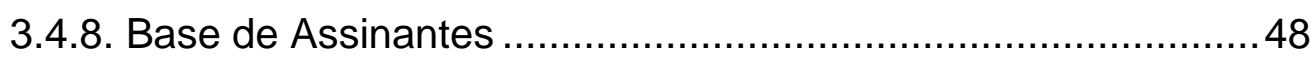

3.5. Seleção de Variáveis de Desempenho .........................................49 
3.5.1. Crescimento da Base de Assinantes ........................................49

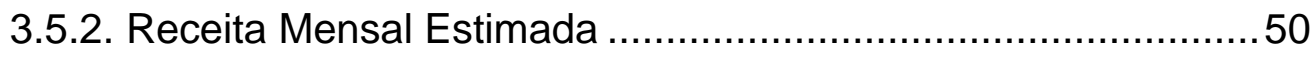

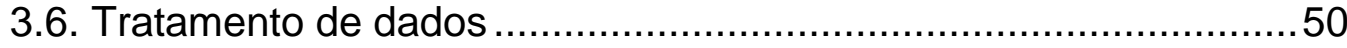

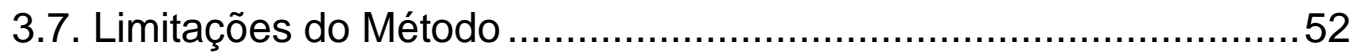

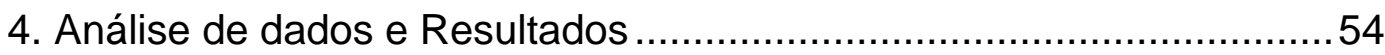

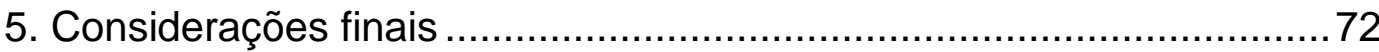

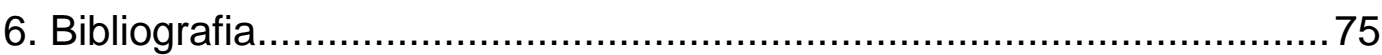

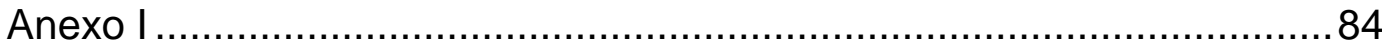

Anexo II - Histogramas de distribuição de frequência por variável ...........89

Anexo III - Normal Q-Q Plot por variável ............................................99 


\section{Lista de Figuras}

Figura 1 - Número de nomeações ao Oscar por Estúdio .........................12

Figura 2 - Dinâmica de tipos estratégicos ...............................................18

Figura 3 - Framework de Porter ....................................................... 30

Figura 4- Framework de Abell ............................................................ 34

Figura 5 - Framework de Chrisman, Hofer e Boulton (1988)....................36

Figura 6 - Plataforma por Cluster .................................................... 63

Figura 7 - Means Plot Receita Estimada ………….......................... 70

Figura 8 - Means Plot Crescimento ................................................... 71 


\section{Lista de Tabelas}

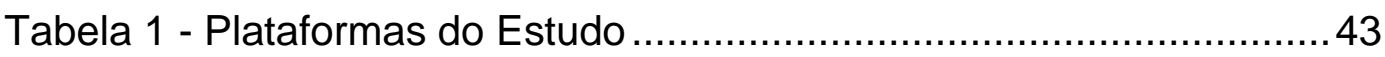

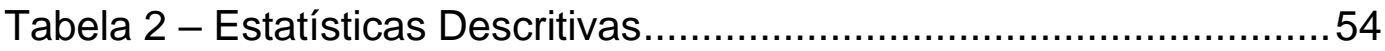

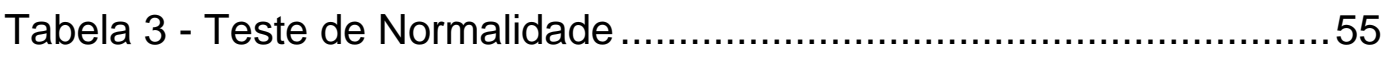

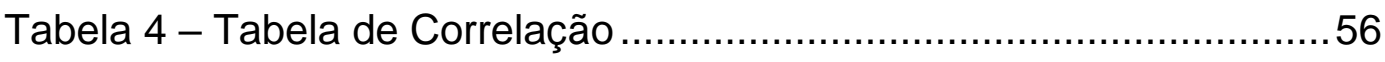

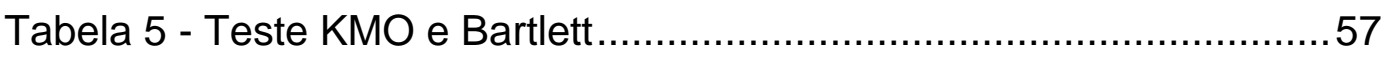

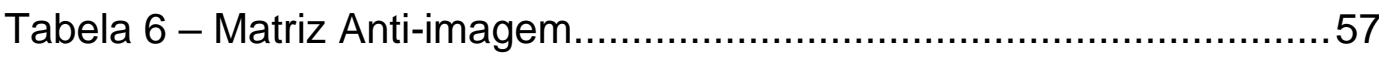

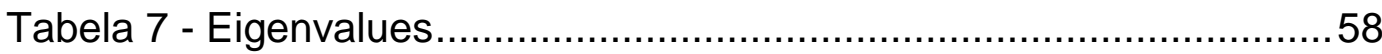

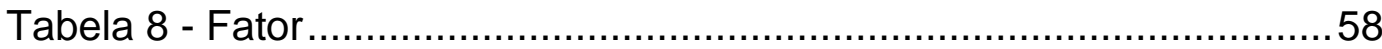

Tabela 9 - Matriz de Centroides Teórica ……………........................59

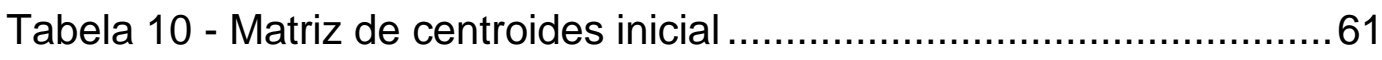

Tabela 11 - Interações de clusterização ...............................................62

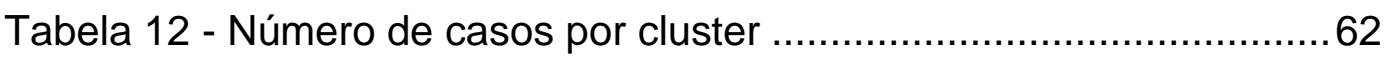

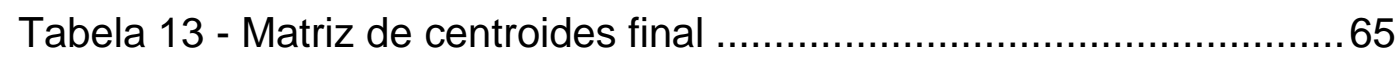

Tabela 14 - Teste não paramétrico de Wilcoxon ......................................65

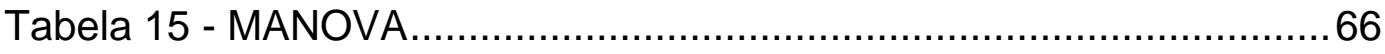

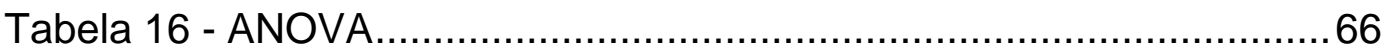

Tabela 17 - ANOVA (Tamhane e Bonferroni) ........................................67 


\section{Introdução}

Há 125 anos os Irmãos Lumière exibiam no Salão Grand Café, em Paris, o que ficou conhecido como a primeira exibição cinematográfica da história. $\mathrm{O}$ audiovisual, desde então, vem sendo grande fonte de entretenimento e forma de expressão artística importante para a humanidade. Daquela época até os dias atuais, muitas foram as mudanças que ocorreram na cadeia produtiva. Hoje, as mudanças não cessaram, e a indústria audiovisual vem sofrendo uma mudança paradigmática, tanto na distribuição, quanto no consumo.

Das exibições em cinemas, aos drive-ins, passando ao vídeo doméstico, e cinema a bordo de aeronaves, hoje a tecnologia de distribuição por streaming permite o consumo em qualquer lugar que se tenha conexão com a internet, iniciando uma nova era na forma de se exibir e consumir o audiovisual.

A indústria do streaming audiovisual cresce em importância de forma acelerada, enquanto outros meios de distribuição audiovisual perdem popularidade, como o cinema, o home vídeo e a TV Paga (HOLZHAUER, 2020). Durante a pandemia do COVID-19, essa mudança se acelerou. Com cinemas fechados e regras de isolamento social, o streaming se mostrou uma grande força no entretenimento doméstico. Muitas empresas, novas e incumbentes do audiovisual, iniciaram suas plataformas de distribuição de vídeo pela internet no período recente, o que ficou conhecido como streaming war (SHAW, 2020). Em conferência realizada nos Estados Unidos, executivos de plataformas americanas mencionaram a existência de mais de 300 plataformas em 2019 (BLOOM, 2019). Isso demonstra uma incrível popularização do meio de distribuição.

Ainda sobre o ganho de relevância do setor, é observado um crescimento recente muito acelerado não só no número de plataformas disponíveis, mas também no consumo do conteúdo audiovisual por esse novo meio de distribuição. Crescimento este também catalisado pelas quarentenas em combate ao Coronavírus. Um estudo da Conviva, uma plataforma de monitoramento do mercado de streaming, indica um crescimento de $20 \%$ na audiência desses serviços apenas em março de 2020 (FIORE, 2020), e de 63\% em relação a 2019 (TREVIZANI, 2020), desde o início da pandemia. Com a população em casa, a 
busca pelo entretenimento doméstico foi intensa e as plataformas de streaming serviram a esse propósito perfeitamente. O Globoplay, por exemplo, observou um crescimento de $145 \%$ em sua base de assinantes durante o primeiro semestre de 2020 em comparação ao mesmo período de 2019, impulsionado pela pandemia (VELOSO e TONDO, 2020).

O aumento de importância da distribuição por streaming não se limita apenas aos números de usuários, horas consumidas e plataformas novas. $\mathrm{O}$ conteúdo disponibilizado pela internet também é atualmente reconhecido como de qualidade. Já em 2019, o Netflix foi premiado no festival de Cannes com dois de seus conteúdos (NETFLIX, 2019) e o número de nomeações ao Oscar vem crescendo de forma acelerada, como pode ser visto no gráfico da Figura 1. Além disso, até a tradicional janela de exibição, na qual os grandes lançamentos de filmes eram exibidos em estreias em cinemas lotados, está sofrendo com a mudança. O filme inédito da Mulan, por exemplo, produzido pela Disney, fez sua estreia exclusivamente na plataforma digital Disney+, fato certamente catalisado pelas medidas restritivas ao contágio da pandemia, mas que demonstra uma tendência improvável há um ano (SOLSMAN, 2020).

Figura 1 - Número de nomeações ao Oscar por Estúdio

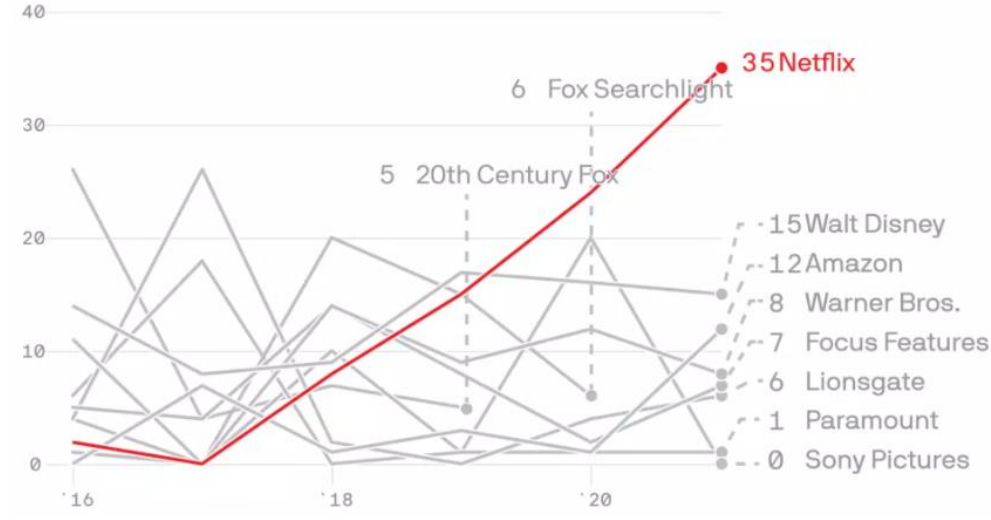

Fonte: AMER, 2021

Os números de faturamento e projeções para o crescimento do mercado de Streaming traduzem esse grande aumento de popularidade e relevância. Segundo o relatório produzido pela Cision, o mercado de streaming chegará a um valor de 149,34 bilhões de dólares em 2026, quando em 2018 o mercado era avaliado em apenas 38,56 bilhões (CISION, 2020), um aumento de $287 \%$. 
Alguns autores já preveem outras mudanças ocasionadas pelo avanço do streaming, em outros quesitos, como o próprio conteúdo em si. Gabriel Barradas (2020) prevê uma alteração na produção do conteúdo, a começar pela forma (duração dos episódios, por exemplo), para depois iniciar uma nova era de um gênero audiovisual particular do streaming, caracterizado por um tênue arco narrativo que conecta os episódios, que não perdem todo o sentido quando vistos individualmente ou fora de ordem. É o que o autor chama de Era Vibranium da TV.

Neste novo ambiente, possibilitado por essa tecnologia, no qual as barreiras de entrada à distribuição ficam reduzidas, e, portanto, altamente competitivo, a definição de um posicionamento estratégico se torna fundamental para o bom desempenho das empresas. A implementação de estratégias competitivas vantajosas, em um cenário globalizado e competitivo como este, se torna cada vez mais relevante para que empresas conquistem desempenho superior sustentável (BARNEY, 1991).

\subsection{Objetivos da Pesquisa}

Este trabalho tem a intenção de estudar a indústria de streaming audiovisual, no âmbito global, identificando as diferentes estratégias utilizadas por meio de variáveis estratégicas selecionadas, verificar como essas estratégias impactam o desempenho das empresas que as adotam e identificar estratégias bem-sucedidas que promovem vantagem competitiva.

\subsection{Objetivos Intermediários}

Os objetivos intermediários que guiarão os estudos e ajudarão a compreender e responder as questões levantadas são:

1 - Identificar quais variáveis estratégicas e de desempenho são relevantes para a análise da indústria do streaming audiovisual.

2 - Identificar a utilização de tipologias teóricas ou de tipologias adhoc para a definição de grupos estratégicos. 
3 - Identificar, de acordo com a tipologia escolhida, as estratégias adotadas pelas empresas do setor;

4 - Analisar o desempenho dos grupos estratégicos constatados, identificando quais trazem vantagem e desvantagem competitiva, ajudando a elucidar as melhores razões do sucesso na indústria.

\subsection{Delimitação do Estudo}

A coleta de dados influenciou na delimitação e escolha das empresas que fazem parte do presente trabalho. Como muitas das variáveis estratégicas são informações sensíveis, normalmente não compartilhadas ao público pelas empresas, foram incluídas nesta pesquisa apenas aquelas que divulgaram seus dados abertamente ou tiveram suas variáveis estimadas por periódicos especializados. Estão de fora da análise, portanto, empresas que não têm dados disponíveis ou estimados, mesmo que de relativa relevância.

Outra delimitação é o setor de streaming analisado. O presente trabalho aborda apenas o streaming audiovisual, deixando de fora outros modelos, como o fonográfico e o textual. Como o âmbito do estudo é global, não há delimitação geográfica na escolha das empresas que participaram do estudo.

\subsection{Relevância do Estudo}

No ambiente de competição acirrada, marcado pelo aumento de plataformas, horas consumidas, e usuários ativos, o estudo da indústria de streaming se faz relevante. A definição das mais relevantes variáveis estratégicas ou a melhor estratégia a se adotar é uma importante informação para aquelas empresas que buscam vantagem competitiva nesta indústria. Em um setor de crescimento acelerado, as estratégias podem mudar de maneira dinâmica. No entanto, atualmente não há estudos deste tipo, com o intuito de identificar as estratégias do setor e quais têm o potencial de apresentar maior desempenho. 
O estudo pode também trazer insights e ideias para outros setores similares, como outros tipos de streaming (o fonográfico e textual), ou com delimitações geográficas, como o mercado norte americano ou brasileiro.

Do ponto de vista acadêmico, o presente trabalho utiliza tipologias teóricas consolidadas e testadas em muitos setores em uma nova indústria em crescimento. É uma contribuição relevante testar a adequação de tais modelos tradicionais em um setor emergente, altamente relacionado com a transformação digital e a indústria 4.0 .

\subsection{Estrutura do Trabalho}

O presente trabalho divide-se, a partir deste ponto, em referencial teórico, onde serão expostas as teorias e definições centrais necessárias ao desenvolvimento do tema; exploração das diferentes tipologias estratégicas teóricas encontradas na literatura e escolha de uma delas para o desenvolvimento do presente trabalho; contextualização do mercado de streaming; metodologia, onde será abordado a técnica estatística utilizada; análise dos resultados; e conclusão. 


\section{Revisão de Literatura}

O objetivo deste capítulo é apresentar os principais conceitos que fundamentam o presente trabalho, expondo as definições centrais necessárias para o desenvolvimento do tema.

\subsection{Estratégia}

Do grego, Strategia, que significa a "arte do general" e Strategus, "o general superior", a estratégia se origina no âmbito militar (LIDDELL e SCOTT, 1940). Não é uma ciência exata, com respostas prontas e certas. A ideia central é analisar o ambiente, os concorrentes, e a si mesmo, de forma a identificar os desafios, fraquezas, forças, oportunidades e ameaças, aproveitando aquilo o que for positivo e superando o que for negativo. Como resultado de uma boa estratégia, atinge-se desempenho superior e vantagem competitiva em relação aos concorrentes (PORTER, 1980, 1985).

É um conceito fundamental para qualquer negócio, e, por este motivo, abordado por muitos acadêmicos. Von Newman \& Mongenstern (1994) dão uma definição ampla de que estratégia consiste em um plano completo que define as escolhas que o jogador irá optar em todas as situações possíveis. Dessa definição extrai-se a amplitude e grande aplicabilidade do conceito, não só aos negócios, mas também ao esporte, por exemplo.

Andrews (1980) define estratégia de forma menos abrangente como sendo o padrão de decisões de uma empresa que determina e revela seus objetivos e propósitos, produz as principais políticas e planos para atingimentos desses objetivos, define a amplitude de negócios que a empresa persegue, o tipo de organização econômica ou humana que a empresa é ou deseja ser, e, por fim, a natureza da contribuição econômica ou não econômica que presta a seus acionistas, colaboradores, clientes e comunidades.

Mintzberg (1987) também contribui para a definição de estratégia. Segundo esse autor, a estratégia é o somatório das decisões tomadas por uma organização em todos os aspectos, do comercial ao estrutural. $\mathrm{O}$ autor adiciona o fator de 
aprendizagem ao conceito, ao defender que a estratégia evolui com o processo de aprendizagem dos gestores.

A estratégia é sempre anterior à ação e desenvolvida conscientemente e com um propósito. Neste sentido, Michael (1973) percebe a estratégia como uma tarefa de apreciar um ambiente complexo de mudanças ambientais e de tomar decisões fundamentais em situações de grandes transformações. Nessa interpretação, a estratégia se relaciona muito mais com lidar construtivamente com o desafio das mudanças ambientais do que com oponentes e corrobora com a ideia de que a estratégia precede a ação.

Barney e Herterly (2006) define estratégia como a teoria que guia à vantagem competitiva - criação de um valor econômico superior ao da concorrência. Valor econômico, por sua vez, é a diferença entre os benefícios percebidos pelo consumidor do bem ou serviço e o custo econômico total destes bens ou serviços. Deste modo, a vantagem competitiva de uma empresa é maior na medida da diferença entre o valor econômico que cria e o valor econômico de seus concorrentes.

Mitzberg (1987) consolida as definições de estratégia em 5 conceitos observados em firmas, os chamados 5 P's: plano (plan), padrão (pattern), posição (position), perspectiva (perspective) e estratagema (ploy). A estratégia como plano é tida como um curso de ações conscientemente intencionais para se lidar com uma situação. Estratégia como padrão é tida como consistência no comportamento, intencional ou não. Tida como estratagema, a estratégia seria uma forma de manobra que despista o oponente. Como posicionamento, a estratégia é tida em seu contexto ambiental, isto é, localizar uma organização em seu ambiente, em uma visão externa à empresa. Como perspectiva, por outro lado, tem-se a visão interna à empresa, como uma maneira de se enxergar e perceber o mundo.

A maioria das empresas entendem primeiramente a estratégia como um plano que a firma define para atingir seus objetivos. $\mathrm{O}$ desenho, no entanto, não se adequa perfeitamente à realidade, pois o inesperado pode acontecer, afastando-as do plano inicial. Mesmo assim, por ter traçado um plano inicial, a empresa não perde coerência na sua tomada de decisão e consegue manter uma determinada 
direção em seus atos. Neste sentido, a estratégia é entendida como um padrão a ser seguido no comportamento da empresa.

Desta forma, pode-se identificar duas estratégias paralelas: uma relacionada à teoria, a estratégia pretendida, e outra relacionada à incerteza da prática, estratégia realizada. Essa última é composta por estratégias pretendidas que não divergiram em seu plano de ação, nomeadas de estratégias deliberadas, e de estratégias que sofrem mudanças pelo aprendizado e alterações ambientais não anteriormente previstas, as estratégias emergentes (MITZBERG; AHKSTRAND; LAMPEL, 2009). A dinâmica desses tipos estratégicos é organizada na Figura 2:

Figura 2 - Dinâmica de tipos estratégicos

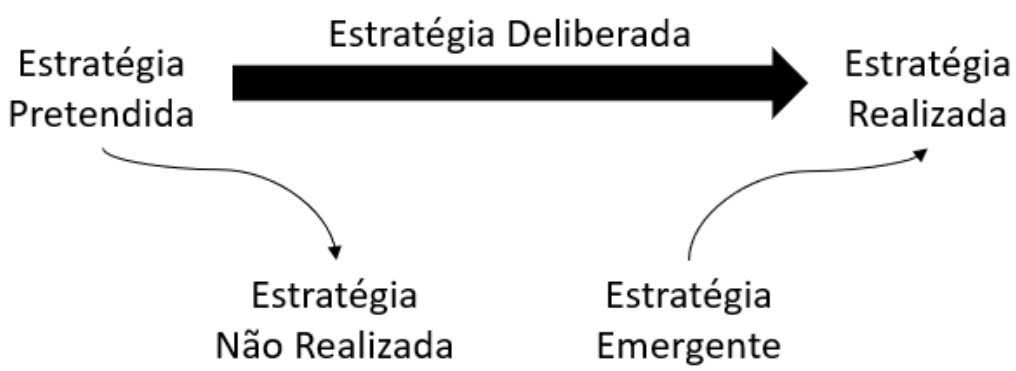

Fonte: Elaborado pelo Autor, adaptada de Mitzberg, Ahkstrand e Lampel (2009)

Outra perspectiva proposta para estudar o processo de formação estratégica é o da posição, relativa à localização geográfica da empresa em relação aos seus produtos e mercados (MINTZBERG, 1987). Veremos que o aspecto geográfico é um dos pontos analisados no presente trabalho e muito relevante no mercado do streaming, marcado por grandes empresas internacionais, mesmo com a presença de importantes players locais e regionais.

\subsection{Vantagem Competitiva}

De acordo com Barney (1991), a vantagem competitiva é a adoção de uma estratégia que agregue valor, de forma que a concorrência não escolha o mesmo caminho estratégico, de forma a obter desempenho superior. A competitividade estratégica, segundo Porter (1980), é conquistar a diferenciação e sustentá-la por 
um período longo. Barney (1991) entende isto como sendo a definição de vantagem competitiva sustentável.

O Modelo VRIO (BARNEY, 1991), neste sentido, é uma metodologia baseada na análise dos recursos internos das empresas que visa potencializar sua vantagem competitiva e torná-la sustentável. Segundo este modelo, o recurso se torna competitivo quando assume quatro características: valor, raridade, imitabilidade e organização.

Quanto ao valor, analisa-se o recurso em sua habilidade de explorar uma oportunidade ou mitigar uma ameaça do mercado. Quanto à raridade, observa-se o fornecimento limitado do recurso ao longo do tempo. Quanto à imitabilidade, a pergunta a ser respondida é se empresas sem o recurso enfrentam uma desvantagem de custo para obtê-lo ou desenvolvê-lo comparado às empresas que já o possuem. Por fim, quando a empresa possui recursos identificados como de valor, raros e de difícil imitação, o próximo passo é organizar a empresa de forma que possa explorar esses recursos. Isso pode se dar de diversas formas, como modelos de compensação dos funcionários e executivos, estrutura organizacional e sistemas de gestão. A capacidade dinâmica, outro conceito, desenvolvido por Teece (2014), que ajuda a compreender o comportamento agitado do mercado de streaming, é a capacidade de uma organização de criar, expandir, ou modificar sua base de recursos. Podem adotar diferentes formas, como entrar em negócios novos, expandir negócios por meio de crescimento interno, aquisições, alianças estratégicas, criação de novos produtos, processos produtivos ou na gestão de uma mudança lucrativa e de crescimento.

O conceito envolve a capacidade de identificar a necessidade e a oportunidade de mudança, formular uma resposta à necessidade e à oportunidade, e implementar um caminho de ações. Nesse sentido, diferentes capacidades dinâmicas atendem esses diferentes propósitos.

O conceito se relaciona com a habilidade de identificar oportunidades estratégicas em um ambiente em mudança, o que pode significar uma potencial fonte contínua de vantagem competitiva. Nesse sentido, capacidades de processos de informação ganham particular importância. 
Prahalad e Hamel (1990) desenvolvem, ainda neste sentido, o conceito de core competencies (competências centrais, em tradução livre). Pode ser definido como a combinação harmônica de múltiplos recursos e habilidades que distinguem a empresa em seu mercado atuante, e, como consequência, são fonte de sua competitividade.

As core competencies preenchem três critérios: 1) proveem acesso potencial a uma grande variedade de mercados; 2) deve ter papel relevante na percepção dos benefícios do produto ou serviço pelo consumidor e; 3) deve ser difícil de imitar pelos competidores. Um exemplo relacionado ao mercado de streaming e cinema é o know-how de produzir conteúdo de qualidade, estrutura pronta e onerosa, tecnologias de produção desenvolvidas internamente (como cenários e áudio), entre outros diferenciais.

Outro modelo que auxilia o estudo da vantagem competitiva é o da matriz SWOT, desenvolvida a partir dos trabalhos de Albert Humphrey (FRIESNER, 2008). Segundo esse modelo, a vantagem competitiva se dá por meio de escolhas estratégicas que proporcionam melhor adequação às forças, fraquezas, oportunidades e ameaças. Isto é, aspectos internos à empresa - forças e fraquezas e aspectos externos, ambientais, que envolvem a firma - oportunidades e ameaças.

Em relação às ameaças e oportunidades, dois modelos nos auxiliam a entender essas forças externas à companhia: o modelo de 5 forças de Porter e o modelo de análise macro-ambiental (PESTEL).

Porter (1980) defende que a indústria influencia o desempenho das empresas que a compõe. Diante dessa premissa, se torna relevante analisar as forças que a indústria imprime nas empresas e como estas reagem e são afetadas por elas.

As forças determinam o potencial lucro da indústria. Analisando-as, podese, em princípio, estimar o potencial de uma determinada indústria sem necessariamente analisar as empresas que a compõe individualmente. Diferentes indústrias, nesse sentido, apresentam diferentes potenciais, na medida em que as forças atuam de formas distintas e peculiares a cada uma delas. 
Porter (1980) define cinco forças que impactam o desempenho de uma indústria: ameaça de entrada, rivalidade entre concorrentes, ameaça de produtos substitutos, poder de barganha dos fornecedores e poder de barganha dos clientes.

Ameaça de entrada. Novos entrantes representam uma ameaça às empresas incumbentes. Além de trazerem novas habilidades e capacidades, disputam o mercado consumidor, aumentando e acirrando a concorrência. Uma das consequências do aumento da oferta no setor pode significar uma redução de preços, reduzindo, portanto, a rentabilidade da indústria (PORTER, 1980).

Barreiras de entrada definem a intensidade dessa força. A introdução de uma empresa em uma indústria pode requerer muito capital, concessões, patentes ou escala, por exemplo, o que pode impossibilitar este movimento.

Rivalidade entre concorrentes. Essa força mede a intensidade da resposta de empresas já existentes da indústria. Em indústrias de grande rivalidade, os movimentos de empresas concorrentes, como retaliações e respostas, geram impactos relevantes nas demais empresas do setor. Essa pressão gerada pelas demais empresas da indústria impacta o lucro econômico das empresas que a constituem. Sendo assim, quanto mais acirrada for a rivalidade, mais forte será essa força, e maior será o impacto sobre o lucro econômico das empresas. Eventos como corte frequente de preços, introdução recorrente de novos produtos e acirradas campanhas publicitárias são característicos de Indústrias de concorrência acirrada (BARNEY, 2006).

Ameaça de produtos substitutos. Produtos ou serviços substitutos são aqueles oferecidos por empresas concorrentes que atendem as mesmas necessidades dos clientes, nas mesmas proporções, que os oferecidos pela empresa do produto ou serviço original.

Essa força imprime um teto, segundo (PORTER, 1980) que as empresas de uma determinada Indústria podem cobrar sem fazer com que seus clientes migrem para produtos ou serviços substitutos.

Poder de barganha dos fornecedores. Barney (2006) define o papel dos fornecedores como aqueles que disponibilizam às empresas mão-de-obra, matériaprima e produtos e serviços necessários para a produção. Fornecedores têm o 
potencial de pressionar o desempenho de determinada Indústria ao aumentar seus preços ou reduzir a qualidade dos insumos que disponibiliza. Caso as empresas não tenham a capacidade de repassar esses maiores custos aos seus clientes, sua margem fica pressionada e seu desempenho pior.

Eventos como poucos fornecedores, produtos exclusivos ou altamente diferenciados, ameaça de integração vertical para frente, alta dependência do insumo disponibilizado pelos fornecedores, são traços de Indústrias que têm o poder de barganha dos fornecedores como uma força forte.

Poder de barganha de clientes. Segundo Porter (1980), os compradores têm a capacidade de pressionar os preços para baixo ao barganhar por melhor qualidade, mais produtos ou serviços pelo mesmo preço ou, simplesmente, menores preços, acirrando a concorrência e estreitando a margem de lucro da Indústria.

Barney e Hesterly (2006) elencam uma série de elementos que podem caracterizar o poder de barganha dos clientes, como concentração de vendas em um grupo de clientes, produtos não diferenciados entre si, compradores que não obtêm lucro econômico significativo, custo de mudança baixo, compradores com alto nível de informação, entre outros.

O modelo PESTEL, normalmente utilizado em conjunto com o modelo das 5 forças e análise SWOT para análise do ambiente externo da empresa, foca em fatores macro ambientais que podem ter influência profunda em seu desempenho. PESTEL é um acrônimo para Political, Economic, Social, Technological, Environmental e Legal (político, econômico, social, tecnológico, ambiental e legal, respectivamente). Ao longo dos anos, o modelo ainda se desenvolveu, adicionando fatores como Demographics, Intercultural, Ethical e Ecological (demográficos, intercultural, ético e ecológico, respectivamente).

Passando pelos fatores PESTEL originais, o primeiro, político, é o relacionado à intervenção do governo na economia ou em determinada indústria. Qualquer influência que o governo possa ter no negócio é classificada como um fator político, o que pode incluir estabilidade ou instabilidade política, corrupção, política de impostos, trabalhista, ambiental, infraestrutura, entre outros. 
Fatores econômicos são determinantes de uma certa performance econômica. Isto é, incluem o crescimento econômico, taxas de câmbio, de inflação, de juros, emprego, entre outros. Esses elementos podem ter efeitos diretos e indiretos de longo prazo na companhia, pois afetam, por exemplo, o poder de compra dos consumidores e têm potencial de alterar o equilíbrio entre oferta e demanda de uma economia.

A dimensão social representa características demográficas, normas, costumes e valores de uma população em que a empresa atua. Incluem aqui elementos como taxa de crescimento da população, distribuição de idade, de renda, barreiras culturais, entre outros. São fatores especialmente relevantes para empresas que desejam atingir um determinado segmento de clientes.

Fatores tecnológicos são os relacionados às inovações tecnológicas que tem o potencial de afetar as operações de uma indústria e o mercado. Se refere a incentivos à inovação, automação, à atividade de pesquisa e desenvolvimento $(P \& D)$, entre outros. Devem ser observados na decisão de entrar ou não em determinadas indústrias, lançar ou não certos produtos ou de terceirizar atividades produtivas.

Fatores ambientais têm ganhado importância ultimamente. Relevância tem sido atribuída a esses fatores por conta do aumento da escassez de recursos e metas de emissão de carbono e população definidas por governos. Esses fatores incluem aspectos ecológicos e ambientais como clima, mudanças climáticas que afetam indústrias como turismo, agropecuária e seguros. Além disso, influenciam como as empresas operam e produtos que oferecem.

Fatores legais, apesar de relacionados aos fatores políticos, incluem leis mais específicas como antitruste, empregatícias, leis de proteção ao consumidor, patentes e saúde e segurança. É essencial para as empresas terem conhecimentos do ordenamento jurídico para que possam operar dentro da legalidade e eticamente. Se torna um desafio ainda maior para aquelas empresas que atuam internacionalmente, onde cada país tem suas regras e regulamentos. Deve-se também ficar atento às mudanças que podem ocorrer na legislação que impactam o negócio. 


\subsection{Desempenho}

O objetivo da estratégia adotada por uma empresa é a maximização do lucro e sua manutenção a patamares mais elevados que os da concorrência. O desempenho está diretamente relacionado com o atingimento deste objetivo. Pode ser entendido, portanto, como uma variável econômica, relacionada ao lucro, e comparativa, pelo seu caráter competitivo.

Barney (2001) destaca o lado comparativo do conceito ao considerar que existem três tipos básico de desempenho: o normal, abaixo do normal e acima do normal. São classificações que partem da comparação do desempenho de uma determinada empresa com a média do mercado em que ela está inserida, ou com a expectativa de investidores.

Essa perspectiva, no entanto, não abrange toda a amplitude do conceito. Deixa de fora empresas sem fins lucrativos, por exemplo, ao não considerar aspectos subjetivos do desempenho, como a satisfação de clientes, funcionários, fornecedores, entre outros não tão diretamente interessados nos resultados financeiros como os acionistas.

Neste sentido, autores como Cameron e Whetten (1983) destacam três dimensões do desempenho:

1) Teórica - dimensão semelhante ao conceito de estratégias pretendidas de Mitzberg et al (2009), no qual o desenho estratégico é primeiramente realizado no campo da ideia antes de ser aplicado na prática;

2) Empírica - nesta dimensão o enfoque é dado na execução e análise do desempenho estratégico.

3) Gerencial - dimensão em que se foca na formulação de estratégias com o intuito de guiar o gerenciamento à melhores desempenhos empresariais.

Fatores internos e externos podem influenciar o desempenho das empresas. Segundo Porter $(1980,1985)$, fatores externos são aqueles definidos pela estrutura da indústria. Para Hill e Deeds (1996), por outro lado, os fatores internos são aqueles relacionados aos processos da empresa igualmente capazes de influenciar o desempenho, pensamento característico da escola neo-austríaca. Segundo essa 
escola, a estrutura da indústria é influenciada pelo desempenho de seus participantes, e a sustentação da vantagem competitiva determinada por três fatores: inovações, barreiras à imitação e capacidade de imitar inovações concorrentes.

O desempenho pode, ainda, ser descrito por três óticas: o modelo SCP (structure - conduct - performance), a escola de Posicionamento e a escola da Visão Baseada em Recursos (VBR).

O primeiro, SPC, defende que a estrutura da indústria influencia as ações das empresas e, por consequência, seus desempenhos. A unidade de avaliação do desempenho, sob essa ótica, portanto, é a indústria e não as empresas que a compõe (CARNEIRO, 2007).

A escola do Posicionamento, que tem como Porter (1980) principal expoente, identifica dois fatores como definidores da diferença do desempenho entre empresas: a estrutura da indústria e a estratégia adotada. $\mathrm{O}$ primeiro define o potencial médio de cada empresa e o segundo é o fator individual de cada empresa e é responsável pelas diferenças de desempenho entre empresas de uma mesma indústria.

Por fim, a Visão Baseada em Recursos (VBR), defendida por Barney (1991) e Barney et al (2001), sustenta que o desempenho é consequência dos recursos e capacidades de cada empresa. Sob essa ótica, busca-se explicar o desempenho por meio de suas características particulares e não de aspectos estruturais.

Hill e Deeds (1996) analisam o desempenho sob duas perspectivas: o modelo de Porter (1980) e o modelo Neo-Austríaco. No primeiro, a estrutura da indústria determina a natureza da competição e o desempenho observado. $\mathrm{Na}$ segunda, o desempenho das empresas é que produz efeito na estrutura da indústria.

Expostos os principais conceitos do desempenho, analisa-se agora a sua avaliação.

São várias as formas de avaliar o desempenho estratégico de uma empresa. As medidas mais comuns e objetivas são as financeiras ou contábeis, amplamente utilizadas e mais fáceis de se apurar, tendo em vista a obrigatoriedade de levá-las à público para empresas listadas em bolsa de valores, o que torna fácil a comparação entre empresas. Marques (2004) elenca as seguintes medidas contábeis: 
1) Resultado Bruto - diferença entre Receita Operacional Líquida e o custo de vendas.

2) Resultado Operacional - Lucro Bruto depois de computados os resultados acessórios à manutenção das operações.

3) Lucro Antes de Juros e Impostos (LAJIR) - Lucro Operacional + Despesas (Receitas) Financeiras - receitas de dividendos, equivalência patrimonial, entre outros.

4) Lucro Operacional Líquido Após Ajustes e Impostos (NOPLAT) LAJIR - Impostos sobre o LAJIR + Mudanças Líquidas em impostos diferidos.

5) Resultado Residual (RI) - Diferença entre Resultado Operacional e Custo de Capital.

6) Valor Econômico Adicionado (EVA) - Lucro Operacional após o pagamento de impostos - encargos sobre o capital.

7) Resultado Não Operacional - Lucro não operacional.

8) Resultado Líquido - Lucro Líquido

9) Lucro por Ação - Lucro Líquido / número médio ponderado de ações.

Barney (2001) contribui ainda com os seguintes indicadores:

1) Retorno sobre Ativos (ROA) - lucro depois de impostos / ativo total.

2) Retorno sobre Patrimônio Líquido (ROE) - lucro depois de impostos / total do patrimônio líquido dos acionistas.

Apesar dos benefícios de sua utilização, as medidas contábeis podem ser objetivas demais. Isto é, deixa de fora questões subjetivas, além de poderem ter seus números maquiados pela gestão ou por mecanismos contábeis.

Neste sentido, Venkataraman e Ramanujam (1986) propõem o modelo de desempenho em camadas, conceito mais amplo para a medição de desempenho. De acordo com essa proposta, o desempenho da empresa é uma parcela de conceitos mais amplos de efetividade organizacional. É um modelo em camadas por definir três níveis de tipos de indicadores de desempenho:

1) Desempenho Financeiro - medidas contábeis anteriormente abordadas;

2) Desempenho Organizacional - lista que contém indicadores como Market-share, qualidade do produto, qualidade do serviço, efetividade 
do marketing, introdução de novos produtos, entre outros. Segundo o modelo, elementos que ditam o Desempenho Financeiro;

3) Efetividade Organizacional - camada que abrange aspectos mais genéricos do desempenho, ligados ao objetivo da organização, como a satisfação dos stakeholders.

Por fim, Mauboussin (2012) destaca a importância do crescimento como medida de performance e desempenho de empresas. Segundo o autor, uma das métricas mais utilizadas para medir, gerir e comunicar resultados - comumente chamadas de indicadores chave de performance (key performance indicators) - é o crescimento de vendas, apesar de chamar atenção ao fato de que isso não necessariamente se relaciona com o objetivo de criar valor.

\subsection{Grupos Estratégicos}

Porter (1980) define grupos estratégicos como empresas de um segmento que adotam estratégias similares, culminando em desempenhos estratégicos semelhantes. Similarmente, Hunt (1972, apud SILVA E MELO, 1998) afirma que grupos estratégicos são constituídos por empresas pertencentes a uma mesma Indústria e que apresentam comportamentos semelhantes em dimensões estratégicas consideradas relevantes.

Caves e Porter (1977) entendem que barreiras de mobilidade são construídas pelos participantes de grupos estratégicos, dificultando a entrada de novas empresas à adoção de estratégia similar à do grupo. Isso cria, portanto, uma homogeneidade de condições entre as empresas integrantes do grupo, o que explica o desempenho similar.

Por outro lado, para Cool e Shendel (1987), apenas as barreiras de mobilidade não são suficientes para explicar a similaridade do desempenho dentro dos grupos. Para estes autores, níveis de maturidade e fatores mercadológicos não podem ser ignorados e o modelo de estudo desses grupos estratégicos deve ser mais complexo, envolvendo outras variáveis.

As tipologias abordadas na próxima seção se propõem a identificar grupos estratégicos e organizá-los em estratégias genéricas que sejam aplicáveis a todas as indústrias. 


\subsection{Tipologias Estratégicas}

Segundo a definição de Chrisman (1988), estratégia descreve as características fundamentais do encontro que uma organização promove entre suas habilidades, recursos, oportunidades e ameaças de seu ambiente externo, que a habilita a atingir seus objetivos e metas.

O conceito de estratégia genérica, por sua vez, parte da ideia de que é possível definir uma tipologia estratégica suficientemente ampla para que seja aplicável a qualquer empresa, de qualquer tipo de indústria, em qualquer nível de maturidade (Herbert e Deresky, 1987).

Chrisman (1988) define quatro objetivos de um sistema classificatório (de estratégias genéricas): (1) diferenciação, (2) generalização, (3) identificação e (4) obtenção de informação. A diferenciação é necessária para validar generalizações. A generalização, por sua vez, é requerida pois o objetivo primário de uma classificação é prover a fundação para estudos comparativos, sendo a melhor classificação aquela que permite as mais úteis investigações comparativas. Uma identificação confiável é necessária para garantir consistência e comparabilidade em estudos futuros. Por fim, um sistema de classificação também deve ser capaz de guardar e extrair informações para facilitar seu uso e aplicação das generalizações em estudos comparativos.

Dito isto, para atingir esses objetivos, os sistemas classificatórios e suas categorias devem ser (1) mutualmente excludentes, (2) internamente homogêneos, (3) coletivamente exaustivo, (4) estáveis e (5) baseados em linguagem e nomes relevantes. Além disso, o sistema em si deve (6) ser baseado em características chave do fenômeno observado, (7) ter um propósito geral, ao invés de um propósito específico, (8) deve ser parcimonioso, (9) hierárquico por natureza e (10) independente do tempo em que é aplicado.

Para ser mutualmente excludente, nenhum item classificado pode ser atribuído a mais de uma categoria. Membros de uma classificação, por outro lado, devem guardar mais semelhanças entre eles do que com membros de outra classificação. Há neste ponto um trade off entre o nível de homogeneidade e a 
qualidade da generalização. Achados sólidos de uma população restrita são melhores que achados marginais ou uma generalização questionável de uma população mais ampla, porém menos homogênea. Todas as estratégias elencadas devem caber à alguma classificação do sistema, que não deve ser significativamente afetada pelas alterações de características dos membros, isto é, ao se alterar a amostragem, o sistema deve continuar válido e estável. A classificação normalmente se baseia em uma característica única dominante ou em um conjunto de características mais relevantes. Portanto, a classe deve ter um nome que guarde relação com essas características chave, tornando a identificação fácil.

Um sistema classificatório eficiente deve ser baseado em características chave das entidades que são classificadas (Darwin, 1859/1958). As mais úteis características são aquelas que teoricamente e praticamente medem similaridades entre estratégias de um grupo e diferenças entre estratégias dos demais grupos (McKelvey, 1978). Classificações devem ter propósito específico ou genérico. Classificações específicas focam em estratégias específicas, em estratégias de ambientes específicos ou em estratégias elaboradas para circunstâncias específicas. Por outro lado, classificações genéricas, como a de Porter (1980), são aplicáveis a todas as situações e estratégias. Uma classificação genérica é mais importante e mais útil do que classificações específicas por permitirem predições amplas do comportamento dos membros classificados, por servirem como um bom método de organizar estudos funcionais, além de atuar como um sistema de obtenção de informação amplo e inclusivo (McKelvey, 1982). A parcimônia em classificação quer dizer que pesquisadores estejam aptos a agrupar entidades similares e diferenciá-las de entidades diferentes com o mínimo de classificações possível sem sacrificar atributos classificatórios (homogeneidade, por exemplo).

\subsubsection{Tipologia de Porter}

A tipologia de Porter (1980, 1985) é composta por três estratégias genéricas: liderança em custo, diferenciação e enfoque (enfoque em custo e enfoque em diferenciação). Segundo o autor, as empresas que aplicam uma, e apenas uma, das três estratégias apresentam melhor desempenho do que aquelas que buscam uma estratégia híbrida ou que fracassam em adotar uma das três, se tornando uma "stuck in the middle" (meio-termo). 
Figura 3 - Framework de Porter

\begin{tabular}{|c|c|c|}
\hline \multirow{2}{*}{ ALVO ESTRATÉGICO } & \multicolumn{2}{c|}{ VANTAGEM ESTRATÉGICA } \\
\cline { 2 - 3 } No âmbito de toda a indústria observada pelo cliente & \multicolumn{1}{c|}{ Posição de baixo custo } \\
\cline { 2 - 3 } Apenas um segmento particular & DIFERENCIAÇÃO & LIDERANÇA NO CUSTO TOTAL \\
\cline { 2 - 3 } & \multicolumn{3}{|c|}{ ENFOQUE } \\
\hline
\end{tabular}

Fonte: Porter (1980)

A estratégia de liderança em custo total é atingida quando a empresa é capaz de fazer com que seu custo total seja menor que o de seus concorrentes (BARNEY, 2006). O custo inferior atua como mecanismo de defesa da empresa contra a rivalidade de seus concorrentes, em particular no que tange a guerra de preços. Essas empresas têm maior facilidade de lidar com a pressão exercida pelos fornecedores, tendo maior fôlego para continuar na indústria do que seus concorrentes (Carneiro et al, 1997).

A perseguição da estratégia de liderança em custo total apresenta alguns benefícios, como retornos acima da média do mercado, supondo o mesmo nível de preço aos clientes e menores custos, e uma defesa à barganha tanto de clientes quanto de fornecedores. Em relação aos compradores, estes terão como referência o menor preço praticado no mercado. Enquanto na ponta fornecedora, o nível menor de custo da empresa pode ser utilizado para amortecer eventuais aumentos de preço de insumos. $\mathrm{O}$ fator de baixo custo também pode significar uma barreira de entrada, dado o nível de escala necessário para se manter o nível reduzido de preço, além de proteção à substituição por produtos substitutos.

Porter (1980) afirma ser a estratégia de liderança em custo total uma boa defesa às pressões das cinco forças. Dado que a pressão causada reduzirá os lucros até o nível do próximo concorrente mais eficiente, que será eliminado antes do que o lucro da empresa em questão. Para isso, no entanto, a empresa pode enfrentar desafios na implementação dessa estratégia, uma vez que um determinado nível de escala é exigido para compensar as menores margens. O início da implementação dessa estratégia pode resultar em prejuízos iniciais, mas quando atingida, o lucro pode ser reinvestido em equipamentos e instalações que sustentarão a posição de líder em custo. 
Carneiro et al (1997) apresenta a crítica de que a perseguição da liderança em custo total dá uma ênfase excessiva aos custos internos. Essa busca por soluções internas pode fazer com que oportunidades de melhores relações com atores externos (ambiente competitivo) passem despercebidas.

O exemplo clássico de empresa que persegue a estratégia de liderança em custo é o Wallmart. Empresa de varejo americana que tem como objetivo manter seus preços abaixo da concorrência.

A estratégia de diferenciação segundo a tipologia de Porter $(1980,1985)$ pressupõe que a empresa ofereça um produto considerado único pelos seus clientes. Isto é, dotado de atributos que dificilmente produtos concorrentes alcançam. A diferenciação também serve de mecanismo de defesa para a empresa, mas de forma diferente da liderança em custo. A diferenciação promove lealdade e menor sensibilidade a preço, reduzindo o poder de barganha dos compradores, além de isolar a empresa da rivalidade de seus concorrentes.

Barney (2006) defende que a diferenciação é uma estratégia em que a empresa busca atingir a vantagem competitiva aumentando o valor percebido de seus produtos e serviços em comparação ao valor percebido dos produtos e serviços de outras empresas.

Um exemplo de empresa que persegue a estratégia de diferenciação é a Apple. Empresa de eletrônicos, software e serviços online que apresentam preços superiores ao de seus concorrentes, justificado por uma diferenciação de seus produtos e serviços.

Por fim, a estratégia de enfoque se apoia na capacidade da firma de atender melhor o seu alvo estratégico do que aqueles concorrentes que tentam atender a indústria como um todo (ou vários segmentos de mercado ao mesmo tempo). O alvo deve ser suficientemente estreito para que a empresa o atenda mais eficazmente e pode ser atendido através de uma posição de custo mais baixo ou diferenciação (Carneiro et al, 1997).

Isto é, foca-se em um grupo comprador, um segmento da linha do produto ou mercado geográfico. Enquanto as estratégias de custo e diferenciação almejam o âmbito de toda uma Indústria, as estratégias de enfoque buscam atender um alvo 
específico. Um exemplo de empresa que persegue a estratégia de enfoque é o a empresa de produtos cosméticos e serviços Beleza Natural, específico para cabelos crespos e cacheados.

Porter (1980) defende que as empresas que adotam essa estratégia são capazes de atender seu alvo estratégico estreito de forma mais efetiva e eficaz quando comparadas às empresas com alvos amplos. A empresa que persegue a estratégia de enfoque é mais eficaz em se diferenciar ou em reduzir seus custos, dado as necessidades específicas de seu alvo particular.

O meio-termo (stuck in the middle) é atingido ao se fracassar no desenvolvimento e implementação de uma das três estratégias descritas anteriormente. Segundo Porter (1980), a empresa que se encontra no meio-termo se encontra em uma situação estratégica inferior e que, por isso, apresentará desempenho inferior às demais. Há, no entanto, críticas na literatura quanto a capacidade de uma empresa de buscar simultaneamente as estratégias de liderança em custo e diferenciação em um ou mais de um segmento alvo sem perder desempenho (Dess e Davis, 1984; White, 1986; Miller e Dess, 1993; Hill, 1988; Karnani, 1984).

A tipologia de Porter é altamente difundida na literatura, mas não é, de forma alguma, livre de críticas. Há autores que entendem que a estratégia de diferenciação, por exemplo, deveria ser desmembrada em uma classificação mais precisa, dado que a diferenciação pode ser atingida por um leque extenso de estratégias competitivas distintas, que requerem estrutura e competências particulares para sua implementação (Carneiro et al, 1997).

Neste sentido, Kim e Lim (1988) defendem que a estratégia de diferenciação deva ser subdividida em diferenciação de produto (atributos específicos, qualidade) e diferenciação por marketing (propaganda, nível de serviço). Miller (1992), por sua vez, propõe três tipos de diferenciação: por qualidade, por imagem e por inovação. O mesmo autor, em 1992, após uma pesquisa entre empresas não diversificadas encontrou três tipos de diferenciação: por qualidade, por pioneirismo e por força de vendas (Carneiro et al, 1997).

Segundo Chrisman (1988), a classificação de Porter não inclui diferenciação de segmento. Isto é, o sistema exclui ou classifica erroneamente a empresa que 
diferencia de forma não ampla na indústria. Em outras palavras, a tipologia de Porter não é internamente homogênea, dado que não há diferenciação entre companhias de escopo amplo ou estreito, que se valem de armas competitivas diferentes em segmentos de produtos/mercados distintos.

Além disso, Chrisman (1988) argumenta que a tipologia genérica de Porter (1980) não é coletivamente exaustiva, por excluir estratégias "stuck in the middle". Dess e Davis (1984) e Sandberg (1986) apontam que excluir essa estratégia pode criar problemas de identificação. Ademais, autores como Hall (1983), Dess e Davis (1984) e Chriman (1988) afirmam haver companhias bem-sucedidas usando liderança em custo e diferenciação simultaneamente em um ou mais de um produto/segmentos de mercado.

Um exemplo de empresa que persegue custo e diferenciação e ainda apresenta boa performance é a IKEA, na opinião de Hattangadi (2018). A empresa varejista de móveis persegue a liderança em custo ao buscar fornecedores de peças de baixo custo e ao deixar a montagem dos móveis aos seus clientes, reduzindo custos de entrega tanto para consumidores quanto para fornecedores. Apesar disso, a empresa também se aproxima de uma estratégia de diferenciação ao inovar a forma como se compra móveis. As lojas IKEA são prédios únicos, desenhados para que os clientes circulem por toda a dependência, ornamentados com quartos decorados com muito estilo, oferecendo muitas opções e sugestões de decoração aos clientes.

\subsubsection{Tipologia de Abell}

As estratégias genéricas propostas por Abell (1980) são baseadas na ideia de que o negócio pode ser definido pelo escopo de sua oferta, pelo grau de diferenciação competitiva e pela extensão que suas ofertas são diferenciadas através de diferentes produtos/segmentos de mercado. Segundo o autor, escopo e diferenciação devem ser observados em três dimensões: (1) grupos de consumidores, (2) função dos consumidores e (3) tecnologias. Ao longo dessas três dimensões uma empresa pode seguir três estratégias genéricas: diferenciação, não diferenciação e enfoque, como mostra a Figura 4. 
Figura 4- Framework de Abell

\begin{tabular}{lll|l|} 
& \multicolumn{2}{c}{ Diferenciação por Segmento } \\
& & \multicolumn{1}{c}{ Sim } & \multicolumn{1}{c}{ Não } \\
\cline { 3 - 4 } Escopo Ampla & Diferenciado & Não Diferenciado \\
\cline { 3 - 4 } & Estreita & \multicolumn{2}{|c|}{ Foco } \\
\cline { 3 - 3 } & &
\end{tabular}

Fonte: Chrisman (1988), adaptado pelo Autor

A estratégia de diferenciação descreve os negócios de escopo amplo que usa diferentes armas de diferenciação competitiva em vários dos segmentos em que compete. A estratégia de não diferenciação também é relativa a negócios de atuação ampla, mas usa apenas uma arma de diferenciação competitiva em todas as frentes. A estratégia de enfoque segundo o framework de Abell descreve negócios com escopos estreitos que usam apenas uma arma competitiva. Segundo o autor, estratégia de enfoque é usualmente acompanhada de algum tipo de diferenciação competitiva.

O modelo de Abell, assim como o de Porter, atinge vários dos parâmetros de um bom sistema classificatório: mutualmente exclusivo, estável, baseado em duas ou três características chave, propósito genérico, parcimoniosa, capaz de acomodar uma estrutura hierárquica e independente do tempo. Entretanto, ao contrário do modelo de Porter, a tipologia de Abell é coletivamente exaustivas por ser capaz de cobrir todos os tipos de combinações de escopo e diferenciação por segmento.

No entanto, segundo Chrisman (1988), a tipologia de Abell não abrange uma importante distinção entre estratégias. Sandberg (1986) entende ser necessário incluir em estratégias não diferenciadas tanto empresas sem estratégias bem definidas "stuck in the middle" quanto negócios que adotam liderança em custo. Dito de outra forma, a tipologia de Abell não é internamente homogênea por considerar apenas escopo e diferenciação por segmento, mas deixar de fora tipos de armas competitivas que uma organização pode usar em produtos ou segmentos de mercado.

Além disso, Chrisman (1988) destaca que, ao contrário da tipologia de Porter, o modelo de Abell tem a desvantagem de usar termos inapropriados. Abell 
usa diferenciação para descrever escopos amplos e utilização de diferentes armas competitivas nos diferentes segmentos em que compete. Usualmente, no entanto, o termo diferenciação é usado para descrever diferenciação competitiva, como Porter faz, não diferenciação de segmento. É uma utilização surpreendente do termo haja vista a existência do termo segmentação para descrever justamente isso. O termo não diferenciação para a outra classe de estratégia genérica também causa estranhamento, visto que pode incluir empresas que adotam armas de custo ou diferenciação, desde que tenham escopo amplo e utilize apenas uma dessas armas em todos os segmentos que atua.

\subsubsection{Contribuições de Chrisman à Tipologia de Abell}

Chrisman (1988) propõe a melhoria no sistema de Abell adicionando mais uma dimensão ao framework. Ao adicionar uma dimensão que explicite a diferenciação competitiva e que empresas de escopo estreito também podem segmentar seus produtos/mercados. Fazendo isso, a tipologia de Abell se torna mais homogênea, no entanto, ainda incompleta por não distinguir entre vários tipos de armas competitivas que firmas de escopo amplo ou estreito podem ter como vantagens competitivas.

Diante da omissão de Porter quanto a diferenciação por segmento e a exclusão de Abell dos tipos de armas competitivas que empresas utilizam para buscar vantagem competitiva, tornando ambos os modelos internamente heterogêneos, Chrisman (1988) propõe uma tipologia que inclui componentes estratégicos de escopo, diferenciação por segmento e tipos (ou a falta de) armas competitivas.

Com a inclusão dessas duas dimensões, a proposta de Chrisman inclui 16 estratégias genéricas teóricas possíveis, como mostra a Figura 5. Duas delas são descartadas por contradição teórica. 
Figura 5 - Framework de Chrisman, Hofer e Boulton (1988)

\begin{tabular}{|c|c|c|c|}
\hline \multirow{2}{*}{$\begin{array}{l}\text { Diversidade de vantagem } \\
\text { competitiva por segmento }\end{array}$} & \multirow{2}{*}{$\begin{array}{l}\text { Tipo de vantagem } \\
\text { competitiva }\end{array}$} & \multicolumn{2}{|c|}{ Escopo } \\
\hline & & Amplo & Estreito \\
\hline \multirow{4}{*}{$\begin{array}{l}\text { Sim (diferentes tipos de } \\
\text { vantagens competitivas em } \\
\text { diferentes segmentos de } \\
\text { mercado) }\end{array}$} & Custo/Preço & $\begin{array}{l}\text { custo com } \\
\text { segmentação }\end{array}$ & $\begin{array}{l}\text { enfoque em custo } \\
\text { com segmentação }\end{array}$ \\
\hline & $\begin{array}{c}\text { Custo + } \\
\text { Diferenciação }\end{array}$ & $\begin{array}{l}\text { utilidade com } \\
\text { segmentação }\end{array}$ & $\begin{array}{l}\text { enfoque em utilidade } \\
\text { com segmentação }\end{array}$ \\
\hline & Diferenciação & $\begin{array}{l}\text { diferenciação com } \\
\text { segmentação }\end{array}$ & $\begin{array}{c}\text { enfoque em } \\
\text { diferenciação com } \\
\text { segmentação }\end{array}$ \\
\hline & Nenhuma & $\begin{array}{l}\text { falta de } \\
\text { segmentação }\end{array}$ & $\begin{array}{c}\text { enfoque em falta de } \\
\text { segmentação }\end{array}$ \\
\hline \multirow{4}{*}{$\begin{array}{l}\text { Não (mesmo tipo de } \\
\text { vantagem competitiva em } \\
\text { diferentes segmentos de } \\
\text { mercado) }\end{array}$} & Custo/Preço & $\begin{array}{c}\text { custo em mercado } \\
\text { de massa }\end{array}$ & enfoque em custo \\
\hline & $\begin{array}{c}\text { Custo + } \\
\text { Diferenciação }\end{array}$ & $\begin{array}{c}\text { utilidade em } \\
\text { mercado de massa }\end{array}$ & $\begin{array}{l}\text { enfoque em } \\
\text { utilidade }\end{array}$ \\
\hline & Diferenciação & $\begin{array}{l}\text { diferenciação em } \\
\text { mercado de massa }\end{array}$ & $\begin{array}{l}\text { enfoque em } \\
\text { diferenciação }\end{array}$ \\
\hline & Nenhuma & $\begin{array}{l}\text { falta de vantagem em } \\
\text { mercado de massa }\end{array}$ & $\begin{array}{c}\text { falta de vantagem } \\
\text { em enfoque }\end{array}$ \\
\hline
\end{tabular}

(1) Utilidade foi usada para representar a obtenção simultânea, de forma equilibrada, das vantagens competitivas de custo e diferenciação no(s) principal(is) segmento(s) de produto/mercado em que a empresa atua.

(2) As categorias que aparecem cruzadas (falta de segmentação e enfoque em falta de segmentação) são teoricamente inconsistentes e devem ser excluidas da tipologia.

Fonte: Carneiro et al (1997)

Alguns autores, ainda, defendem uma abordagem contingencial, na qual o conjunto de estratégias viáveis é limitado pelas características do ambiente (Hambrick, 1983; Murray, 1988). De acordo com Varadarajan (1985), uma estratégia só atinge desempenho superior em função de configurações particulares do ambiente, da estrutura da indústria, do comportamento do consumidor, das estruturas organizacionais e da disponibilidade de recursos. Outros autores, como Chrisman, Hofer e Boulton (1988) listam autores que desenvolveram tipologias de estratégias genéricas aplicáveis a circunstâncias específicas como indústrias em declínio, empresas de manufatura e integração vertical.

\subsubsection{Tipoligia de Mintzberg}

Mintzberg (1988) afirma que as estratégias genéricas abordadas anteriormente erram ao focarem de forma muito estreita em tipos especiais de estratégia ou por proporem agregações arbitrárias. O autor então propõe uma nova tipologia que parte do conceito de diferenciação e com nível de detalhamento maior que as de Porter (1980, 1985). Segundo Mintzberg (1988), as empresas podem se 
diferenciar por preço, por imagem, por suporte, por qualidade, por Design (projeto), ou não se diferenciar (não-diferenciação).

Na diferenciação por preço, a empresa diferencia seu produto ao cobrar um preço mais baixo. Caso não haja significativas diferenças em atributos ou qualidade entre as demais ofertas, o consumidor tenderá a preferir o de mais baixo preço. A empresa pode obter maiores lucros caso a redução da margem seja compensada com maiores volumes de venda, ou caso desenvolva estrutura produtiva que lhe permita custo de produção mais baixo.

A diferenciação por imagem ocorre quando a empresa desenvolve a imagem do produto de forma a o tornar distinto dos demais, dado que um dos atributos do produto é a forma como consumidores o percebem em comparação com produtos concorrentes. A imagem pode ser criada com propaganda ou técnicas de promoção. Essa técnica de diferenciação está intimamente relacionada com o conceito de sinalização de valor, o qual destaca a importância dos detalhes quando os compradores não são capazes de discernir inteiramente as diferenças e semelhanças entre produtos concorrentes (Carneiro et al, 1997).

A diferenciação por suporte é uma forma de diferenciar o produto sem alterar seus atributos intrínsecos, oferecendo algo além do produto, o que Mintzberg (1988) também chama de diferenciação periférica. Normalmente, esse "extra" está relacionado ao nível de serviço agregado (menor prazo de entrega, financiamento à venda, assistência técnica) ou com ofertas complementares.

A estratégia de diferenciação por qualidade se caracteriza por oferecer um produto que, embora não essencialmente diferente, é melhor que os concorrentes. Neste sentido, o produto pode ser considerado melhor de três maneiras: maior confiabilidade, maior durabilidade ou melhor desempenho.

A diferenciação por design (projeto) é atingida ao oferecer o produto atribuído de características distintas dos concorrentes. Trata-se de oferecer um produto diferente, em substituição ao da concorrência (Carneiro et al, 1997). A diferença entre essa estratégia e a de qualidade, é que não se busca a entrega de um produto melhor em qualidade, mas simplesmente "diferente". 
A não-diferenciação é atingida pela cópia das ações de outras empresas. É possível que dê certo, desde que o mercado ofereça espaço para produtos concorrentes e a empresa se especialize em acompanhar e imitar os lançamentos concorrentes, suportando com ações inovadoras ou marketing eficiente. Assemelha-se ao conceito de stuck in the middle desenvolvido por Porter (1980), com a diferença de que Mintzberg (1988) defende que essa estratégia pode ser ativamente buscada pela empresa, enquanto Porter (1980) afirma ser uma estratégia residual, e que Mintzberg (1988) não condena essa estratégia com desempenho necessariamente inferior às demais.

No presente trabalho será utilizada a tipologia de Porter (1980) dada a sua prevalência nos estudos empíricos, alta aderência à realidade e maior parcimônia em relação à de Chrisman (1988).

\subsection{Streaming}

O streaming de mídia é uma tecnologia emergente que está alterando o entretenimento como conhecemos. Como um processo tecnológico, é definido como a entrega contínua de multimedia ao usuário final, podendo ser um produto audiovisual, sonoro ou até textual (Larson, 2007). Permite o acesso ao conteúdo sem o download de todos os arquivos necessários previamente ao uso. O streaming pode ser entendido tanto como uma inovação tecnológica como prática cultural que co-configura audiência e indústria (Burroughs, 2015).

O Netflix assume a posição de pioneirismo dessa Indústria. A empresa iniciou suas atividades com o aluguel de vídeo doméstico (DVDs) por correio, e, em 2007, introduziu o serviço de streaming como hoje conhecemos. Já em 2010 inicia seu processo de internacionalização e em 2012 começa também a produzir seus próprios conteúdos. A empresa ficou por um tempo expressivo atuando praticamente sozinha no mercado, quando, recentemente, enfrenta uma onda de novos concorrentes.

Muitos autores (e. g., Richardson, 2011 e Christensen, Raynor e McDonald, 2015) consideram a distribuição audiovisual pela internet como uma inovação disruptiva, que derrubou empresas incumbentes do modelo de vídeo doméstico, como a Blockbuster, em pouquíssimo tempo (do início do streaming pelo Netflix 
em 2007 à falência da Blockbuster em 2010 decorreram apenas 3 anos). Hoje vemos diversas empresas consolidadas no mercado audiovisual (de TV Paga e TV aberta, por exemplo) entrando nesse novo setor em busca de novas fontes de receita e evitando o mesmo destino.

A história da Netflix, que se confunde com a história do próprio streaming, confirma a tecnologia como uma inovação disruptiva. Em 2011, a Netflix renomeou seu serviço de aluguel de DVDs (modelo de negócio original) para Qwikster, mantendo a marca Netflix apenas para a distribuição online por streaming (Gobry, 2011). Essa ideia foi chancelada por Christensen, autor do livro "O Dilema da Inovação", como uma forma da empresa evitar o dilema característicos de mercados afetados por inovações disruptivas, como pode ser extraído do tweet abaixo, datado de setembro de 2011:

“The conclusion I've come to as well via@businessinsider Netflix Splits Itself In Two To Avoid The Innovator's Dilemma" (CHRISTENSEN, 2011)

Essa nova tecnologia causou quebras paradigmáticas não apenas na distribuição do conteúdo, mas também em sua produção e consumo. Formas inéditas do consumo surgem com o streaming audiovisual, como o time-shifting e o binge watch. A primeira é a possibilidade de assistir quanto quiser, facilitando a reprise (rewatchability) dos programas e a segunda a maratona de séries (assistir uma obra seriada em sequência, sem interrupção). O binge watching é a prática que remete ao ato de ler um romance policial, porém com a totalidade da narrativa ao alcance do leitor. Para Matrix (2014), a maratona de obras seriadas se tornou um padrão de consumo entre os mais jovens, que seguem a tendência de migrar da grade televisiva tradicional para a conveniência do consumo sob demanda de vídeos e engajamento de fãs na internet. Ambas as modalidades de consumo, segundo Massaralo e Mesquita (2016), são fenômenos característicos dos serviços sob demanda. 
Ainda sobre a forma de consumir o conteúdo, diferentemente de outros mercados audiovisuais, como o cinema e a TV Paga, o streaming a possibilidade de envolvimento de múltiplas telas, para além das amarras pré-definidas da programação televisiva. Permite a manifestação de novas práticas de visualização, além de uma interatividade e maior avaliação dos títulos (Massarolo e Mesquita, 2016).

Quanto à produção do conteúdo, as plataformas de streaming têm a capacidade de obter uma enorme quantidade de dados sobre seus clientes e seu comportamento ao consumir o produto (padrões de comportamento). Este fator possibilita algoritmos de recomendação, que direcionam e propõe o conteúdo da plataforma baseado em rastros digitais deixados por seus clientes, potencializando o alcance de cada título do catálogo. Além disso, o uso dessas informações não se limita ao sistema de recomendação ou compra/licenciamento de conteúdos novos que seus clientes demonstram interesse de assistir. Alteram também a própria forma de produzir o conteúdo. A Netflix, por exemplo, se valeu das informações coletadas de seus assinantes para construir a série House of Cards. Padrões de consumo identificados por meio de Big Data demonstraram interesses específicos, que foram propositalmente inseridos na produção. Como por exemplo, após análises, concluiu-se que as mesmas pessoas que assistiam a série original da BBC também assistiam filmes protagonizados por Kevin Spacey, da mesma maneira que se averiguou o grande interesse do público por obras seriadas dramáticas e filmes dirigidos por David Fincher. Essas observações guiaram a escolha desse ator e diretor para a produção da série original Netflix (Massarolo e Mesquita, 2016). A produção de conteúdo, portanto, é mais direcionada no streaming do que em outros mercados audiovisuais, como o cinema e a TV Paga (Carr, 2013).

Diante do enorme sucesso a partir da popularização do Netflix, outras empresas, inclusive grandes incumbentes de outros mercados audiovisuais, começam a migrar para o Streaming. É o caso, por exemplo, da Disney, que recentemente lançou seu serviço Disney+, que já conta com 74 milhões de assinantes apenas um ano após sua estreia. Até mesmo grandes empresas de outros setores se aventuram no streaming, como a varejista Amazon, que disponibiliza o seu serviço de streaming, prime vídeo, em conjunto com seu serviço de entregas 
gratuitas, o Amazon Prime. No Brasil, o maior exemplo é o Globoplay, plataforma vídeo sob demanda do tradicional canal aberto de TV.

$\mathrm{O}$ crescimento acelerado não se limita à poucas plataformas, mas no mercado como um todo. Segundo relatório da Grand View Research (2020), o mercado global de streaming foi avaliado em 42,6 bilhões de dólares em 2019 e tem uma projeção de crescer a uma taxa anual de 20,4\% de 2020 a 2027. Inovações como blockchain e inteligência artificial, na melhora da qualidade de imagem e mudanças na produção do conteúdo, dão a expectativa de catalisar o crescimento.

Quanto aos modelos de negócio, atualmente há quatro categorias amplas de monetização do conteúdo exibido. São eles o Subscription Video On Demand (SVOD), o Transactional Video On Demand (TVOD), o Advertisement Video On Demand (AVOD) e o Virtual Multichannel Video Programming Distributor (vMVPD). O primeiro é o mais popular entre as plataformas atualmente existentes, adotado pelas maiores, como Netflix e Disney+. Neste modelo, o assinante paga uma assinatura mensal que lhe dá acesso a todo o acervo, sem limitações. O segundo, TVOD, é o que mais se assemelha às tradicionais videolocadoras. $\mathrm{O}$ cliente, neste modelo, faz uma transação por conteúdo, podendo ser tanto de compra e venda, quanto de aluguel. Nos dois casos, não há download do conteúdo, o que caracteriza o streaming. O terceiro, AVOD, é o modelo que monetiza o conteúdo por meio de anúncios, sem necessariamente ter a necessidade de cobrar o cliente. Por fim, o vMVPD é o modelo que se assemelha à atual TV Paga, onde o cliente, por meio de uma assinatura mensal tem acesso à canais lineares pela internet (STRATEGUS, 2020) 


\section{Metodologia}

\subsection{Tipo de Pesquisa}

Vergara (1986) classifica as pesquisas em dois tipos: quanto aos fins e quanto aos meios. A primeira é ainda subdividida em exploratória, descritiva, explicativa, metodológica, aplicada e intervencionista. A segunda se subdivide em pesquisa de campo, pesquisa de laboratório, documental, bibliográfica, ex post facto, pesquisa-ação e estudo de caso.

Quanto aos fins, a presente pesquisa é classificada como descritiva, já que ambiciona descrever as estratégias, seus desempenhos relativos e o ambiente competitivo da indústria de streaming audiovisual. Se propõe também a identificar a estratégia que define os melhores desempenhos entre as empresas observadas e a analisar a relação entre as estratégias competitivas, a posição dos grupos estratégicos e a identificação dos grupos com estratégia superior. É uma pesquisa hipotético-dedutiva, por conta da construção de conjecturas baseada em hipóteses e quantitativa, por se valer de técnicas estatísticas para quantificar opiniões e informações.

Quanto aos meios a pesquisa pode ser classificada como bibliográfica, tendo em vista a busca por dados na literatura em seus diversos meios, como livros, revistas, periódicos e internet. Também é empírica por utilizar dados reais observados.

\subsection{Universo e Amostra}

O universo estudado é o mercado de streaming audiovisual global, com suas empresas atuantes tanto no âmbito global quanto local. Para se ter um tamanho da dimensão de empresas atuantes neste mercado atualmente, Cook (2021) lista pelo menos 200 empresas de streaming audiovisual disponíveis em 2021, em uma lista não exaustiva.

Deste Universo, foram excluídas as empresas que atuam somente no modelo AVOD (monetizado por meio da publicidade) e TVOD (monetizado por meio de 
transações únicas de aluguel ou compra). Há, portanto, na lista de empresas analisadas, apenas representantes dos modelos SVOD e vMVPD, ainda que algumas delas tenham paralelamente AVOD e TVOD disponíveis aos seus clientes. Esse recorte decorre da seleção de variáveis de desempenho do presente trabalho. Como o desempenho é medido por meio da base de assinantes (crescimento) e receita estimada (base de assinantes vezes preço), para incluir as plataformas AVOD e TVOD, o trabalho deveria ser mais abrangente, incluindo também a receita publicitária e número de transações (e preço médio das transações), o que se mostrou impossível por conta da sensibilidade desse tipo de informação.

A amostra foi do tipo não probabilística e é composta por 37 empresas. Essa lista é composta por empresas relevantes do mercado que têm seus dados disponíveis, seja em balanços, periódicos especializados ou sites de inteligência de mercado. Abaixo a lista com suas respectivas informações de país de origem, número de assinantes na data de coleta e ano de lançamento:

Tabela 1 - Plataformas do Estudo

\begin{tabular}{|c|c|c|c|c|}
\hline Nome & $\begin{array}{l}\text { País de } \\
\text { Origem }\end{array}$ & $\begin{array}{l}\text { Número de } \\
\text { Assinantes }\end{array}$ & $\begin{array}{l}\text { Ano de } \\
\text { Lançamento }\end{array}$ & $\begin{array}{l}\text { Data da } \\
\text { coleta }\end{array}$ \\
\hline Acorn TV & $\begin{array}{l}\text { Estados } \\
\text { Unidos }\end{array}$ & 1.000 .000 & 01/07/2011 & $27 / 02 / 2020$ \\
\hline Alt Balaji & Índia & 1.700 .000 & $16 / 04 / 2017$ & $27 / 04 / 2020$ \\
\hline Apple TV+ & $\begin{array}{l}\text { Estados } \\
\text { Unidos }\end{array}$ & 33.600 .000 & $01 / 11 / 2019$ & $24 / 01 / 2020$ \\
\hline BET+ & $\begin{array}{l}\text { Estados } \\
\text { Unidos }\end{array}$ & 1.000 .000 & 19/09/2019 & $15 / 08 / 2020$ \\
\hline Blim & México & 7.000 .000 & $22 / 02 / 2016$ & $19 / 02 / 2020$ \\
\hline BritBox & Inglaterra & 1.500 .000 & $07 / 03 / 2017$ & $04 / 03 / 2020$ \\
\hline Catchplay & Taiwan & 1.000 .000 & $01 / 01 / 2017$ & $30 / 09 / 2020$ \\
\hline CBS All Access & $\begin{array}{l}\text { Estados } \\
\text { Unidos }\end{array}$ & 4.000 .000 & $28 / 10 / 2014$ & $28 / 02 / 2020$ \\
\hline Crunchyroll & $\begin{array}{l}\text { Estados } \\
\text { Unidos }\end{array}$ & 3.000 .000 & $14 / 05 / 2006$ & $18 / 11 / 2020$ \\
\hline Curiosity Stream & $\begin{array}{l}\text { Estados } \\
\text { Unidos }\end{array}$ & 13.000 .000 & $18 / 03 / 2015$ & $22 / 01 / 2020$ \\
\hline DAZN & Inglaterra & 8.000 .000 & $01 / 08 / 2016$ & $06 / 01 / 2020$ \\
\hline Disney+ & $\begin{array}{l}\text { Estados } \\
\text { Unidos }\end{array}$ & 73.700 .000 & $12 / 11 / 2019$ & $12 / 11 / 2020$ \\
\hline Eros Now & Índia & 29.300 .000 & $01 / 01 / 2012$ & $25 / 11 / 2019$ \\
\hline ESPN+ & $\begin{array}{l}\text { Estados } \\
\text { Unidos }\end{array}$ & 10.300 .000 & $12 / 04 / 2018$ & $27 / 06 / 2020$ \\
\hline Globoplay & Brasil & 2.500 .000 & $01 / 12 / 2015$ & $18 / 11 / 2020$ \\
\hline HBO Now & $\begin{array}{l}\text { Estados } \\
\text { Unidos }\end{array}$ & 8.000 .000 & $07 / 04 / 2015$ & $01 / 02 / 2019$ \\
\hline
\end{tabular}




\begin{tabular}{|c|c|c|c|c|}
\hline HBO Max & $\begin{array}{l}\text { Estados } \\
\text { Unidos }\end{array}$ & 4.100 .000 & $27 / 05 / 2020$ & $23 / 07 / 2020$ \\
\hline Hoichoi & Índia & 13.000 .000 & 20/09/2017 & $21 / 09 / 2020$ \\
\hline Hotstar & Índia & 8.000 .000 & $01 / 05 / 2015$ & $01 / 05 / 2020$ \\
\hline $\begin{array}{l}\text { Hulu (Live TV + } \\
\text { SVOD) }\end{array}$ & $\begin{array}{l}\text { Estados } \\
\text { Unidos }\end{array}$ & 4.100 .000 & 03/05/2017 & $12 / 11 / 2020$ \\
\hline Hulu (SVOD Only) & $\begin{array}{l}\text { Estados } \\
\text { Unidos }\end{array}$ & 32.500 .000 & $17 / 11 / 2010$ & $12 / 11 / 2020$ \\
\hline iFlix & Malásia & 17.000 .000 & $01 / 11 / 2017$ & $10 / 03 / 2020$ \\
\hline iQiyi & China & 100.000 .000 & $22 / 04 / 2010$ & $01 / 12 / 2019$ \\
\hline Looke & Brasil & 180.000 & $28 / 04 / 2015$ & $16 / 02 / 2018$ \\
\hline Mediaset Infinity & Itália & 400.000 & $01 / 12 / 2013$ & $01 / 05 / 2019$ \\
\hline Monomax & Tailândia & 380.000 & $01 / 02 / 2016$ & $01 / 07 / 2020$ \\
\hline Mubi & $\begin{array}{l}\text { Estados } \\
\text { Unidos }\end{array}$ & 9.000 .000 & $14 / 02 / 2007$ & $03 / 11 / 2019$ \\
\hline Netflix & $\begin{array}{l}\text { Estados } \\
\text { Unidos }\end{array}$ & 203.663 .000 & $18 / 09 / 2011$ & $31 / 12 / 2020$ \\
\hline Now TV & Inglaterra & 1.600 .000 & $17 / 07 / 2012$ & $01 / 05 / 2020$ \\
\hline Philo & Inglaterra & 750.000 & $14 / 11 / 2017$ & $18 / 11 / 2020$ \\
\hline Prime Video & Inglaterra & 150.000 .000 & 07/09/2006 & $14 / 10 / 2020$ \\
\hline Starz Play & $\begin{array}{l}\text { Estados } \\
\text { Unidos }\end{array}$ & 8.600 .000 & $05 / 04 / 2016$ & $20 / 04 / 2020$ \\
\hline Tencent Video & China & 112.000 .000 & $01 / 04 / 2011$ & $26 / 06 / 2020$ \\
\hline Videoland & Holanda & 750.000 & $01 / 01 / 2010$ & $18 / 11 / 2020$ \\
\hline Youtube Premium & $\begin{array}{l}\text { Estados } \\
\text { Unidos }\end{array}$ & 20.000 .000 & $21 / 10 / 2015$ & $04 / 02 / 2020$ \\
\hline Zee 5 & Índia & 56.300 .000 & $14 / 02 / 2018$ & $01 / 12 / 2019$ \\
\hline Youtube TV & $\begin{array}{l}\text { Estados } \\
\text { Unidos }\end{array}$ & 3.000 .000 & $28 / 02 / 2017$ & $30 / 10 / 2020$ \\
\hline
\end{tabular}

\subsection{Coleta de Dados}

Os dados utilizados neste estudo, como o número de assinantes, foram coletados de periódicos especializados em audiovisual, de demonstrativos financeiros, e de provedores de pesquisa de mercado renomados que estimam as variáveis de desempenhos escolhidas. As fontes de dados para cada plataforma podem ser encontradas no Anexo I.

Outros dados como preço, período de degustação e número de países em que o serviço está disponível foram coletados diretamente nos sites das empresas, também disponíveis no Anexo I. 


\subsection{Seleção de Variáveis Estratégicas}

A escolha das variáveis estratégicas foi bastante relacionada com a disponibilização das informações ao público. Nem todas as variáveis desejadas, neste sentido, foram passíveis de coleta, o que representa uma das limitações do presente trabalho. Variáveis como aparelhos em que o serviço está disponível, qualidade de imagem, entre outras não foram possíveis de serem coletadas, justamente pela falta de disponibilidade desses dados para todas as empresas analisadas.

As variáveis estratégicas selecionadas, no entanto, representam atributos e características relevantes das empresas de streaming, além de estarem disponíveis ao público. Feita essa seleção, primeiramente baseada na literatura e em minha experiência e estudo sobre o tema, dois profissionais, especialistas do mercado audiovisual, foram consultados, além de acadêmicos, que validaram a seleção, tanto daquelas que já possuíam embasamento na literatura, quanto as inéditas para o modelo.

\subsubsection{Preço}

A informação coletada relativa ao preço é a do plano mensal básico, isto é, o valor da assinatura mensal no plano mais simples. Muitas das plataformas apresentam uma gama de oferta, como planos anuais, semestrais, planos que variam na qualidade da imagem, número de acessos simultâneos, presença ou não de propaganda, entre outros. Para simplificação, a subscrição mensal mais simples foi escolhida para todas as plataformas.

O preço foi considerado como variável estratégica pois serve de indicativo a perseguição de uma determinada estratégia pela empresa. Liderança em preço não se confunde com Liderança em Custo. Uma companhia pode possuir o menor custo de produção e ainda assim não exercer o menor preço do mercado. No entanto, empresas que perseguem a Liderança em Custo, segundo Stahl e Grigsby (1997), normalmente competem no preço, sendo bastante eficientes nesta forma de competição, por possuírem uma estrutura de custo menor. 


\subsubsection{Período de degustação}

Maioria das empresas de streaming disponibilizam, na primeira assinatura, um período de degustação, onde o cliente pode ter acesso ao conteúdo de forma gratuita por um período determinado. Após o fim deste período, a cobrança é realizada normalmente de forma recorrente. Foi coletado o número de dias em que os consumidores podem ter acesso ao acervo antes da primeira cobrança.

Serviços de streaming menores, que não possuem grandes orçamentos de marketing para alcançar novos usuários, assim como grandes serviços que almejam expandir seus serviços internacionalmente, para países onde não possuem total reconhecimento da marca, comumente recorrem ao período de degustação (Kagan, 2020). Percebe-se, portanto, uma substituição de gastos em marketing por um período de prestação de serviço de forma gratuita. Como há uma decisão de estrutura de custo envolvida, faz sentido afirmar que quanto maior o período de trial, mais se aproxima de uma estratégia de Liderança em Custo, já que há economia de despesas na aquisição do cliente.

O tema tem ganhado importância recentemente, ao se ver grandes empresas como Disney+ e Netflix abandonarem o período de degustação. Isso é claramente uma decisão estratégica, como se vê no caso da Disney, por exemplo. Seu acervo tem um grande valor por conter filmes clássicos e lançamentos longa metragem, que poderiam ser facilmente assistidos ao longo de uma semana de forma gratuita durante o trial. Outras empresas, no entanto, possuem acervos que não podem ser facilmente assistidos em poucos dias.

\subsubsection{Geografia de atuação}

As plataformas de streaming variam bastante em seu âmbito geográfico de atuação. Sendo este local, regional ou global. Foi coletado o número de países em que cada plataforma disponibiliza seus serviços. Essa é uma variável estratégica na medida em que mede a expansão geográfica da empresa, dimensão da posição, um dos 5 P's da estratégia, segundo Mitzberg (1987), além de ser estudado como tema de estratégia em si, como fizeram Hitt, Li e Xu (2016).

\subsubsection{Diversificação de Setor}


Diversos serviços de streaming estão associados a outros serviços e setores da economia. O caso mais emblemático disso é o Prime Video, da Amazon. A empresa oferta diversos serviços a seus clientes, além do audiovisual, como o streaming de música, entrega gratuita do varejo online, armazenamento na nuvem, acesso prioritário a download de lançamentos de livros virtuais, entre outros. Outras plataformas têm por trás grandes estúdios ou programadoras de TV Paga e, portanto, não estão limitadas ao streaming audiovisual, como é o caso do Globoplay, da Globo, que também possui uma emissora de TV Aberta, canais de TV Paga, Jornal, Rádio, entre outros. Essas empresas ficam caracterizadas, portanto, com a diversificação setorial. Por outro lado, há empresas que se restringem ao streaming audiovisual, oferecendo apenas isto a seus clientes, como é o caso da Netflix.

Pode ser considerada uma variável estratégica por medir a diluição do risco por meio da diversificação e a possível contribuição de outros setores no sucesso do serviço de streaming. Neste sentido, Oladineji e Udosen (2019) estudaram o efeito da redução do risco pela diversificação na performance de empresas do setor de manufatura.

\subsubsection{Amplitude da Oferta}

Esta variável está relacionada ao tipo de conteúdo que a plataforma disponibiliza ao assinante. Podendo ser de nicho quando focada em um tipo determinado de conteúdo, como é o caso do Crunchyroll, serviço especializado em animes (desenhos japoneses), ou amplos, quando apresenta todo tipo de conteúdo no acervo, de documentários a animações infantis. Essa variável estratégica é muito útil à aderência ao framework de Porter, por ter grande relevância na perseguição das estratégias de enfoque (PORTER, 1985).

\subsubsection{Marca}

A variável mede a proeminência da marca do serviço. Isto é, se a marca da plataforma é reconhecida pelo público geral, ou se há uma grande companhia por trás do serviço. O caso mais emblemático de marca proeminente é o da Disney+. A variável é pertinente por destacar o quão relevante é a construção da marca por trás do serviço, além de representar, de uma forma indireta, os investimentos em 
Marketing por parte das empresas, já que esse tipo de despesa não é comumente divulgado publicamente. Neste sentido, Hsu, Wang e Chen (2013) examinaram os impactos do valor da marca na performance financeira de empresas.

\subsubsection{Diversificação de Modelo de Negócios}

Como modelo de negócios, o Streaming existe em 4 tipos amplos: SVOD, TVOD, AVOD e vMVPD. No primeiro - subscription video on demand-, o cliente do serviço paga uma assinatura (mensal, anual, trimestral) e tem acesso a um catálogo de filmes e séries. Este é o modelo mais comum entre empresas de streaming, em que se destaca o Netflix.

O TVOD - transactional video on demand - é o modelo transacional, que mais se aproxima de uma locadora ou loja de filmes virtual. O cliente neste serviço tem a opção de comprar ou alugar o filme virtualmente (sem necessariamente fazer o download do arquivo).

O AVOD - ad-supported video on demand -, também conhecido como FVOD - free video on demand - é aquele em que não se paga para ter acesso ao conteúdo. Neste caso, a remuneração se dá pela publicidade.

Por fim, no vMVPD - virtual multichannel video programming distributor - a empresa atua como uma operadora de TV por assinatura virtual. O cliente paga uma assinatura recorrente e tem acesso à canais lineares.

Essa variável estratégica, portanto, mede o número de modelos de negócio que a plataforma acumula. Isto é, de um, quando pratica apenas um dos modelos, a quatro, quando o cliente pode optar por qualquer um dos modelos ou a combinação deles.

\subsubsection{Base de Assinantes}

Variável que mede o número de assinantes na data de coleta de dados. Representa a quantidade de clientes ativos e pagantes que a plataforma acumulou e reteve até o momento. Representa, aproximadamente, a estrutura da empresa, dado que quanto maior o número de assinantes, mais robusta devem ser as operações, a tecnologia (para suportar o número elevado de acessos simultâneos), o marketing, entre outros. O número absoluto de assinantes também é um indicativo da 
importância do efeito de rede, isto é, quanto do valor daquela plataforma deriva do número de usuários que ela retem (STOBIERSKI, 2020). Em outras palavras, quanto mais usuários, maior será a chance de haver recomendações entre grupos de amigos, que por sua vez, contribuem ainda mais para a alavancagem do serviço.

\subsection{Seleção de Variáveis de Desempenho}

A escolha das variáveis de desempenho enfrenta similar desafio da seleção das variáveis estratégicas. Muitas das variáveis de desempenho desejadas não são divulgadas ao público por configurarem informações sensíveis. Mesmo as variáveis escolhidas para medir o desempenho não foram divulgadas pelas próprias empresas em muitos casos. Nestas ocasiões, foram utilizadas estimativas elaboradas por sites de pesquisa de mercado.

Variáveis de desempenho desejadas, mas que tiveram suas coletas de dados impossibilitadas pela falta de informação foram: Lifetime Value, ROI, Receita, ARPU, taxa de cancelamento (churn), Vendas mensais, entre outras. Diante disso, as seguintes variáveis de desempenho foram coletadas e validadas com profissionais e acadêmicos: crescimento de base de assinantes desde os inícios das atividades e receita bruta estimada, que se expõe a seguir.

\subsubsection{Crescimento da Base de Assinantes}

Medida que avalia a rapidez do crescimento da base de assinantes. Avaliado pelo número total de assinaturas que o serviço acumula dividido pelo tempo, em meses, que se decorre entre a data de coleta do dado e a data de lançamento da plataforma. É importante destacar que algumas das plataformas tiveram sua base de assinantes coletadas antes do período da pandemia causada pelo COVID-19, o que pode configurar uma desvantagem em relação àquelas que tiveram dados coletados após o período de quarentena. Isso se deve ao fato da popularização dos serviços de

streaming como entretenimento doméstico durante os chamados lockdowns, nos quais a indústria como um todo observou um crescimento em usuários. 
O crescimento é compreendido como variável de desempenho de maneira incontestável, segundo Santos e Brito (2012), por se tratar de um dos motivos de existência de um negócio. É capaz de demonstrar a capacidade de uma firma de aumentar o seu tamanho (Whetten, 1987). Ao crescer, mesmo que a um mesmo nível de lucratividade, a empresa aumentará o nível de receitas e geração de caixa. Além disso, o crescimento pode trazer benefícios como economias de escala e poder de mercado, o que pode significar aumento de lucratividade futuro (Santos e Brito, 2012).

\subsubsection{Receita Mensal Estimada}

O valor de receita mensal não é divulgado ao público pela grande maioria de serviços de streaming. Apenas aqueles de companhias abertas divulgam seus demonstrativos de resultado, como Netflix e Disney+. Diante disso, utilizou-se a multiplicação da informação de preço da assinatura pelo número de base de assinantes para se estimar o valor de receita que a plataforma é capaz de obter mensalmente. Vale o destaque que é um valor estimado, tendo em vista a variedade de ofertas já explicitada na variável estratégica preço e o número muitas vezes estimado do número de assinantes. É, no entanto, uma boa aproximação para avaliar ganhos de escala ou capacidade de gerar receitas apesar de poucos clientes.

Santos e Brito (2012) entendem que, assim como o crescimento, a lucratividade é um motivador da atividade empresarial e, por isso, deve ser incluída como métrica de desempenho. A lucratividade, infelizmente, não é divulgada abertamente pelas empresas, especialmente as que não são listadas em bolsa. Diante disso, como forma de se aproximar ao máximo dessa variável, optou-se por utilizar a receita bruta, um dos principais condutores da lucratividade.

\subsection{Tratamento de dados}

Os dados foram tratados quantitativamente por meio de procedimentos estatísticos. O software utilizado foi o SPSS (Statistical Package for the Social Sciences), com o objetivo de estudar a indústria de streaming audiovisual, 
identificar a importância da estratégia no atingimento da vantagem competitiva e analisar o desempenho das empresas.

Cada empresa foi classificada em seu grupo estratégico com base na tipologia de Porter (1988), por meio da análise de K-Means cluster. A diferença estatística entre clusters foi avaliada por MANOVA (ibid.). As variáveis de desempenho foram comparadas entre grupos por meio da ANOVA, com o intuito de identificar os grupos com melhor e pior desempenho (ibid.). Abaixo detalha-se as 9 etapas do procedimento:

A análise de dados segue o seguinte procedimento em 8 passos:

1) preparação da base de dados - constituiu no tratamento dos dados coletados dos balanços das empresas, de seus sites, periódicos especializados e sites de inteligência de mercado. Para eliminar distorções de escala e dimensão, todas as variáveis foram transformadas em z score, transformando, assim, todas as variáveis em um grupo homogêneo de informação (Hair et al, 2003);

2) teste de normalidade - nesta etapa pretendeu-se analisar a natureza das variáveis estratégicas e de desempenho, identificando aquelas acentuadamente nãonormais, que podem distorcer o resultado do estudo. Para tanto, são utilizados os testes Kolmogorov-Smirov e Shapiro-Wilk nos testes de normalidade (Hair et al, 2003);

3) análise de correlação - neste passo, buscou-se correlações elevadas entre variáveis (Hair et al, 2003);

4) redução do espaço estratégico - ao identificar as variáveis altamente correlacionadas na etapa anterior, utilizou-se fatores para diminuir o número total de variáveis, sem, no entanto, perder pode explanatório (Hair et al, 2003). Valeu-se da análise de fator (Component Analysis) para a escolha do número de fatores, rotação varimax e o cálculo de fatores por summated-scales das variáveis com peso maior ou igual a 0,7 ;

5) classificação e agrupamento das empresas em grupos estratégicos - na utilização da tipologia de Porter, pretendeu-se nesta etapa o agrupamento de todas as amostras em 5 grupos estratégicos. Para tanto, foi utilizada a análise de Cluster K-Means, que forma os grupos a partir da distância euclidiana e localiza os 
centroides (Hair et al, 2003). Para tanto, foi necessário elaborar a matriz teórica de centroides, de acordo com os quartis;

6) Comparação das matrizes - aqui pretendeu-se verificar se a matriz alvo de centroide inicial é igual a matriz final. Para isso, o teste não paramétrico Wilcoxon Signed Rank foi utilizado. Em seguida verificou-se se os centroides dos grupos estratégicos são diferentes estatisticamente entre si, por meio do teste Wilk's Lambda (Hair et al, 2003).

7) análise da diferença estatística entre clusters por meio da distância entre centroides - verificou-se a aplicabilidade da tipologia de Porter ao se observar a existência de distâncias significativas entre os centroides dos clusters. Isto é, se os grupos são estatisticamente distintos entre si. Aqui foram utilizados a análise múltipla de variância (MANOVA) e o teste de Wilk's Lambda para observar diferenças entre as médias de desempenho dos 5 grupos (Hair et al, 2003).

8) análise de desempenho dos clusters por variável de desempenho verificou-se a aplicabilidade da tipologia de Porter no caso concreto e identificouse quais grupos estratégicos apresentam melhor desempenho, ao observar a existência de diferenças significativas entre as médias de desempenho de cada grupo obtido na análise de cluster. Foram utilizadas a análise de variância (ANOVA) e os testes de Bonferroni e Tamahane com means plot que permitiu verificar o resultado de cada grupo estratégico por variável de desempenho (Hair et al, 2003).

\subsection{Limitações do Método}

A coleta de dados apresentou algumas dificuldades e limitações. A maior delas foi o acesso às informações, consideradas sensíveis, e não divulgadas pelas empresas. Muitas das informações utilizadas, como as de base de assinantes, por exemplo, foram obtidas de estimativas elaboradas por sites de pesquisa de mercado, ou de periódicos especializados em audiovisual, que obtiveram os dados em entrevistas ou conferências com executivos das empresas selecionadas.

O fato de que nem todas as variáveis estratégicas e de desempenho foram retiradas da literatura ou de trabalhos diretamente relacionados com o presente, e 
de que tiveram de ser debatidas e validadas com profissionais, especialistas e acadêmicos como descrito acima, representa uma fragilidade do trabalho.

Há limitações também relacionadas às técnicas estatísticas utilizadas. O número de elementos da amostra não foi definido probabilisticamente, mas de forma conveniente (o acesso aos dados determinou o número de empresas estudadas).

Há, por fim, uma limitação temporal quanto à coleta dos dados. Algumas empresas apresentam dados mais recentes do que outras. Isto atribui uma fragilidade ao trabalho no que tange dados anteriores à pandemia, os quais não abrangem o crescimento acelerado do primeiro trimestre de 2020. Os dados coletados datam entre os períodos de fevereiro de 2018 a dezembro de 2020, sendo os mais recentes disponíveis. Há, portanto, empresas com dados anteriores ao crescimento proporcionados pela quarentena. 


\section{Análise de dados e Resultados}

Das variáveis estratégicas e de desempenho, foram extraídas as estatísticas descritivas expostas na Tabela 2. Com o intuito de eliminar distorções de escala e dimensão, todas as variáveis foram transformadas em $\mathrm{z}$ score. Depois de transformadas, foi testada a normalidade das variáveis estratégicas e de desempenho. Suas distribuições de frequências foram observadas individualmente por meio de Histogramas (Anexo II) e Normal Q-Q Plot (Anexo III), além de aplicados os testes de Kolmogorov-Smirnov e Shapiro-Wilk (Tabela 3) com nível de significância 0,05 , testando as hipóteses abaixo:

Ho: A distribuição é normal.

Há: A distribuição não é normal.

Tabela 2 - Estatísticas Descritivas

Descriptive Statistics

\begin{tabular}{|l|r|r|r|r|r|}
\hline & N & Minimum & Maximum & \multicolumn{1}{|c|}{ Mean } & Std. Deviation \\
\hline Base & 37 & 180000 & 203663000 & 25511432,43 & 45856646,05 \\
Preço Pacote Básico & 37 & 1,7 & 65,0 & 10,978 & 13,2237 \\
Amplitude Oferta & 37 & 0 & 1 &, 84 &, 374 \\
Diversificação (setor) & 37 & 0 & 1 &, 78 &, 417 \\
Diversificação do modelo & 37 & 1,0 & 3,0 & 1,486 &, 6507 \\
Marca & 37 & 0 & 1 &, 68 &, 475 \\
Geografia & 37 & 1 & 200 & 54,62 & 78,368 \\
Trial & 37 & 0 & 60 & 14,08 & 13,084 \\
Receita Estimada & 37 & 571804,5 & 1830930370 & 183895814,8 & 366296925,2 \\
Crescimento & 37 & 5454,5 & 16800000,0 & 1036886,962 & 2940792,758 \\
Valid N (listwise) & 37 & & & & \\
\hline
\end{tabular}

Fonte: SPSS

Das estatísticas descritivas expostas na Tabela 2, percebe-se uma forte internacionalização dos serviços de Streaming, dado uma média de atuação em 50 países. Percebe-se que o período de trial médio é de cerca de 2 semanas. Em média, os serviços de Streaming adotam 1,5 modelo de negócio. Por conta da média superior a 0,5 das variáveis binárias Marca, Diversificação Setorial e Amplitude da Oferta, conclui-se, respectivamente, que a maioria das plataformas possuem marcas proeminentes, optam por uma diversificação setorial (ou são, em sua origem, de 
outros segmentos audiovisuais) e não definem um segmento de mercado específico (ao se adotar uma amplitude de oferta de conteúdo).

Tabela 3 - Teste de Normalidade

Tests of Normality

\begin{tabular}{|c|c|c|c|c|c|c|}
\hline & \multicolumn{3}{|c|}{ Kolmogorov-Smirnov ${ }^{a}$} & \multicolumn{3}{|c|}{ Shapiro-Wilk } \\
\hline & Statistic & df & Sig. & Statistic & df & Sig. \\
\hline $\begin{array}{l}\text { Zscore: Preço Pacote } \\
\text { Básico }\end{array}$ &, 340 & 37 &, 000 &, 558 & 37 &, 000 \\
\hline Zscore: Amplitude Oferta &, 506 & 37 &, 000 & ,445 & 37 &, 000 \\
\hline $\begin{array}{l}\text { Zscore: Diversificação } \\
\text { (setor) }\end{array}$ & ,482 & 37 &, 000 &, 508 & 37 &, 000 \\
\hline $\begin{array}{l}\text { Zscore: Diversificação do } \\
\text { modelo }\end{array}$ &, 367 & 37 & .000 &, 705 & 37 & .000 \\
\hline Zscore(Marca) & ,428 & 37 &, 000 &, 591 & 37 &, 000 \\
\hline Zscore(Geografia) &, 337 & 37 &, 000 &, 677 & 37 &, 000 \\
\hline Zscore(Trial) &, 300 & 37 &, 000 &, 775 & 37 &, 000 \\
\hline Zscore: Base Ln & ,073 & 37 &, $200^{*}$ & 980 & 37 &, 744 \\
\hline $\begin{array}{l}\text { Zscore: Receita } \\
\text { Estimada Ln }\end{array}$ & 102 & 37 & $200^{*}$ & ,984 & 37 &, 856 \\
\hline Zscore: Crescimento Ln &, 065 & 37 &, $200^{*}$ & 977 & 37 &, 618 \\
\hline
\end{tabular}

${ }^{*}$. This is a lower bound of the true significance.

a. Lilliefors Significance Correction

Fonte: SPSS

Ao analisar os resultados da Tabela 3, observa-se que a significância foi menor que 0,05 para todas as variáveis estratégicas, menos a de base de assinantes, e maior que 0,05 para as duas variáveis de desempenho, receita estimada e crescimento. Desta forma, rejeita-se a hipótese nula para as variáveis estratégias, a exceção da Base, sendo, portanto, distribuições não normais. Já para as variáveis de desempenho e variável estratégica de Base, a distribuição é normal. Os resultados são consistentes para ambos os testes Kolmogorov-Smirnov e Shapiro-Wilk.

Com o objetivo de analisar o grau de correlação entre variáveis, o terceiro passo do método, foi realizada a medição se valendo do coeficiente de correlação de Pearson. Neste teste, a hipótese nula é de que o valor da correlação é estatisticamente igual a zero. Significâncias maiores que 0,05 , portanto, confirmam essa hipótese. A tabela apresenta os resultados. 
Tabela 4 - Tabela de Correlação

\begin{tabular}{|c|c|c|c|c|c|c|c|c|c|c|c|}
\hline \multicolumn{12}{|c|}{ Correlations } \\
\hline & & Base & $\begin{array}{l}\text { Preço Pacote } \\
\text { Básico }\end{array}$ & $\begin{array}{c}\text { Amplitude } \\
\text { Oferta }\end{array}$ & $\begin{array}{l}\text { Diversificação } \\
\text { (setor) }\end{array}$ & $\begin{array}{c}\text { Diversificação } \\
\text { do modelo }\end{array}$ & Marca & Geografia & Trial & $\begin{array}{c}\text { Receita } \\
\text { Estimada }\end{array}$ & Crescimento \\
\hline \multirow[t]{3}{*}{ Base } & Pearson Correlation & 1 &,- 163 & 176 &,- 145 & .024 & ,301 & $371^{1}$ &, $394^{\pi}$ & $922^{\prime \prime \prime}$ &, 200 \\
\hline & Sig. (2-tailed) & &, 336 & ,297 & 391 & .889 & .071 & .024 & .016 &, 000 &, 236 \\
\hline & $\mathrm{N}$ & 37 & 37 & 37 & 37 & 37 & 37 & 37 & 37 & 37 & 37 \\
\hline \multirow[t]{3}{*}{ Preço Pacote Básico } & Pearson Correlation & $\begin{array}{l}-163 \\
\end{array}$ & 1 & .162 & .184 &,- 103 & .138 &,- 208 &,- 157 & .014 &,- 105 \\
\hline & Sig. (2-tailed) &, 336 & &, 337 & .275 & 544 & .416 &, 217 &, 352 &, 934 &, 537 \\
\hline & $\mathrm{N}$ & 37 & 37 & 37 & 37 & 37 & 37 & 37 & 37 & 37 & 37 \\
\hline \multirow[t]{3}{*}{ Amplitude Oferta } & Pearson Correlation & 176 & .162 & 1 & $.481^{\prime \prime}$ & .219 & $478^{\prime \prime \prime}$ &,$- 457^{\prime \prime \prime}$ & .111 & ,174 & .134 \\
\hline & Sig. (2-tailed) & .297 &, 337 & &, 003 & 192 &, 003 & .005 & .514 &, 303 & .427 \\
\hline & $\mathrm{N}$ & 37 & 37 & 37 & 37 & 37 & 37 & 37 & 37 & 37 & 37 \\
\hline \multirow[t]{3}{*}{ Diversificação (setor) } & Pearson Correlation &,- 145 & ,184 & $.481^{m}$ & 1 &,- 011 & $.478^{\prime \prime \prime}$ &,$- 554^{\mathrm{N \prime}}$ &, 049 & $\begin{array}{l}-187 \\
\end{array}$ &, 066 \\
\hline & Sig. (2-tailed) &, 391 & .275 & .003 & & 948 &, 003 &, 000 & .773 &, 269 & 697 \\
\hline & $\mathrm{N}$ & 37 & 37 & 37 & 37 & 37 & 37 & 37 & 37 & 37 & 37 \\
\hline \multirow[t]{3}{*}{ Diversificação do modelo } & Pearson Correlation & .024 &,- 103 &, 219 &,- 011 & 1 &,- 015 & .051 & 096 &,- 061 & $\begin{array}{l}-124 \\
\end{array}$ \\
\hline & Sig. (2-tailed) & 889 &, 544 &, 192 & 948 & & 932 &, 764 & .570 &, 719 & 463 \\
\hline & $\mathrm{N}$ & 37 & 37 & 37 & 37 & 37 & 37 & 37 & 37 & 37 & 37 \\
\hline \multirow[t]{3}{*}{ Marca } & Pearson Correlation & .301 & .138 & $.478^{m}$ & $.478^{\prime \prime \prime}$ &,- 015 & 1 &,- 266 & 174 & .260 & .220 \\
\hline & Sig. (2-tailed) & .071 & .416 &, 003 &, 003 &, 932 & & .111 &, 302 & .120 & .192 \\
\hline & $\mathrm{N}$ & 37 & 37 & 37 & 37 & 37 & 37 & 37 & 37 & 37 & 37 \\
\hline \multirow[t]{3}{*}{ Geografia } & Pearson Correlation & $371^{n}$ &,- 208 &,$- 457^{\text {"m }}$ &,$- 554^{\prime \prime}$ & 051 &,- 266 & 1 &, 163 & $.431^{\prime \prime \prime}$ & .130 \\
\hline & Sig. (2-tailed) & .024 &, 217 & .005 &, 000 & .764 & 111 & &, 334 &, 008 & .444 \\
\hline & $\mathrm{N}$ & 37 & 37 & 37 & 37 & 37 & 37 & 37 & 37 & 37 & 37 \\
\hline \multirow[t]{3}{*}{ Trial } & Pearson Correlation & $394^{\circ}$ &,- 157 & .111 & .049 & .096 & .174 & .163 & 1 & .324 &,- 060 \\
\hline & Sig. (2-tailed) &, 016 &, 352 & .514 &, 773 & .570 &, 302 &, 334 & & .051 &, 723 \\
\hline & $\mathrm{N}$ & 37 & 37 & 37 & 37 & 37 & 37 & 37 & 37 & 37 & 37 \\
\hline \multirow[t]{3}{*}{ Receita Estimada } & Pearson Correlation & $922^{\prime \prime}$ & .014 & .174 & $\begin{array}{l}-187 \\
\end{array}$ &,- 061 & .260 & $.431^{\prime \prime}$ & 324 & 1 & .149 \\
\hline & Sig. (2-tailed) &, 000 &, 934 &, 303 &, 269 &, 719 &, 120 &, 008 & .051 & & 379 \\
\hline & $\mathrm{N}$ & 37 & 37 & 37 & 37 & 37 & 37 & 37 & 37 & 37 & 37 \\
\hline \multirow[t]{3}{*}{ Crescimento } & Pearson Correlation & .200 &,- 105 & .134 & 066 &,- 124 & .220 & .130 &,- 060 & .149 & 1 \\
\hline & Sig. (2-tailed) & .236 &, 537 & .427 & .697 & .463 & 192 & .444 &, 723 &, 379 & \\
\hline & $\mathrm{N}$ & 37 & 37 & 37 & 37 & 37 & 37 & 37 & 37 & 37 & 37 \\
\hline
\end{tabular}

Fonte: SPSS

Da tabela, extrai-se que a variável estratégica Receita Estimada é fortemente correlacionada com a variável Base, o que era de se esperar, dado que aquela é calculada com base nesta. Percebe-se também uma correlação entre as variáveis estratégicas Diversificação Setorial e Amplitude da Oferta, Marca e Amplitude da Oferta, Marca e Diversificação Setorial, Geografia e Amplitude da Oferta e, por fim, Geografia e Diversificação Setorial.

Com o intuito de analisar variáveis estratégicas correlacionadas em conjunto, foi realizada a análise de fator exploratória. Fruto dessa análise, foram agrupadas algumas das variáveis estratégicas em fatores, e, portanto, consideradas conjuntamente. Das 8 variáveis estratégicas, 4 são analisadas isoladamente, como se fossem fatores individuais, e 4 em conjunto, em um único fator. Cada um deles pode ser observado a seguir:

F1: Modelo Diversificado (variável diversificação do modelo) 
F2: Estrutura de Mercado de Massa e Efeito de Rede (variável base de assinantes)

F3: Oferta de Período de Degustação (variável Trial)

F4: Estratégia de Ponta de Preço (variável Preço)

F5: Diversificação de Oferta Localizada + Força da Marca (variáveis diversificação de setor, amplitude da oferta, marca consideradas positivas e variável Geografia considerada negativamente).

Tabela 5 - Teste KMO e Bartlett

KMO and Bartlett's Test

\begin{tabular}{|c|c|c|}
\hline \multicolumn{2}{|c|}{ Kaiser-Meyer-Olkin Measure of Sampling Adequacy. } &, 729 \\
\hline \multirow{3}{*}{$\begin{array}{l}\text { Bartlett's Test of } \\
\text { Sphericity }\end{array}$} & Approx. Chi-Square & 37,955 \\
\hline & df & 10 \\
\hline & Sig. &, 000 \\
\hline
\end{tabular}

Fonte: SPSS

Tabela 6 - Matriz Anti-imagem

\begin{tabular}{|c|c|c|c|c|c|c|}
\hline \multicolumn{7}{|c|}{ nti-image Matri } \\
\hline & & $\begin{array}{l}\text { Zscore: } \\
\text { Preço Pacote } \\
\text { Básico }\end{array}$ & $\begin{array}{l}\text { Zscore: } \\
\text { Amplitude } \\
\text { Oferta }\end{array}$ & $\begin{array}{l}\text { Zscore: } \\
\text { Diversificação } \\
\text { (setor) }\end{array}$ & $\begin{array}{l}\text { Zscore } \\
\text { (Marca) }\end{array}$ & $\begin{array}{c}\text { Zscore } \\
\text { (Geografia) }\end{array}$ \\
\hline \multirow[t]{5}{*}{ Anti-image Covariance } & $\begin{array}{l}\text { Zscore: Preço Pacote } \\
\text { Básico }\end{array}$ & .945 &,- 029 &,- 034 &,- 034 & .089 \\
\hline & Zscore: Amplitude Oferta &,- 029 & ,636 &,- 098 &,- 219 & 170 \\
\hline & $\begin{array}{l}\text { Zscore: Diversificação } \\
\text { (setor) }\end{array}$ &,- 034 &,- 098 & .559 &,- 201 & .252 \\
\hline & Zscore(Marca) &,- 034 &,- 219 &,- 201 & 685 &,- 061 \\
\hline & Zscore(Geografia) & ,089 & 170 &, 252 &,- 061 & ,633 \\
\hline \multirow[t]{5}{*}{ Anti-image Correlation } & $\begin{array}{l}\text { Zscore: Preço Pacote } \\
\text { Básico }\end{array}$ & $869^{\mathrm{a}}$ & -037 & -047 &,- 042 & .115 \\
\hline & Zscore: Amplitude Oferta &,- 037 &, $768^{\mathrm{a}}$ & -164 &,- 331 &, 268 \\
\hline & $\begin{array}{l}\text { Zscore: Diversificação } \\
\text { (setor) }\end{array}$ &,- 047 &,- 164 &, $718^{\mathrm{a}}$ &,- 324 &, 424 \\
\hline & Zscore(Marca) &,- 042 &,- 331 &,- 324 &, $708^{\mathrm{a}}$ &,- 093 \\
\hline & Zscore(Geografia) &, 115 & .268 & .424 & -.093 & $697^{\mathrm{a}}$ \\
\hline
\end{tabular}

a. Measures of Sampling Adequacy(MSA)

Fonte: SPSS 
Tabela 7 - Eigenvalues

Total Variance Explained

\begin{tabular}{|l|r|r|r|r|r|r|}
\hline \multirow{2}{*}{ Component } & \multicolumn{3}{|c|}{ Initial Eigenvalues } & \multicolumn{3}{|c|}{ Extraction Sums of Squared Loadings } \\
\cline { 2 - 7 } & \multicolumn{1}{|c|}{ Total } & \% of Variance & Cumulative \% & Total & \% of Variance & Cumulative \% \\
\hline 1 & 2,447 & 48,936 & 48,936 & 2,447 & 48,936 & 48,936 \\
2 &, 928 & 18,566 & 67,502 & & & \\
3 &, 733 & 14,670 & 82,172 & & & \\
4 &, 519 & 10,375 & 92,547 & & & \\
5 &, 373 & 7,453 & 100,000 & & & \\
\hline
\end{tabular}

Fonte: SPSS

Tabela 8 - Fator

Component Matrix ${ }^{\mathrm{a}}$

\begin{tabular}{|l|r|}
\hline & Component \\
\cline { 2 - 2 } & 1 \\
\hline Zscore: Preço Pacote & \\
Básico &, 778 \\
Zscore: Amplitude Oferta &, 819 \\
Zscore: Diversificação & \\
(setor) &, 699 \\
Zscore(Marca) &,- 740 \\
Zscore(Geografia) & \\
\hline
\end{tabular}

Extraction Method: Principal Component Analysis.

a. 1 components extracted.

Fonte: SPSS

$\mathrm{O}$ resultado do teste KMO e de Bartlett, expostos na Tabela 5, justificam a utilização da análise exploratória de fator. O KMO (Kaiser-Meyer-Olkin Measure of Adequacy) é uma estatística que indica a proporção de variância nas variáveis que podem ser consequência de um fator subjacente. Valores altos, próximos a um, geralmente indicam a utilidade da análise de fator para os dados analisados. O teste de esfericidade de Bartlett, por sua vez, testa a hipótese de que a matriz de correlação é uma matriz identidade, o que pode indicar que as variáveis não são correlacionadas e, portanto, não suscetíveis à análise de fator. Valores pequenos, menores que 0,05 de significância, indicam que a análise de fator pode ser útil para os dados. A matriz anti-imagem de correlação da Tabela 6 coloca em destaque a diagonal principal, que mede a adequação da amostra para cada variável. Como os resultados são acima de 0,5 para todas as variáveis, a análise fator é aceita. Foram 
realizadas rodadas anteriores, retirando as variáveis estratégicas da análise de fator quando apresentavam valores menores que 0,5 na diagonal principal. As variáveis retiradas foram consideradas como fatores isolados. A Tabela 7 mostra o resultado dos Eigenvalues. Como um componente apresenta Eigenvalue maior que 1, essa é a quantidade de fatores utilizada, isto é, apenas um fator explica mais variância do que as variáveis individualmente. Por fim, a tabela 8 apresenta a matriz de componentes do Fator resultante da análise.

Depois de realizada a análise de fator, os fatores resultantes foram utilizados para se fazer o agrupamento das empresas do estudo em grupos estratégicos. Para isso, foi utilizada a análise de cluster. Malhotra (2006) descreve a formação de clusters como uma técnica de classificação em casos relativamente homogêneos. Isto é, os objetos de cada cluster são semelhantes entre si, mas diferentes de objetos de outros clusters.

No SPSS, a análise de cluster utilizada foi a K-Means, método que aglutina objetos mutuamente exclusivos. A aglutinação, por sua vez, é realizada a partir de uma matriz teórica de centroides elaborada a priori e inserida no programa. Esta matriz teórica, por sua vez, foi definida com base na teoria de Porter (1980) e determina o centro de cada cluster, ou grupo estratégico. Abaixo a matriz teórica que dá origem à matriz de centroides original:

Tabela 9 - Matriz de Centroides Teórica

$\begin{array}{llllll} & \text { F1 } & \text { F2 } & \text { F3 } & \text { F4 } & \text { F5 } \\ \text { DIF } & \text { Q1 } & \text { Q2 } & \text { Q2 } & \text { Q1 } & \text { Q1 } \\ \text { CUSTO } & \text { Q3 } & \text { Q3 } & \text { Q3 } & \text { Q3 } & \text { Q2 } \\ \text { ENF DIF } & \text { Q1 } & \text { Q1 } & \text { Q2 } & \text { Q1 } & \text { Q1 } \\ \text { ENF CUSTO } & \text { Q1 } & \text { Q1 } & \text { Q3 } & \text { Q3 } & \text { Q1 } \\ \text { STUCK } & \text { Q2 } & \text { Q2 } & \text { Q2 } & \text { Q2 } & \text { Q2 }\end{array}$

Fonte: Elaboração do Autor

O centroide de cada cluster foi definido na matriz teórica de acordo com os quartis: $\quad$ Q1: Quartil inferior - 25\% da distribuição de frequência

Q2: Mediana

Q3: Quartil superior - 75\% da distribuição de frequência 
O Fator 1, Modelo Diversificado, constituído pela variável Diversificação de Modelo, recebe o quartil inferior para as estratégias de Diferenciação, Enfoque em Diferenciação e Enfoque em Custo na matriz teórica por se entender que essas estratégias não combinam com vários modelos de negócios simultâneos. Espera-se que tanto na diferenciação, quanto no enfoque, a plataforma concentre seus esforços em um único modelo. Por outro lado, aqueles que perseguem a estratégia de Liderança em Custo ficam dispostos a se valer de mais de um modelo para reduzir o preço da mensalidade, por exemplo, como é o caso daquelas que além do SVOD também incluem o AVOD para reduzir o valor da assinatura.

O Fator 2, Estrutura de Mercado de Massa e Efeito de Rede, que tem como base a variável estratégica Base de Assinantes, recebe o quartil inferior para as estratégias de Enfoque por se entender que as plataformas que perseguem essas estratégias esperam menos assinantes, justamente por focarem em determinado segmento de mercado. Por outro lado, a Estratégia de Liderança em Custo recebe o quartil superior já que plataformas que perseguem essa tipologia buscam a escala e aquisição do maior número de assinantes possível. Por fim, para a Estratégia de Diferenciação, o tamanho da base de assinantes foi considerado como não relevante e, por isso, recebe o quartil intermediário.

O Fator 3, Oferta de Período de Degustação, variável Trial, recebe o quartil superior na matriz teórica para as Estratégias Liderança em Custo e Enfoque em Custo por se entender que plataformas que classificadas nessas tipologias disponibilizam um maior período de consumo gratuito do conteúdo. Já para as tipologias de Enfoque em Diferenciação e Diferenciação, o período de trial foi considerado como não relevante, dado que não há, aparentemente, uma relação direta com o período de degustação e o valor da assinatura. Percebe-se atualmente, inclusive, o abandono do período de degustação por muitas plataformas, o que evidencia uma queda de importância dessa variável estratégica.

O Fator 4, Estratégia de Ponta de Preço (variável Preço), é um dos mais diretos na atribuição dos quartis segundo a tipologia de Porter. Preços mais altos se relacionam com as estratégias de Diferenciação e Enfoque em Diferenciação, enquanto preços baixos são característicos das estratégias de Liderança em Custo e Enfoque em Custo. 
Por fim, o Fator 5, Diversificação de Oferta Localizada + Força da Marca (variáveis diversificação de setor, amplitude da oferta e marca consideradas positivas e variável Geografia considerada negativamente), recebe o quartil inferior nas estratégias de Diferenciação e nas de Enfoque por se considerar que quanto mais se está preocupado em especializar o seu serviço ou de atacar um determinado segmento de marcado, menor será o interesse de diversificar o setor de atuação pela empresa. Por outro lado, a importância de se construir uma marca forte para se conquistar uma escala necessária ao atingimento da Liderança em Custo, justifica o quartil intermediário para essa estratégia. Para a tipologia Stuck In The Middle, conforme a teoria de Porter, recebe a mediana para todos os Fatores. O fato de a variável Geografia estar nesse fator também justifica o primeiro quartil para as variáveis de Enfoque, uma vez que ao se expandir a área de atuação, se está renunciando a uma segmentação de mercado local ou regional.

Tabela 10 - Matriz de centroides inicial

Initial Cluster Centers

\begin{tabular}{|l|r|r|r|r|r|}
\hline & \multicolumn{6}{|c|}{ Cluster } \\
\cline { 2 - 6 } & 1 & \multicolumn{1}{|c|}{2} & 3 & \multicolumn{1}{c|}{4} & \multicolumn{1}{c|}{5} \\
\hline F1 &,- 75 &, 79 &,- 75 &,- 75 &,- 75 \\
F2 &, 13 &, 75 &,- 79 &,- 79 &, 13 \\
F3 &,- 54 & 1,22 &,- 54 & 1,22 &,- 54 \\
F4 &,- 45 &,- 07 &,- 45 &,- 07 &,- 30 \\
F5 &,- 40 &, 36 &,- 40 &,- 40 &, 36 \\
\hline
\end{tabular}

Input from FILE Subcommand

Fonte: SPSS

Com base na tabela de centroides inicial, o algoritmo K-Means cluster calculou novos centroides em 5 iterações, apresentados na seguinte tabela para dar origem aos grupos estratégicos, para, em seguida, gerar a matriz de centroides final, atribuindo as empresas em cada um dos clusters. 
Tabela 11 - Interações de clusterização

Iteration History ${ }^{a}$

\begin{tabular}{|l|c|c|c|c|c|}
\hline \multirow{2}{*}{ Iteration } & \multicolumn{6}{|c|}{ Change in Cluster Centers } \\
\cline { 2 - 6 } & 1 & 2 & 3 & \multicolumn{1}{c|}{4} & \multicolumn{1}{c|}{5} \\
\hline 1 &, 887 &, 463 &, 698 &, 420 &, 831 \\
2 &, 498 &, 418 &, 231 &, 708 &, 268 \\
3 &, 311 &, 207 &, 000 &, 000 &, 180 \\
4 &, 000 &, 132 &, 000 &, 000 &, 155 \\
5 &, 000 &, 000 &, 000 &, 000 &, 000 \\
\hline
\end{tabular}

a. Convergence achieved due to no or small change in cluster centers. The maximum absolute coordinate change for any center is, 000 . The current iteration is 5 . The minimum distance between initial centers is, 771 .

\section{Fonte: SPSS}

Tabela 12 - Número de casos por cluster

\section{Number of Cases in each} Cluster

\begin{tabular}{|ll|r|}
\hline Cluster & 1 & 5,000 \\
& 2 & 11,000 \\
& 3 & 7,000 \\
& 4 & 3,000 \\
& 5 & 11,000 \\
Valid & & 37,000 \\
Missing & &, 000 \\
\hline
\end{tabular}

Fonte: SPSS

Das 37 plataformas da pesquisa, todas foram alocadas em um dos grupos estratégicos, da seguinte maneira: 5 em Diferenciação (14\%), 11 em Liderança em Custo (30\%), 7 em Enfoque em Diferenciação (19\%), 3 em Enfoque em Custo (8\%) e 11 em Stuck In The Middle ou Sem Posicionamento (30\%).

O fato de terem muitas empresas alocadas no grupo Stuck In The Middle se deve à maturidade do setor. Como há muitas empresas novas e o setor como um todo ainda não atingiu a maturidade total, é normal que um mix de estratégias seja utilizado, já que ainda não é certo qual estratégia é a mais bem sucedida.

A Figura 6 abaixo apresenta a alocação de cada plataforma por cluster: 
Figura 6 - Plataforma por Cluster

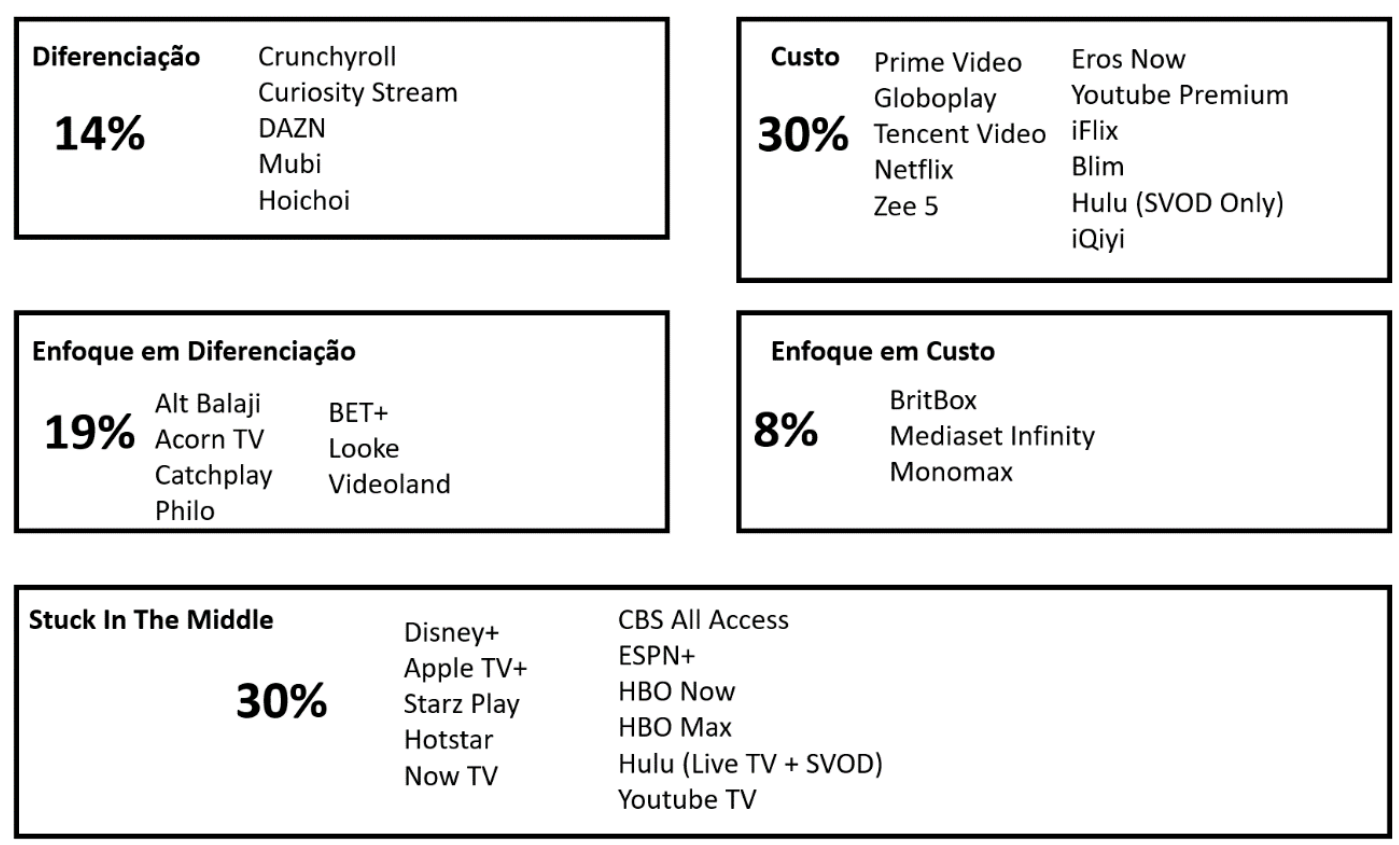

Fonte: Elaboração do Autor

Cabe aqui a avaliação da alocação das empresas estudadas nos Grupos Estratégicos. O Grupo Diferenciação ficou bastante coerente com as características das empresas que o integram. Crunchyroll, especializado em animes, Curiosity Stream, que possui apenas documentários em seu acervo, DAZN, apenas conteúdos esportivos, Mubi, com conteúdos independentes selecionados, e Hoichoi, com conteúdos Bengali, possuem traços marcantes de diferenciação de seus serviços. Como atuam globalmente ou em regiões populosas, sem o foco em determinado segmento de mercado, cabem no Grupo de Diferenciação.

Quanto ao Grupo de Liderança em Custo, a alocação de empresas também faz sentido. Por exemplo, o Prime Video, marcado por seu reduzido preço, Globoplay, que possui o modelo AVOD além dos modelos SVOD e vMVPD, iFlix, que busca a escala com preços baixos além da utilização do AVOD em combinação com a assinatura, Hulu, que reduz o preço da oferta SVOD com a exposição de publicidade aos seus clientes, entre outros, combinam bastante com a perseguição da Estratégia de Liderança em Custo. Cabe aqui o destaque da alocação do Netflix neste Grupo Estratégico. O preço da assinatura básica, relativamente baixo, e a busca por escala no âmbito global justificam essa alocação. 
O Grupo Estratégico Enfoque em Diferenciação teve alocação das empresas Acorn TV, focada em conteúdos da Grã-bretanha, Videoland, disponível apenas em Holandês, Catchplay, com conteúdos tailandeses em seu acervo, podem ser considerados como Enfoque em uma perspectiva global por limitarem seus alvos em segmentos específicos, sem perder a busca por um diferencial.

Mediaset Infinity, caracterizado por seus conteúdos em italiano, BritBox, com conteúdos ingleses em seu acervo, Monomax, com conteúdos tailandeses, se enquadram coerentemente no Enfoque em Custo, por limitarem o segmento de mercado que atacam por conta de seus conteúdos e a busca por um menor preço.

Por fim, o Grupo Estratégico Stuck In The Middle recebe boa parte das empresas estudadas, muito por conta do nível de maturidade dessa indústria. Como ainda não há muitas empresas incumbentes, ainda não se sabe ao certo qual a estratégia vencedora, e, por isso, é comum que empresas acabem por adotar traços de diferentes grupos estratégicos simultaneamente. A Apple TV+, por exemplo, apesar de oferecer um ano de assinatura gratuita aos compradores de hardware Apple, o que se aproxima de uma estratégia de Liderança em Custo, se aproxima da diferenciação pelo próprio preço dos hardwares, muito acima da média do mercado. A Disney+ ao mesmo tempo oferece grandes quantidades de conteúdo infantil, o que representa um traço de diferenciação e até mesmo de enfoque, por limitar seu segmento de mercado às crianças, também inclui em seu acervo documentários do National Geographic, consumido por públicos mais adultos. A alocação de marcas expoentes como Disney+, ESPN+ e Youtube TV neste grupo estratégico também pode ser justificado pela força de suas marcas, que potencialmente são diferenciadas, mas que por serem destaques em proeminência, atraem muitos clientes, possibilitando um ganho de escala e consequente redução do preço da assinatura.

A seguir, a tabela de centroides final e o resultado do teste não paramétrico de Wilcoxon signed rank para a distância entre os centroides iniciais e finais, onde a hipótese nula é de que os centroides teóricos e finais, fator a fator, são a alternativa é de que são diferentes. 
Tabela 13 - Matriz de centroides final

Final Cluster Centers

\begin{tabular}{|l|r|r|r|r|r|}
\hline \multirow{2}{*}{} & \multicolumn{6}{|c|}{ Cluster } \\
\cline { 2 - 6 } & 1 & \multicolumn{1}{|c|}{2} & 3 & \multicolumn{1}{c|}{4} & \multicolumn{1}{c|}{5} \\
\hline F1 &,- 13 &, 93 &,- 31 &,- 75 &,- 47 \\
F2 &, 15 &, 95 & $-1,18$ & $-1,31$ &, 09 \\
F3 &,- 08 &, 70 &,- 69 & 1,22 &,- 56 \\
F4 &,- 32 &,- 37 &,- 22 &,- 23 &, 72 \\
F5 & $-1,53$ &, 17 &,- 17 &, 58 &, 48 \\
\hline
\end{tabular}

Fonte: SPSS

Tabela 14 - Teste não paramétrico de Wilcoxon

Test Statistics ${ }^{a}$

\begin{tabular}{|l|r|r|r|r|r|}
\hline & F1F - F1I & F2F - F2I & F3F - F3I & F4F - F4I & F5F - F5I \\
\hline Z & $-1,826^{\mathrm{b}}$ &,$- 944^{\mathrm{C}}$ &,$- 730^{\mathrm{C}}$ &,$- 405^{\mathrm{b}}$ &,$- 135^{\mathrm{b}}$ \\
Asymp. Sig. (2-tailed) &, 068 &, 345 &, 465 &, 686 &, 893 \\
\hline
\end{tabular}

a. Wilcoxon Signed Ranks Test

b. Based on negative ranks.

c. Based on positive ranks.

Fonte: SPSS

Como se pode observar, todas as significâncias são maiores que 0,05 , não rejeitando, portanto, a hipótese nula. Desta forma, conclui-se que a matriz inicial é estatisticamente igual à final.

A seguir, foi utilizada a MANOVA (análise multivariada da variância) que segundo Malhotra (2006) se assemelha ao teste ANOVA só que para mais de duas variáveis conjuntamente dependentes. O objetivo deste passo é identificar diferenças entre grupos simultaneamente ao longo de múltiplas variáveis dependentes.

Isto é, deseja-se observar se os grupos estratégicos encontrados têm posicionamento estatisticamente iguais ou diferentes. As hipóteses testadas são:

Ho: Os centroides dos clusters são iguais

Há: Os centroides de pelo menos um dos clusters é diferente dos outros 
Tabela 15 - MANOVA

Multivariate Tests ${ }^{\text {a }}$

\begin{tabular}{|ll|r|r|r|r|r|}
\hline Effect & & \multicolumn{1}{|c|}{ Value } & \multicolumn{1}{c|}{ F } & Hypothesis df & \multicolumn{1}{c|}{ Error df } & \multicolumn{1}{c|}{ Sig. } \\
\hline Intercept & Pillai's Trace &, 341 & $2,898^{\mathrm{b}}$ & 5,000 & 28,000 &, 031 \\
& Wilks' Lambda &, 659 & $2,898^{\mathrm{b}}$ & 5,000 & 28,000 &, 031 \\
& Hotelling's Trace &, 518 & $2,898^{\mathrm{b}}$ & 5,000 & 28,000 &, 031 \\
& Roy's Largest Root &, 518 & $2,898^{\mathrm{b}}$ & 5,000 & 28,000 &, 031 \\
\hline QCL_1 & Pillai's Trace & 2,279 & 8,207 & 20,000 & 124,000 &, 000 \\
& Wilks' Lambda &, 016 & 11,783 & 20,000 & 93,815 &, 000 \\
& Hotelling's Trace & 9,612 & 12,735 & 20,000 & 106,000 &, 000 \\
& Roy's Largest Root & 5,161 & $31,998^{\mathrm{C}}$ & 5,000 & 31,000 &, 000 \\
\hline
\end{tabular}

a. Design: Intercept + QCL_1

b. Exact statistic

c. The statistic is an upper bound on $\mathrm{F}$ that yields a lower bound on the significance level.

Fonte: SPSS

Do que se extrai da Tabela 15, o nível de significância é zero, rejeitando, portanto, a hipótese nula de que os grupos são iguais. Ou seja, os grupos estratégicos formados são estatisticamente diferentes, com pelo menos um cluster com centroide diferente dos outros.

Na etapa de análise de desempenho dos grupos estratégicos, o objetivo é de verificar se cada variável de desempenho possui diferença estatisticamente significativa de média de desempenho de um grupo estratégico para outro.

Para isso, é utilizada a ANOVA (teste de análise de variância) com as seguintes hipóteses:

Ho: As médias de desempenho são iguais entre grupos

Há: As médias de desempenho são diferentes entre pelo menos dois grupos

Tabela 16 - ANOVA

ANOVA

\begin{tabular}{|c|c|c|c|c|c|c|}
\hline & & $\begin{array}{l}\text { Sum of } \\
\text { Squares }\end{array}$ & df & Mean Square & $\mathrm{F}$ & Sig. \\
\hline \multirow{3}{*}{$\begin{array}{l}\text { Zscore: Receita } \\
\text { Estimada Ln }\end{array}$} & Between Groups & 24,162 & 4 & \multirow{3}{*}{$\begin{array}{r}6,041 \\
, 370\end{array}$} & \multirow[t]{3}{*}{16,329} & \multirow[t]{3}{*}{.000} \\
\hline & Within Groups & 11,838 & 32 & & & \\
\hline & Total & 36,000 & 36 & & & \\
\hline \multirow[t]{3}{*}{ Zscore: Crescimento Ln } & Between Groups & 17,604 & 4 & \multirow{3}{*}{$\begin{array}{r}4,401 \\
, 575\end{array}$} & \multirow[t]{3}{*}{7,656} & \multirow[t]{3}{*}{, 000} \\
\hline & Within Groups & 18,396 & 32 & & & \\
\hline & Total & 36,000 & 36 & & & \\
\hline
\end{tabular}


Fonte: SPSS

Como pode ser observado na Tabela 16 , os valores menores que 0,05 para ambas as variáveis de desempenho rejeitam a hipótese nula de que os grupos apresentam desempenho igual. Há, portanto, pelo menos um grupo que se destaca estatisticamente no desempenho do que outro.

Com o intuito de aprofundar a análise, foi aplicado a ANOVA com Tamhane e Bonferroni. Neste passo, além de se ter uma melhor visualização, é possível observar os grupos estratégicos com melhor e pior desempenho.

Tabela 17 - ANOVA (Tamhane e Bonferroni)

\begin{tabular}{|c|c|c|c|c|c|c|c|c|}
\hline \multicolumn{9}{|c|}{ Multiple Comparisons } \\
\hline & & \multirow{2}{*}{$\begin{array}{l}\text { (l) Cluster Number of } \\
\text { Case }\end{array}$} & \multirow{2}{*}{$\begin{array}{l}\text { (J) Cluster Number of } \\
\text { Case }\end{array}$} & \multirow{2}{*}{$\begin{array}{c}\text { Mean } \\
\text { Difference (I- } \\
\mathrm{J})\end{array}$} & \multirow[b]{2}{*}{ Std. Error } & \multirow[b]{2}{*}{ Sig. } & \multicolumn{2}{|c|}{ 95\% Confidence Interval } \\
\hline DependentVariable & & & & & & & Lower Bound & Upper Bound \\
\hline Zscore: Receita & \multirow[t]{20}{*}{ Bonferroni } & \multirow[t]{4}{*}{1} & 2 &,- 72323174 &, 32804610 & 348 & $-1,7122740$ & ,2658105 \\
\hline & & & 3 & $1,30021440^{*}$ &, 35613350 & .009 &, 2264901 & 2,3739387 \\
\hline & & & 4 & 1,30021440 & .44417652 & .062 & -.0389551 & 2,6393839 \\
\hline & & & 5 &,- 37263463 &, 32804610 & 1,000 & $-1,3616769$ &, 6164076 \\
\hline & & \multirow[t]{4}{*}{2} & 1 &, 72323174 & .32804610 & 348 &,- 2658105 & 1,7122740 \\
\hline & & & 3 & $2,02344614^{*}$ & .29406756 & .000 & 1,1368475 & 2,9100448 \\
\hline & & & 4 & $2,02344614^{x}$ & 39615330 &, 000 &, 8290642 & 3,2178281 \\
\hline & & & 5 & ,35059710 & .25934321 & 1,000 & -.4313094 & 1,1325036 \\
\hline & & \multirow[t]{4}{*}{3} & 1 & $-1,30021440^{\circ}$ & 35613350 & 009 & $-2,3739387$ &,- 2264901 \\
\hline & & & 2 & $-2,02344614^{*}$ & .29406756 & .000 & $-2,9100448$ & $-1,1368475$ \\
\hline & & & 4 & OE-8 & .41970736 & 1,000 & $-1,2653962$ & 1,2653962 \\
\hline & & & 5 & $-1,67284903^{*}$ & .29406756 &, 000 & $-2,5594477$ &,- 7862504 \\
\hline & & \multirow[t]{4}{*}{4} & 1 & $-1,30021440$ & .44417652 & ,062 & $-2,6393839$ & ,0389551 \\
\hline & & & 2 & $-2,02344614^{\circ}$ & ,39615330 &, 000 & $-3,2178281$ &,- 8290642 \\
\hline & & & 3 & OE-8 & .41970736 & 1,000 & $-1,2653962$ & 1,2653962 \\
\hline & & & 5 & $-1,67284903^{*}$ & .39615330 &, 002 & $-2,8672310$ &,- 4784671 \\
\hline & & \multirow[t]{4}{*}{5} & 1 &, 37263463 &, 32804610 & 1,000 &,- 6164076 & 1,3616769 \\
\hline & & & 2 &,- 35059710 & .25934321 & 1,000 & $-1,1325036$ &, 4313094 \\
\hline & & & 3 & $1,67284903^{*}$ & 29406756 &, 000 &, 7862504 & 2,5594477 \\
\hline & & & 4 & $1,67284903^{*}$ & 39615330 &, 002 & 4784671 & 2,8672310 \\
\hline & \multirow[t]{20}{*}{ Tamhane } & \multirow[t]{4}{*}{1} & 2 &,- 72323174 & 28852176 & .225 & $-1,6801104$ & .2336470 \\
\hline & & & 3 & $1,30021440^{*}$ &, 26701230 & ,007 & ,3371657 & 2,2632631 \\
\hline & & & 4 & 1,30021440 & .26647043 & .092 & -.2648546 & 2,8652834 \\
\hline & & & 5 &,- 37263463 & ,20393145 & .630 & $-1,0811336$ & ,3358644 \\
\hline & & \multirow[t]{4}{*}{2} & 1 &, 72323174 & .28852176 & .225 &,- 2336470 & 1,6801104 \\
\hline & & & 3 & $2,02344614^{*}$ &, 33418784 & .000 & 9366490 & 3,1102432 \\
\hline & & & 4 & $2,02344614^{*}$ &, 33375505 & .004 &, 7325937 & 3,3142986 \\
\hline & & & 5 &, 35059710 &, 28631099 &, 935 &,- 5783059 & 1,2795001 \\
\hline & & \multirow[t]{4}{*}{3} & 1 & $-1,30021440^{\circ}$ &, 26701230 & .007 & $-2,2632631$ &,- 3371657 \\
\hline & & & 2 & $-2,02344614^{x}$ &, 33418784 & .000 & $-3,1102432$ &,- 9366490 \\
\hline & & & 4 & OE-8 & 31534615 & 1,000 & $-1,3527525$ & 1,3527525 \\
\hline & & & 5 & $-1,67284903^{*}$ &, 26462189 & .001 & $-2,5992477$ &,- 7464504 \\
\hline & & \multirow[t]{4}{*}{4} & 1 & $-1,30021440$ & 26647043 & .092 & $-2,8652834$ &, 2648546 \\
\hline & & & 2 & $-2,02344614^{*}$ &, 33375505 &, 004 & $-3,3142986$ &,- 7325937 \\
\hline & & & 3 & $0 \mathrm{E}-8$ &, 31534615 & 1,000 & $-1,3527525$ & 1,3527525 \\
\hline & & & 5 & $-1,67284903^{*}$ & 26407511 & .036 & $-3,1960668$ &,- 1496313 \\
\hline & & \multirow[t]{4}{*}{5} & 1 & .37263463 &, 20393145 & .630 &,- 3358644 & 1,0811336 \\
\hline & & & 2 &,- 35059710 &, 28631099 & .935 & $-1,2795001$ & .5783059 \\
\hline & & & 3 & $1,67284903^{x}$ &, 26462189 & ,001 &, 7464504 & 2,5992477 \\
\hline & & & 4 & $1,67284903^{*}$ & 26407511 & .036 & .1496313 & 3,1960668 \\
\hline
\end{tabular}




\begin{tabular}{|c|c|c|c|c|c|c|c|c|}
\hline \multirow[t]{40}{*}{ Zscore: Crescimento Ln } & \multirow[t]{20}{*}{ Bonferroni } & \multirow[t]{4}{*}{1} & 2 &,- 73864652 & ,40894529 & ,803 & $-1,9715957$ & ,4943026 \\
\hline & & & 3 & 89026883 & 44395931 & .535 &,- 4482458 & 2,2287835 \\
\hline & & & 4 & 1,07808926 &, 55371454 &, 604 &,- 5913318 & 2,7475103 \\
\hline & & & 5 &,- 53247092 & ,40894529 & 1,000 & $-1,7654201$ & .7004782 \\
\hline & & \multirow[t]{4}{*}{2} & 1 & .73864652 &, 40894529 &, 803 &,- 4943026 & 1,9715957 \\
\hline & & & 3 & $1,62891536^{*}$ &, 36658733 & .001 &, 5236733 & 2,7341574 \\
\hline & & & 4 & $1,81673579^{*}$ & .49384836 &, 009 &, 3278082 & 3,3056633 \\
\hline & & & 5 &, 20617561 &, 32329964 & 1,000 &,- 7685563 & 1,1809075 \\
\hline & & \multirow[t]{4}{*}{3} & 1 &,- 89026883 &, 44395931 &., 535 & $-2,2287835$ &, 4482458 \\
\hline & & & 2 & $-1,62891536^{*}$ &, 36658733 &, 001 & $-2,7341574$ &,- 5236733 \\
\hline & & & 4 & ,18782043 & .52321106 & 1,000 & $-1,3896342$ & 1,7652750 \\
\hline & & & 5 & $-1,42273975^{n}$ &, 36658733 &, 005 & $-2,5279818$ &,- 3174977 \\
\hline & & \multirow[t]{4}{*}{4} & 1 & $-1,07808926$ & .55371454 & .604 & $-2,7475103$ & 5913318 \\
\hline & & & 2 & $-1,81673579^{\wedge}$ & .49384836 &, 009 & $-3,3056633$ &,- 3278082 \\
\hline & & & 3 &,- 18782043 & .52321106 & 1,000 & $-1,7652750$ & 1,3896342 \\
\hline & & & 5 & $-1,61056018^{*}$ & .49384836 & .026 & $-3,0994877$ &,- 1216326 \\
\hline & & \multirow[t]{4}{*}{5} & 1 &, 53247092 & .40894529 & 1,000 &,- 7004782 & 1,7654201 \\
\hline & & & 2 &,- 20617561 &, 32329964 & 1,000 & $-1,1809075$ &, 7685563 \\
\hline & & & 3 & $1,42273975^{\circ}$ &, 36658733 &, 005 &, 3174977 & 2,5279818 \\
\hline & & & 4 & $1,61056018^{*}$ &, 49384836 & .026 &, 1216326 & 3,0994877 \\
\hline & \multirow[t]{20}{*}{ Tamhane } & \multirow[t]{4}{*}{1} & 2 &,- 73864652 &, 31903584 & .408 & $-1,9813684$ & .5040753 \\
\hline & & & 3 & 89026883 &, 33433092 & 251 &,- 3823071 & 2,1628448 \\
\hline & & & 4 & 1,07808926 & .41215673 & .402 &,- 9515024 & 3,1076810 \\
\hline & & & 5 &,- 53247092 & ,41814789 & 922 & $-1,9371274$ &, 8721856 \\
\hline & & \multirow[t]{4}{*}{2} & 1 & .73864652 &, 31903584 & .408 &,- 5040753 & 1,9813684 \\
\hline & & & 3 & $1,62891536^{*}$ &, 26540000 & .000 &, 7464339 & 2,5113968 \\
\hline & & & 4 & 1,81673579 &, 35851522 & 107 &,- 5260454 & 4,1595169 \\
\hline & & & 5 &, 20617561 &, 36538699 & 1,000 &,- 9853707 & 1,3977219 \\
\hline & & \multirow[t]{4}{*}{3} & 1 & -89026883 &, 33433092 & .251 & $-2,1628448$ &, 3823071 \\
\hline & & & 2 & $-1,62891536^{*}$ & 26540000 &, 000 & $-2,5113968$ &,- 7464339 \\
\hline & & & 4 & ,18782043 &, 37219143 & 1,000 & $-1,9935591$ & 2,3692000 \\
\hline & & & 5 & $-1,42273975^{*}$ &, 37881519 & .018 & $-2,6578287$ &,- 1876508 \\
\hline & & \multirow[t]{4}{*}{4} & 1 & $-1,07808926$ & .41215673 & .402 & $-3,1076810$ & .9515024 \\
\hline & & & 2 & $-1,81673579$ &, 35851522 & ,107 & $-4,1595169$ & .5260454 \\
\hline & & & 3 &,- 18782043 &, 37219143 & 1,000 & $-2,3692000$ & 1,9935591 \\
\hline & & & 5 & $-1,61056018$ & ,44899550 & .088 & $-3,4233591$ & ,2022388 \\
\hline & & \multirow[t]{4}{*}{5} & 1 &, 53247092 &, 41814789 & 922 &,- 8721856 & 1,9371274 \\
\hline & & & 2 &,- 20617561 &, 36538699 & 1,000 & $-1,3977219$ & 9853707 \\
\hline & & & 3 & $1,42273975^{*}$ &, 37881519 & .018 &, 1876508 & 2,6578287 \\
\hline & & & 4 & 1,61056018 & 44899550 & 088 & -2022388 & 3,4233591 \\
\hline
\end{tabular}

Fonte: SPSS

A Tabela 17 mostra que o grupo estratégico Diferenciação tem desempenho estatisticamente superior ao de Enfoque em Custo, o grupo Liderança em Diferenciação apresenta melhor desempenho que os grupos Enfoque em Diferenciação e Enfoque em Custo e que o grupo estratégico Stuck In The Middle tem melhor desempenho que os grupos Enfoque em Custo e Enfoque em Diferenciação, segundo os testes de Bonferroni e de Tamhane para a variável Receita Estimada.

Parte dessas relações, resumidas a seguir, são confirmadas também para a variável Crescimento. O grupo Stuck In The Middle aparece com desempenho estatisticamente superior aos grupos Enfoque em Custo e Enfoque em Diferenciação e o grupo Liderança em Custo apresenta desempenho melhor que os grupos Enfoque em Diferenciação e Enfoque em Custo no teste de Bonferroni. Em Tamhane, o grupo Enfoque em Diferenciação apresenta desempenho 
estatisiticamente inferior aos grupos estratégicos Liderança em Custo e Stuck In The Middle.

- Diferenciação > Enfoque em Diferenciação - relação confirmada por Bonferroni e Tamhane para a variável Receita Estimada.

- Liderança em Custo > Enfoque em Diferenciação - relação apontada por ambos os testes para ambas variáveis de desemepenho.

- Liderança em Custo > Enfoque em Custo - relação apontada por ambos os testes para a variável de desempenho Receita Estimada e pelo teste de Bonferroni para a variável Crescimento.

- Stuck In The Middle > Enfoque em Diferenciação - relação identificada por ambos os testes em ambas variáveis de desempenho.

- Stuck In The Middle > Enfoque em Custo - relação identificada por ambos os testes para a variável Receita Estimada e pelo teste de Bonferroni para a variável Crescimento. Este resultado, apesar de ir contra a proposta de Porter, pode decorrer do nível de maturidade da indústria e de seu crescimento acelerado, que pode ter beneficiado empresas sem um posicionamneto estratégico bem definido.

Por fim, foi gerado o means plot das duas variáveis de desempenho:

Receita Estimada: os grupos estratégicos Diferenciação (1), Liderança em Custo (2) e Stuck in The Middle (5) apresentam melhores desempenhos estratégicos que os grupos Enfoque em Diferenciação (3) e Enfoque em Custo (4). 
Figura 7 - Means Plot Receita Estimada

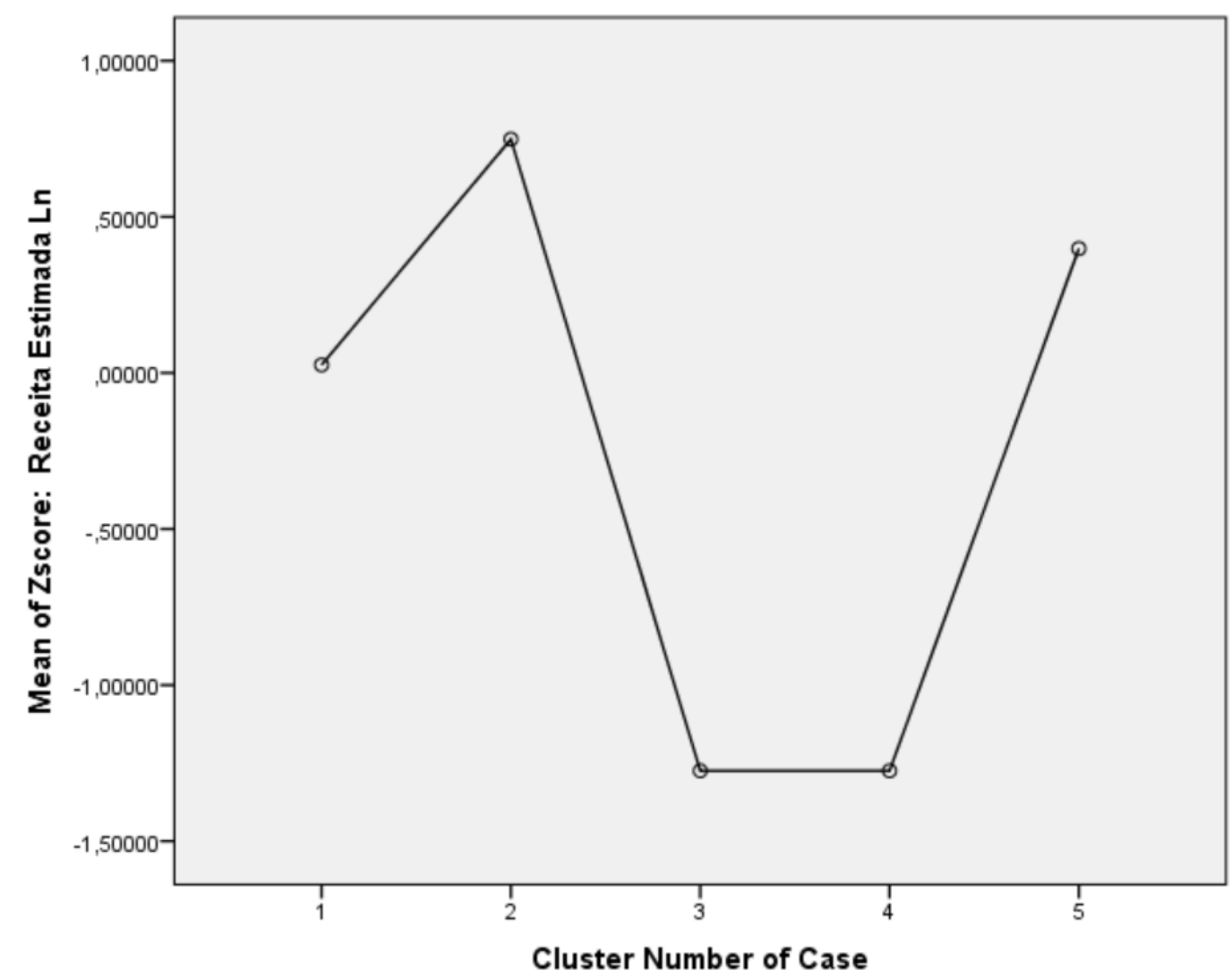

Fonte: SPSS

Crescimento: os grupos Liderança em Custo (2) e Stuck In The Middle (5) apresentam melhores desempenho que os grupos Diferenciação (1), Enfoque em Diferenciação (3) e Enfoque em Custo (4). 
Figura 8 - Means Plot Crescimento

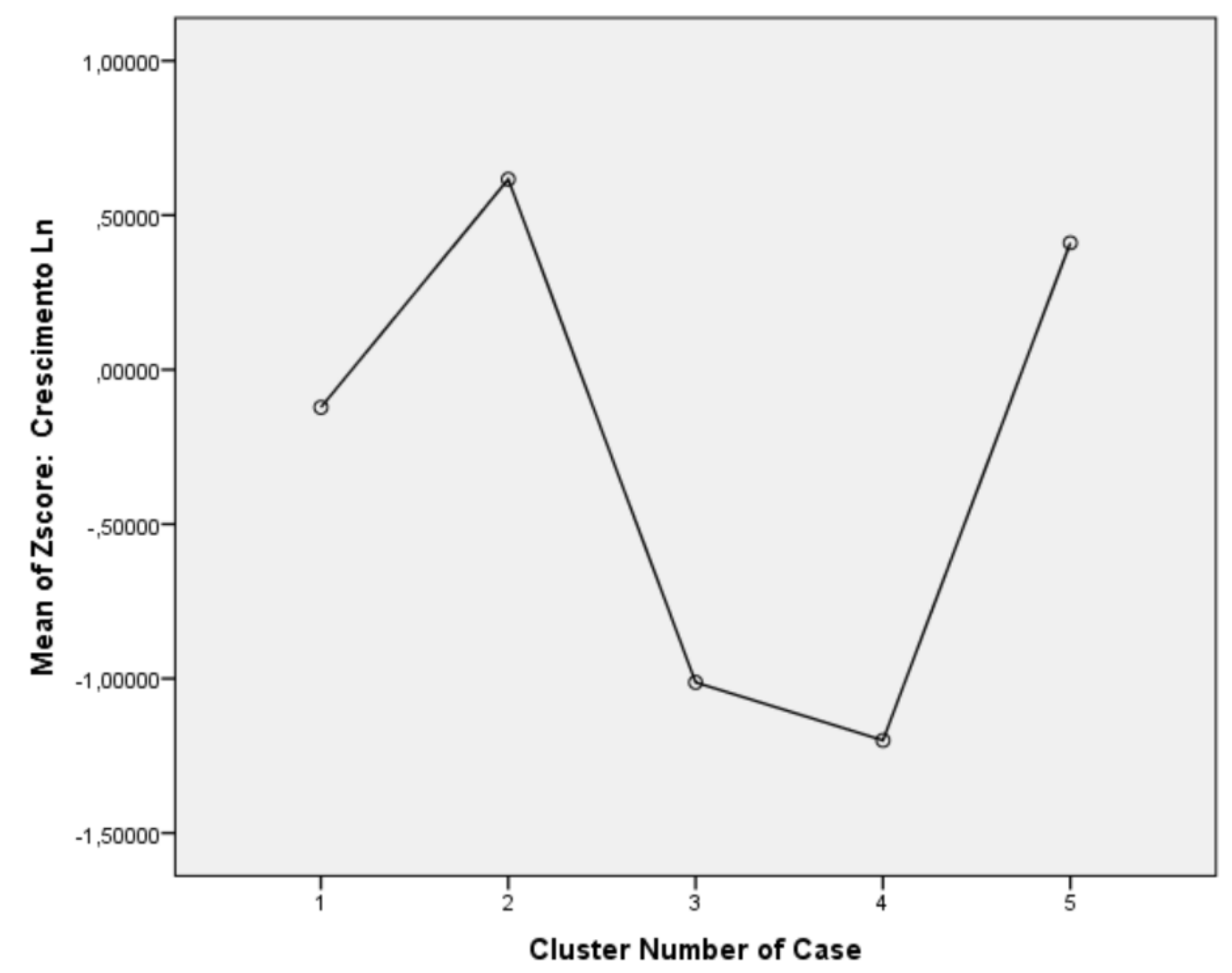

Cabe aqui a relativização dos resultados em relação às variáveis de desempenho selecionadas. Estratégias de enfoque, por definção, são aquelas que restringem sua oferta à segmentos de mercado específicos, o que, consequentemente, resultam em menor número de clientes e patamar de faturamento. Como as variáveis que medem o desempenho no presente trabalho são crescimento e receita, as empresas que perseguem o enfoque ficam naturalmente prejudicadas, não siginificando necessariamente, no entanto, que apresentem pior desempenho em outras métricas como lucratividade ou retenção de clientes. 


\section{Considerações finais}

Diante do rápido crescimento e popularização das plataformas de Streaming observados nos últimos 10 anos, a presente pesquisa se propôs a analisar esse mercado à luz da tipologia de Porter com o objetivo de identificar os grupos estratégicos que apresentam melhor desempenho.

Para se chegar ao objetivo, buscou-se na literatura estratégias competitivas relevantes que poderiam ser aplicadas à Indústria e foram definidas variáveis estratégicas necessárias e disponíveis ao público para medir as estratégias. Posteriormente, foram selecionadas variáveis de desempenho.

Em seguida, as variáveis, de desempenho e estratégicas, foram transformadas em z score para eliminar possíveis distorções de escala e foram realizados testes de normalidade, passo este necessário dada a utilização posterior de testes ANOVA (análise de variância), análise de cluster e MANOVA (análise de variância multivariada). Dos testes de normalidade, observou-se que apenas três variáveis (as duas de desempenho, Crescimento e Receita Estimada, e uma estratégica, Base de Assinantes) tem distribuição normal.

Baseado na tipologia de Porter, foi elaborada uma matriz teórica com o objetivo de identificar os grupos estratégicos. Com base nessa matriz inicial o algoritmo K Means cluster realizou 5 interações e alocou as 37 plataformas em 5 grupos estratégicos.

Vale aqui o comentário sobre a alocação de $30 \%$ das plataformas no cluster Stuck In The Middle. Isto se deve, provavelmente, ao nível de maturidade da indústria e sua recente popularização. Como o mercado cresce como um todo, de maneira relativamente homogênea, mesmo que a empresa não tenha um posicionamento bem definido, ela acaba por se beneficiar da popularização da Indústria. Além disso, como empresas novas em um mercado sem estratégia reconhecidamente bem-sucedida, pode-se esperar a utilização de um mix de traços estratégicos distintos.

Em seguida, foi analisada a proximidade entre matriz de centroides inicial e final por meio do teste de Wilcoxon signed rank. Diante da significância maior que 
0,05, observa-se que a matriz inicial é estatisticamente igual à final. Posteriormente, foi utilizado o teste MANOVA para observar a diferença ou igualdade entre os grupos estratégicos encontrados. Com a significância encontrada de zero, concluise que pelo menos dois grupos estratégicos são estatisticamente diferentes entre si.

Para analisar o desempenho dos clusters criados, valeu-se da ANOVA com os testes de Tamhane e Bonferroni, além do means plot. Com isso, pode-se observar quais grupos apresentam melhor desempenho por variável.

Conclui-se que o modelo é aderente à indústria de streaming audiovisual, apesar do melhor desempenho do grupo Stuck In The Middle em relação aos grupos de Enfoque. Isso se dá, possivelmente, como dito anteriormente, pela maturidade do setor. Diante da recente história dessa indústria e do crescimento generalizado das plataformas, empresas que adotaram elementos estratégicos de tipologias distintas podem ter se beneficiado neste início. Há também o fato de que as variáveis de desempenho escolhidas não favorecem as estratégias de enfoque, que, por definição, atacam um segmento de mercado menor, e, portanto, tendem a ter menor número de clientes e menores patamares de receita. Não significa, no entanto, que sejam estratégias piores ao se observar outras métricas, como lucratividade ou retenção de clientes, por exemplo.

Isso nos leva a comentar sobre as limitações não relacionadas ao método do presente trabalho. A pesquisa apresenta as correlações entre as estratégias e o desempenho, mas não testa sua causalidade. Isto é, as razões pelas quais as empresas se agrupam em determinado grupo, assim como os motivos pelos quais as empresas apresentarem despenhos distintos, não foram possíveis de serem verificadas. Diante disso, investigações mais profundas de casos específicos (estudos de casos) ficam como sugestão de pesquisa, onde as causas desses fenômenos poderiam ser identificadas.

Como sugestão para trabalhos futuros sobre o tema, recomenda-se o aumento da amostra, recolhendo dados sobre mais empresas de streaming audiovisual, além da coleta de dados de outras variáveis estratégicas, como devices disponíveis, qualidade de imagem, qualidade do atendimento, e outras variáveis de desempenho, como ROI, LTV, Churn, entre outros, que para o presente trabalho não se mostraram possível pela não divulgação de dados sensíveis pelas empresas. 
É importante destacar as contribuições teóricas do presente trabalho, como o desenvolvimento de variáveis estratégicas e de desempenho específicas para o setor e o teste do modelo para uma indústria de transformação digital. Há também contribuições práticas, uma vez que empresas de streaming reais podem aproveitar o resultado do modelo para guiar suas decisões estratégicas.

Sugere-se, por fim, a aplicação deste modelo em outros setores do streaming, como o fonográfico e textual, além da aplicação de outras tipologias, como a de Mitzberg (1988). 


\section{Bibliografia}

ABELL, D. F. Defining the business: The starting point of strategic planning. Englewood Cliffs, NJ: Prentice-Hall, 1980

AMER, Aïda. Netflix dominates Oscar nominations. Yahoo Finance. 16 de março de 2021. Disponível em: < https://finance.yahoo.com/news/netflix-dominatesoscar-nominations-093059038.html>

ANDREWS, K. R. The Concept of Corporate Strategy, Irwin, Homewood, Illinois, 1980.

BARNEY, J.B. Strategic Management Journal, 5, pp.171-180, 1991.

BARNEY, J. B. Firm resources and sustained competitive advantage. Journal of Management, 17(1), 99-120, 1991

BARNEY, J.B. Gaining and Sustaining Competitive Advantages, 2nd ed. Perason Education, 2001

BARNEY, J. B., \& HESTERLY, W. Strategic management and competitive advantage: concepts and cases. Upper Saddle River: Prentice Hall., 2006

BARNEY, J. B.; HESTERLY, W. S. VRIO Framework. In Strategic Management and Competitive Advantage (pp. 68-86). New Jersey: Pearson, 2010

BARNEY, J.; WRIGHT, M; KETCHEN, D. The resource-based view of the firm: Ten years after 1991 Journal of Management, v. 27, p. 625-641, 2001.

BARRADAS, Gabriel. Welcome to the Vibranium Age of TV, 2020. Disponível em: < https://gabrielbarradas.medium.com/welcome-to-the-vibranium-age-of-tvc83a6b055622>

BLOOM, D. Insights: How Smaller VOD Services Can Attract Subscribers Amid Epic Competition. Tubefilter. 03 de outubro de 2019. Disponível em: <https://www.tubefilter.com/2019/10/03/insights-how-smaller-vod-services-canattract-subscribers-amid-epic-competition/>. Acessado em 30/11/2020. 
BURROUGHS, BENJAMIN E. Streaming Media: audience and industry shifts in a networked Society. Iowa Research Online, University of Iowa, 2015 Disponível em: 〈https://ir.uiowa.edu/cgi/viewcontent.cgi?article=5890\&context=etd >

CAMERON, K. S. e WHETTEN, D. A. Perceptions of organizational effectiveness over organizational life cycles. Administrative Science Quarterly, 1983

CARNEIRO, Jorge M. T.; CAVALCANTI, Maria A. F. D.; SILVA, J. F. Porter Revisado: Análise Crítica da Tipologia Estratégica do Mestre. RAC, v.1, n.3, Set/Dez. 1997: 7-30.

CARNEIRO, Jorge M. T. Desempenho de Exportação de Empresas Brasileiras: Uma Abordagem Integrada. Tese de Doutorado não Publicada. Coppead, Instituto de Pós-Graduação e Pesquisa em Administração de Empresas, Universidade Federal do Rio de Janeiro, 2007

CARR, David. THE MEDIA EQUATION: Giving Viewers What They Want. The New York Times, 2013. Disponível em: < https://cn.nytimes.com/business/20130301/c01carr/en-us/>

CAVES, R. E.; PORTER, M. E. From Entry Barriers to Mobility Barriers: Conjectural Decisions and Contrived Deterrence to New Competition. Quarterly Journal of Economics, p. 241-261, 1977.

CHRISMAN, J. J. Strategy, skills, and success: An exploratory study. Unpubished doctoral dissertation, University of Georgia, Athens, 1986.

CHRISMAN, J. J., Hofer, C. W. \& Boulton, W. R. Toward a system for classifying business strategies. The Academy of Management Review, Vol. 13, No. 3 (Jul., 1988), pp. 413-428.

CHRISTENSEN, C. “The conclusion I've come to as well via@ @usinessinsider Netflix Splits Itself In Two To Avoid The Innovator's Dilemma". 19 de Setembro de 2011. Twitter: @ claychristensen. Disponível em: <https://twitter.com/claychristensen/status/115846823079456769>

CHRISTENSEN, Clayton, M; RAYNOR, Michael E.; MCDONALD, Rory. What Is Disruptive Innovation? Harvard Business Review, 2015. Disponível em: < https://hbr.org/2015/12/what-is-disruptive-innovation> 
CISION, 2020. Video Streaming Market Size is Projected to Reach USD 149.34 Billion by 2026. Disponível em: < https://www.prnewswire.com/newsreleases/video-streaming-market-size-is-projected-to-reach-usd-149-34-billionby-2026--valuates-reports301142025.html\#: :text=The\%20global\%20video\%20streaming\%20market, 18.3 \%25\%20from\%202019\%20to\%202026.>

COOL, K.; SCHENDEL, D. Strategic groups formation and performance: The case of the U.S. Pharmaceutical Industry, 1963 - 1982. Management Science, v. 33, n. 9, p. 1102-1125, 1987.

COOK, Sam. The Complete List of Streaming Services in $2021-200+$ Services. Fixed, 2021. Disponível em: < https://flixed.io/complete-list-streaming-services2021/>

DARWIN, C. The origin of species: By means of natural selection on the preservation of favoured races in the strugle for life. New York: Mentor Books, 1958 (Original work published 1859)

DESS, G. G., \& Davis, P. S. Porter's (1980) generic strategies as determinants of strategic group membership and organizational performance. Academy of Management Journal, 27, 467-488, 1984.

FIORE, Matheus. Com Pandemia, audiência de streaming de vídeo cresce $20 \%$ no mundo durante mês de março. B9. 31 de março de 2020. Disponível em: <https://www.b9.com.br/123993/com-pandemia-audiencia-de-streaming-devideo-cresce-20-no-mundo-durante-o-mes-de-marco/>

FOSS N. J. Research in strategy, economics and Michael Porter. Journal of Management Studies, v.33, n.1, p.1-24, Jan. 1996.

FRIESNER, Tim. History of SWOT Analysis, 2008. Disponível em: < https://www.researchgate.net/publication/288958760_History_of_swot_analysis>

GOBRY, Pascal-Emmanuel. Netflix Splits Itself In Two To Avoid The Innovator's Dilemma. Business Insider, 2011. Disponível em: < https://www.businessinsider.com.au/netflix-splits-itself-in-two-to-avoid-theinnovators-dilemma-2011-9> 
GRAND VIEW RESEARCH, 2020. Video Streaming Market Size, Share \& Trends Analysis Report By Streaming Type, By Solution, By Platform, By Service, By Revenue Model, By Deployment Type, By User, By Region, And Segment Forecasts, $2020 \quad-\quad 2027 . \quad$ Disponível em: < https://www.grandviewresearch.com/industry-analysis/video-streaming-market> HALL, W. K. Survival strategies in a hostile envorinment. In R. G. Hamermesh (Ed.) Strategic management (pp. 151-169). New York: Wiley, 1983

HAMBRICK, D. C. High profit strategies in mature capital goods industries: a contingency approach. Academy of Management Journal, v.26, n.4, p.687-707, 1983.

HARRIGAN, K. R. Strategies for declining businesses. Lexington, MA: Lexington Books, 1980

HATTANGADI, Vidya. Stuck in middle can be solved with a flexible approach. VH. 8 de Janeiro de 2018. Disponível em: < https://drvidyahattangadi.com/stuckin-middle/>

HERBERT, T. T.; Deresky, H. Generic strategies: an empirical investigation of typology and strategy content. Strategic Management, 1987.

HILL, C. W. \& DEEDS, D. L. The importance of industry structure for the determination of the firm profitability: a neo-austrian perspective. Journal of Management Studies, v. 33, n. 4, p. 429-451, 1996.

HILL, C. W. L. Differentiation versus low cost or differentiation and low cost: a contingency framework. Academy of Management Review, v.13, n.3, p.401-412, Julho 1988.

HITT, Michael A., LI, Dan e XU, Kai. International Strategy: From Local to Global nad Beyond. Jornal of World Business, Elsevier, vol. 51 (1), pages 58-73, 2016. DOI: $10.1016 /$ j.jwb.2015.08.016

HOFER, C. W., \& Schendel, D. E. Strategy formulation: Analytical concepts. St. Paul, MN: West, 1978. 
HOLZHAUER, Brett. Americans Are Cord Cutting In Record Numbers - And It's Not Slowing Down Anytime Soon. Forbes. 2 de Novembro de 2020. Disponível em: $\quad<$ https://www.forbes.com/advisor/personal-finance/americans-are-cordcutting-in-record-numbers-and-its-not-slowing-down-anytime-soon/>

HSU, Feng J., WANG, Tsai Y. e CHEN, Um Y. The Impact of Brand Value on Financial Performance. Advances in Management \& Applied Economics, vol. 3, no.6, 2013, 129-141 ISSN: 1792-7544 (print version), 1792-7552(online) Scienpress Ltd, 2013

HUNT, M. S. Competition in the Major Home Appliance Industry, 1960-1970. Unpublished Doctoral Dissertation, Harvard University, M.A. 1972

KAGAN. Disney+ Ditches Free Trials - Will Other Big Streamers Follow Suit? 24 de julho de 2020. Disponível em: < https://www.spglobal.com/marketintelligence/en/news-insights/blog/disneyditches-free-trials-will-other-big-streamers-follow-suit>

KARNANI, A. Generic competitive strategies: na analytical approach. Strategic Management Journal, v.5, p.367-380, 1984.

KIM, L. \& LIM, Y. Environment, generic strategies and performance in a rapidly changing country: a taxonomic approach. Academy of Management Journal, v.31, p.802-827, 1988.

LARSON, L. A Crash Course in Flash Video. Streaming Media, 2007. Disponível em http://www.streamingmedia.com/article.asp?id=9711\&c=8

LIDDELL, H. George; SCOTT, Robert. A Greek-English Lexicon. revised and augmented throughout by. Sir Henry Stuart Jones. with the assistance of. Roderick McKenzie. Oxford. Clarendon Press, 1940.

MALHOTRA, N. K. Pesquisa de Marketing: Uma orientação aplicada. Porto Alegre, $4^{\text {a }}$ Edição, Bookman, 2006.

MARQUES, J. A. V. C. Análise Financeira das Empresas: liquidez, retorno e criação de valor. Editora UFRJ, 2004 
MASSAROLO, J. C. e MESQUITA, D. Vídeo Sob Demanda: uma nova plataforma televisiva. In: XXV ENCONTRO ANUAL DA COMPOS, 25, 2016, Goiânia. Estudos de Televisão. Goiânia: 2016. P. 1-24.

MATRIX, S. The Netflix Effect: Teens, Bing Watching, and On-Demand Digital Media Trends. Jeunesse: Young People, Textes, Cultures, v.6, n. 1, 2014, pp. 119138.

MAUBOUSSIN, Michael. The True Measures of Success. Harvard Business Review, 2012. Outubro de 2021. Disponível em: < https://hbr.org/2012/10/the-truemeasures-of-success>

MC KELVEY, B. Organizational systematics: Taxonomic lessons from biology. Managment Science, 24, 1428-1440, 1978.

MC KELVEY, B. Organizational systematics: Taxonomy, evolution, classification. Berkeley: University of California Press, 1982.

MICHAEL, D. N. On Learning to Plan and Planning to Learn, Jossey-Bass, San Francisco 1973.

MILES, R. e SNOW, C. Organizational Strategy, Structure, and Process. New York, 1978

MILLER, D. Generic strategies: classification, combination and context. In: SHRIVASTAVA, P. (Ed.). Advances in strategic management. Greenwich, Conn.: Jay Press, 1992. v.8. p.391-408.

MILLER, A.; DESS, G. G. Assessing Porter's (1980): model in terms of its generability, accuracy and simplicity. Journal of Management Studies, v.30, n.4, p.553-585, July 1993.

MINTZBERG, H. The Strategy Concept I: Five Ps For Strategy. California Management Review; Fall 1987; 30, 1; ABI/INFORM Global pg. 11

MINTZBERG, H. Generic strategies: toward a comprehensive framework. In: in R.B. Lamb and P. Shivastava (eds.) Advances in Strategic Management (JAI Press, 1988)

MINTZBERG, Henry; AHLSTRAND, Bruce; LAMPEL, Joseph. Strategy safari: 
Your complete guide through the wilds of strategic management. Upper Saddle River: Pearson Education Limited, 2009.

MURRAY, A. I. A contingency view of Porter's: generic strategies. Academy of Management Review, v.13, n.3, p.390-400, July 1988.

NETFLIX, 2019. Netflix Acquires Cannes Film Festival Award Winners 'Atlantics' and 'I Lost My Body"'. Disponível em: < https://about.netflix.com/en/news/netflix-acquires-cannes-film-festival-awardwinners-atlantics-and-i-lost-my-body>

OLADIMEJI, M. S. \& UDOSEN, I. The Effect of Diversification Strategy on Organizational Performance. Journal of Competitiveness, 11(4), 120-131, 2019. https://doi.org/10.7441/joc.2019.04.08

PORTER, M. E. Competitive Strategy: Techniques for analyzing industries and competitors. New York: Free Press, 1980.

PORTER, M. E. Competitive advantage: Creating and sustaining superior performance. New York: Free Press, 1985.

PRAHALAD, C.K. and HAMEL, G. "The core competence of the corporation", Harvard Business Review (v. 68, no. 3) pp. 79-91, 1990.

RICHARDSON, Adam. Netflix's Bold Disruptive Innovation. Harvard Business Review. Setembro, 2011. Disponível em: <https://hbr.org/2011/09/netflix-bolddisruptive-innovation>

SANDBERG, W. R. New venture performance: The role of strategy and industry structure. Lexington, MA: Lexington Books, 1986.

SANTOS, Juliana B. e BRITO, Luiz A. L. Toward a Subjective Measurement Model for Firm Performance. ANPAD. BAR, Rio de Janeiro, v. 9, Special Issue, art. 6, pp. 95-117, Maio 2012. Disponível em: <https://www.scielo.br/pdf/bar/v9nspe/07.pdf>

SHAW, Lucas. The Early Winners and Losers of the Streaming Wars. Bloomberg. 26 de Julho de 2020. Disponível em: $<$ https://www.bloomberg.com/news/newsletters/2020-07-26/the-early-winnersand-losers-of-the-streaming-wars> 
SHRIVASTAVA, P. (Ed.). Advances in strategic management. Greenwich, Conn.: Jay Press, 1988. v.5. p.1-67.

SILVA, J. F.; MELO, M. A. C. Tipologias Estratégicas Concorrentes: Um teste empírico na industria brasileira de seguros. In $28^{\circ}$ ENANPAD, 1998, Foz do Iguaçu. Paraná: ANPAD, n. único, 1998.

SOLSMAN, Joan E. Mulan's (2020) online release: Everything to know. Disponível em: < https://www.cnet.com/news/mulan-disney-plus-free-2020movie-new-live-action/>

STAHL, M. J e GRIGSBY, D. W. Strategic Management: Total Quality and Global Competition. Blackwell Publishing, 1997.

STOBIERSKI, Tim. What Are Network Effects? Harvard Business School Online. 12 de Novembro de 2020. Disponível em: < https://online.hbs.edu/blog/post/whatare-network-effects>

STRATEGUS. AVOD vs SVOD vs MVPD vs OTT - Ultimate VOD Guide For Advertisers, 2020. Disponível em: < https://strategus.com/2020/12/avod-vs-svodvs-mvpd-vs-ott-ultimate-guide/>

TEECE, D. J. The Foundations of Enterprise Performance: Dynamic and Ordinary Capabilities in an (Economic) Theory of Firms. Academy of Management Perspectives, 28(4), amp.2013.0116, 2014. https://doi.org/10.5465/amp.2013.0116 TREVIZANI, Rebeca. Consumo de conteúdo audiovisual aumenta na pandemia. Comunicare. 10 de novembro de 2020. Disponível em: $<$ https://www.portalcomunicare.com.br/consumo-de-conteudo-audiovisualaumenta-napandemia/\#: :text=Desde\%20o\%20in\%C3\%ADcio\%20do\%20per\%C3\%ADodo, 63\%25\%20em\%20rela\%C3\%A7\%C3\%A3o\%20a\%202019.>

VANDARAJAN, P. Rajan. A two-factor classification of competitive strategy variables. Strategic Management Journal, Vol. 6, 357-375, 1985

VELOSO, Ana Clara e TONDO, Stephanie. (2020) Com pandemia e novos hábitos, 2020 se torna o ano do streaming no Brasil. Disponível em: < 
https://extra.globo.com/economia/com-pandemia-novos-habitos-2020-se-tornaano-do-streaming-no-brasil-rv1-1-24660806.html>

VENKATRAMAN, N. e GRANT, J. H. Construct Measurement in Organizational Strategy Research: A Critical and a Proposal. The Academy of Management Review, v. 11, n. 1, pp. 71-87, 1986.

VENKATARAMAN N. e RAMANUJAM V. Measurement of Business Performance in Strategy Research: A Comparison of Approaches. Academy of Management Review, Vol. 11, No. 4.

VERGARA, S. C. Projetos e Relatórios de Pesquisa em Administração. São Paulo: Atlas, 2005. 1986

VON NEUMANN, J. \& MORGENSTERN, O. The theory of games and economic behaviour. New York: John Wiley \& Sons, 1944.

WHETTEN, D. A. Organizational growth and decline process. Annual Review of Sociology, 13(1), 335-358, 1987. doi: 10.1146/annurev.so.13.080187.002003

WHITE, R. E. Generic business strategies, organizational context and performance: an empirical investigation. Strategic Management Journal, v.7, p.217- 231, 1986. 


\section{Anexo I}

\section{Fonte de dados de Base de Assinantes por plataforma:}

AltBalaji:

http://www.balajitelefilms.com/pdf/otherdocuments/70\%20Countries.pdf

Apple TV+: https://www.thestreet.com/investing/apple-tv-plus-34-millionsubscribers-

report\#: :text=Apple\%20TV\%2B\%20has\%2033.6\%20million,content\%20on\%20 Amazon\%20Prime\%20Video.

Blim TV: https://www.statista.com/statistics/1097027/latin-america-svodsubscribers-provider/

CBS All Access: https://www.statista.com/statistics/1047393/cbs-all-accesssubscribers-

us/\#: :text=ViacomCBS\%3A\%20number\%20of\%20subscribers\%20in\%20the\%2 OU.S.\%202015\%2D2020\&text=As\%20of\%20February\%202019\%2C\%20estimat es,million\%20reported\%20in\%20August\%202018.

Curiosity Stream: https://www.fiercevideo.com/video/curiositystream-claimsmore-than-13m-paid-subscribers

Looke: https://vejasp.abril.com.br/cultura-lazer/looke-streaming-filmes/

Mubi: https://techcrunch.com/2019/11/18/mubi-india-

launch/\#: :text=Mubi\%20has\%20amassed\%209\%20million\%20subscribers\%2C $\% 20$ the $\% 20$ company\%20said.

Zee 5: https://www.indiantelevision.com/iworld/over-the-top-services/zee5maintains-momentum-with-563-mn-mau-in-third-quarter-190115

DAZN: https://www.boxingscene.com/whats-happening-with-dazn-part-two-145695\#: :text=Another\%20well\%2Dplaced\%20source\%20says,are\%20in\%20th e\%20United\%20States.

Disney +: https://thewaltdisneycompany.com/app/uploads/2020/11/q4-fy20earnings.pdf 
Eros Now: https://erosplc.com/

ESPN+: https://thewaltdisneycompany.com/app/uploads/2020/11/q4-fy20-

earnings.pdf

Hotstar: https://en.wikipedia.org/wiki/Hotstar

Hulu: https://thewaltdisneycompany.com/app/uploads/2020/11/q4-fy20-

earnings.pdf

Youtube Premium: https://www.billboard.com/articles/business/digital-andmobile/8550124/youtube-premium-music-20-million-subscribers

HBO Now: https://www.statista.com/statistics/539290/hbo-now-

subscribers/\#: : :text=Number\%20of\%20HBO\%20Now\%20subscribers $\% 202015$

\%2D2019\&text=As\%20of\%20February\%202019\%2C\%20HBO\%20Now\%20had $\% 20$ around\%20eight\%20million\%20subscribers.

iFlix: https://theconversation.com/streaming-into-southeast-asia-how-netflix-hbocompete-with-regional-players-like-iflix-and-hooq-132453

Tencent: https://technology.informa.com/624701/tencent-acquired-iflix-toexpand-footprint-in-asia

Acorn TV: https://www.fiercevideo.com/video/amc-says-acorn-tv-svod-mayhave-lowest-churn-rate-market

BET+: https://www.androidauthority.com/what-is-bet-plus-1003890/amp/

Catchplay:

https://www.linkedin.com/company/catchplay;https://corporate.catchplay.com/mil estones/

MediaSet Infinity: https://technology.informa.com/613604/mediaset-to-shutdown-pay-dtt-service-at-the-end-of-may

Monomax: https://www.mono.co.th/wp-content/uploads/2020/08/Analystmeeting-Q2-2020.pdf

MyTV Super: https://www.marketing-interactive.com/mytv-super-celebratessecond-birthday-with-huge-growth-and-brand-new- 
dmp\#: :text=myTV\%20SUPER\%20turns\%20two\%20this,by\%20about\%2010\%2 C000\%20per\%20week.

Hoichoi: https://bestmediainfo.com/2020/09/hoichoi-claims-13-millionsubscribers-with-2x-growth-in-revenue/

iQiyi: https://www.statista.com/statistics/1106180/china-online-video-platformiqiyi-subscriptionnumber/\#: :text=Founded\%20in\%20Beijing\%20in\%202010,530\%20million\%20 monthly\%20active\%20users.

Crunchyroll:

https://platform.marketintelligence.spglobal.com/web/client?auth=inherit\#news/ar ticle?id=61036552

Philo:

https://platform.marketintelligence.spglobal.com/web/client?auth=inherit\#news/ar ticle?id=61036552

Globoplay: https://noticiasdatv.uol.com.br/noticia/mercado/guerra-com-doisvencedoreds-por-que-globo-deve-abandonar-o-globoplay-46011

Now TV: https://www.statista.com/statistics/529743/nowtv-households-in-theuk/\#: :text=In\%20the\%20first \%20quarter\%20of\%202020\%2C\%20Now\%20TV $\% 20$ counted\%20roughly,division\%20of\%20telecommunications\%20giant\%20Sk y.

Prime Video: https://www.mediapost.com/publications/article/356813/nbcuspeacock-amazon-prime-video-see-major-gains.html

Prime Video: https://market.us/statistics/online-video-and-streamingsites/amazon-prime-video/

Netflix: https://ir.netflix.net/financials/quarterly-earnings/default.aspx HOOQ: https://www.campaignasia.com/article/hooqs-downfall-can-other-ottplatforms-avoid-the-samefate/459222\#: :text=Five\%20years\%20after\%20launch\%2C\%20Hooq,with\%20s uch\%20big\%2Dname\%20backing. 
Youtube TV: https://www.fiercevideo.com/video/google-says-youtube-tv-hasover-3m-paid-

subscribers\#: :text=YouTube\%20TV\%2C\%20Google's\%20live\%20streaming,m ore $\% 20$ than $\% 203 \% 20$ million\%20subscribers.

Starz Play: https://www.fiercevideo.com/video/starz-sees-142-subscriber-growthspike-amid-covid-19-

crisis\#: :text=Lionsgate $\% 20$ said $\% 20$ in $\% 20$ February $\% 20$ that,up $\% 208 \% 25 \% 20$ ye ar\%20over\%20year.

VideoLand: https://www.statista.com/statistics/873085/netflix-and-videolandsubscribers-in-thenetherlands/\#: :text=Netflix\%20and\%20Videoland\%20were\%20the,had\%20nearl y\%203.2\%20million\%20subscribers.

BritBox: https://www.broadbandtvnews.com/2020/10/06/britbox-us-presidentsteps-down-at-1-5m-subscribers/

\section{Sites das plataformas:}

Netflix: https://www.netflix.com/browse

Prime Video: https://www.primevideo.com/

Tencent Video: https://v.qq.com/

iQiyi: https://www.iq.com/

Disney+: https://www.disneyplus.com/home

Zee 5: https://www.zee5.com/global

Apple TV+: https://www.apple.com/apple-tv-plus/

Hulu: https://www.hulu.com/welcome

Eros Now: https://erosnow.com/

Youtube Premium: https://www.youtube.com/premium

iFlix: https://www.iflix.com/

Curiosity Stream: https://curiositystream.com/ 
Hoichoi TV: https://www.hoichoi.tv/viewplans

ESPN+: https://plus.espn.com/buy-now

Mubi: https://mubi.com/

Staz Play: https://www.starz.com/br/pt/

DAZN: https://www.dazn.com/

Hotstar: https://www.hotstar.com/in

HBO Now: https://www.play.hbonow.com

Blim: http://www.blim.com/

HBO Max: https://www.hbomax.com/

CBS All Access: https://www.paramountplus.com/br/

Crunchyroll: https://www.crunchyroll.com/pt-br

Youtube TV: https://tv.youtube.com/welcome/

Globoplay: https://globoplay.globo.com/

Alt Balaji: https://www.altbalaji.com/

Now TV: https://www.nowtv.com/

BritBox: https://www.britbox.com/

Acorn TV: https://acorn.tv/

Catchplay: https://corporate.catchplay.com/?lan=en

BET+: https://www.bet.com/shows/betplus/bet-plus.html

Philo: https://www.philo.com/

Videoland: https://www.videoland.com/nl/

Mediaset Infinity: https://www.infinitytv.it/

Monomax: https://www.monomax.me/

Looke: https://www.looke.com.br/home 


\section{Anexo II - Histogramas de distribuição de frequência por variável}

\section{Preço}

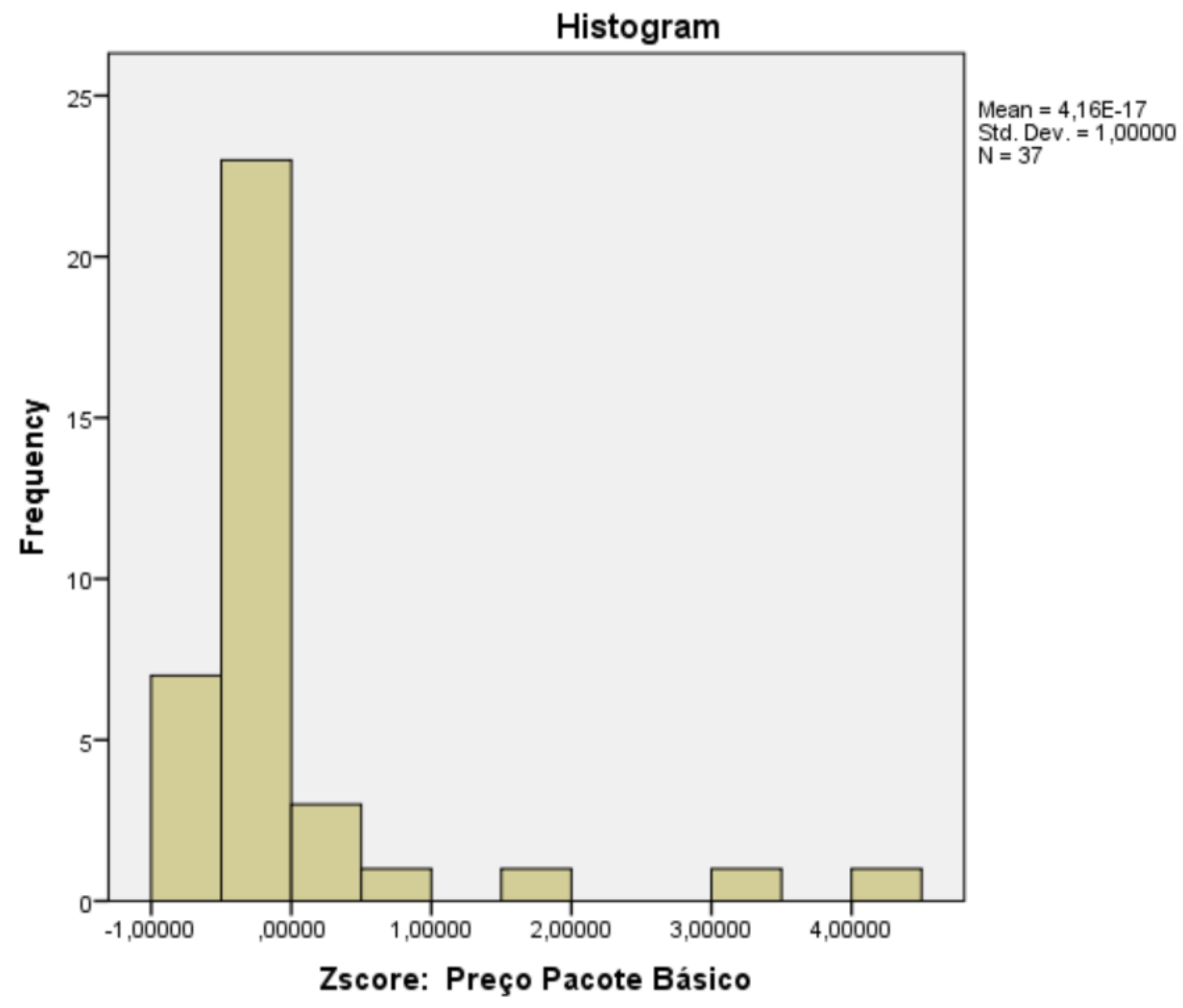




\section{Amplitude da Oferta}

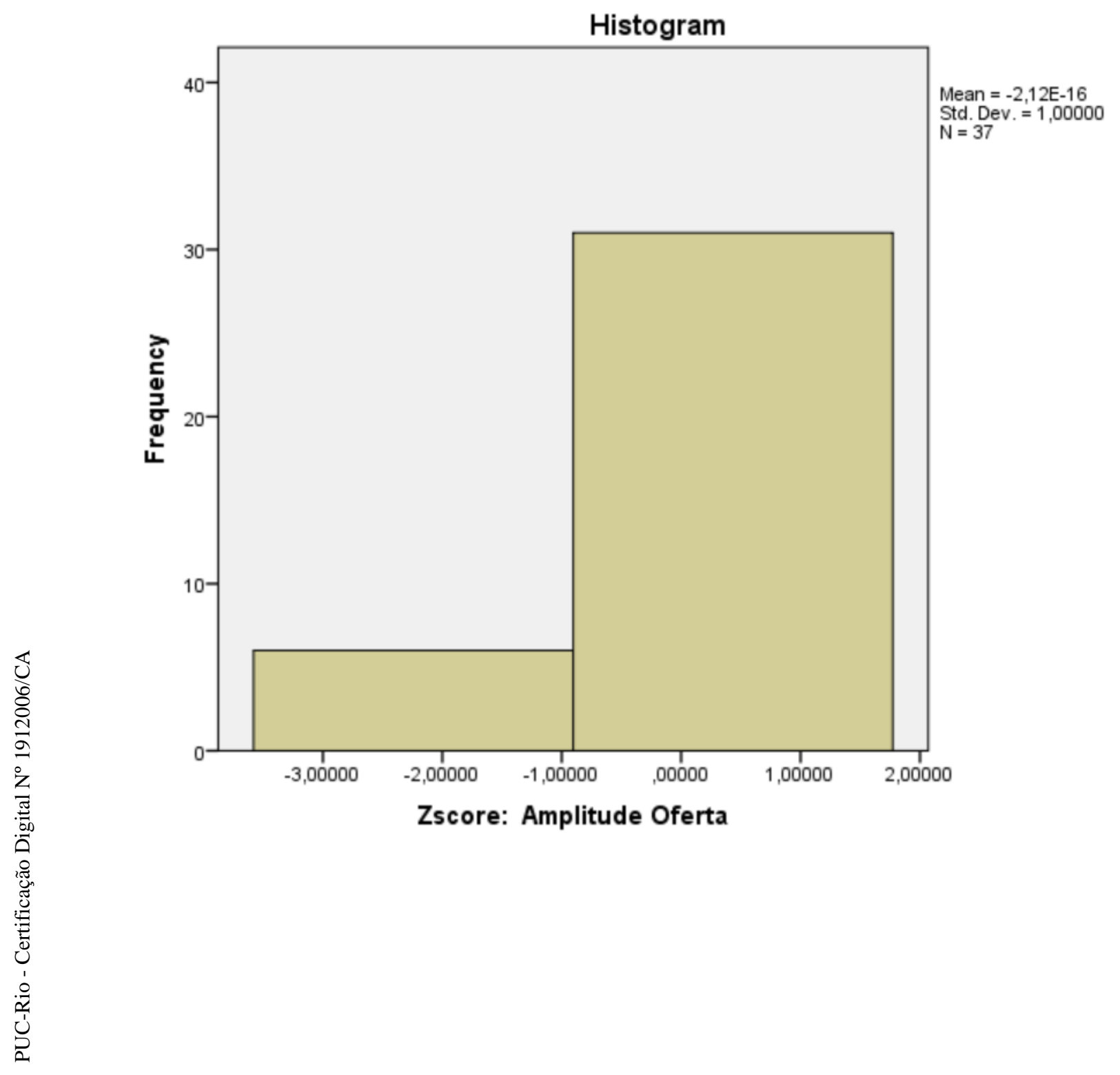


Diversificação de Setor

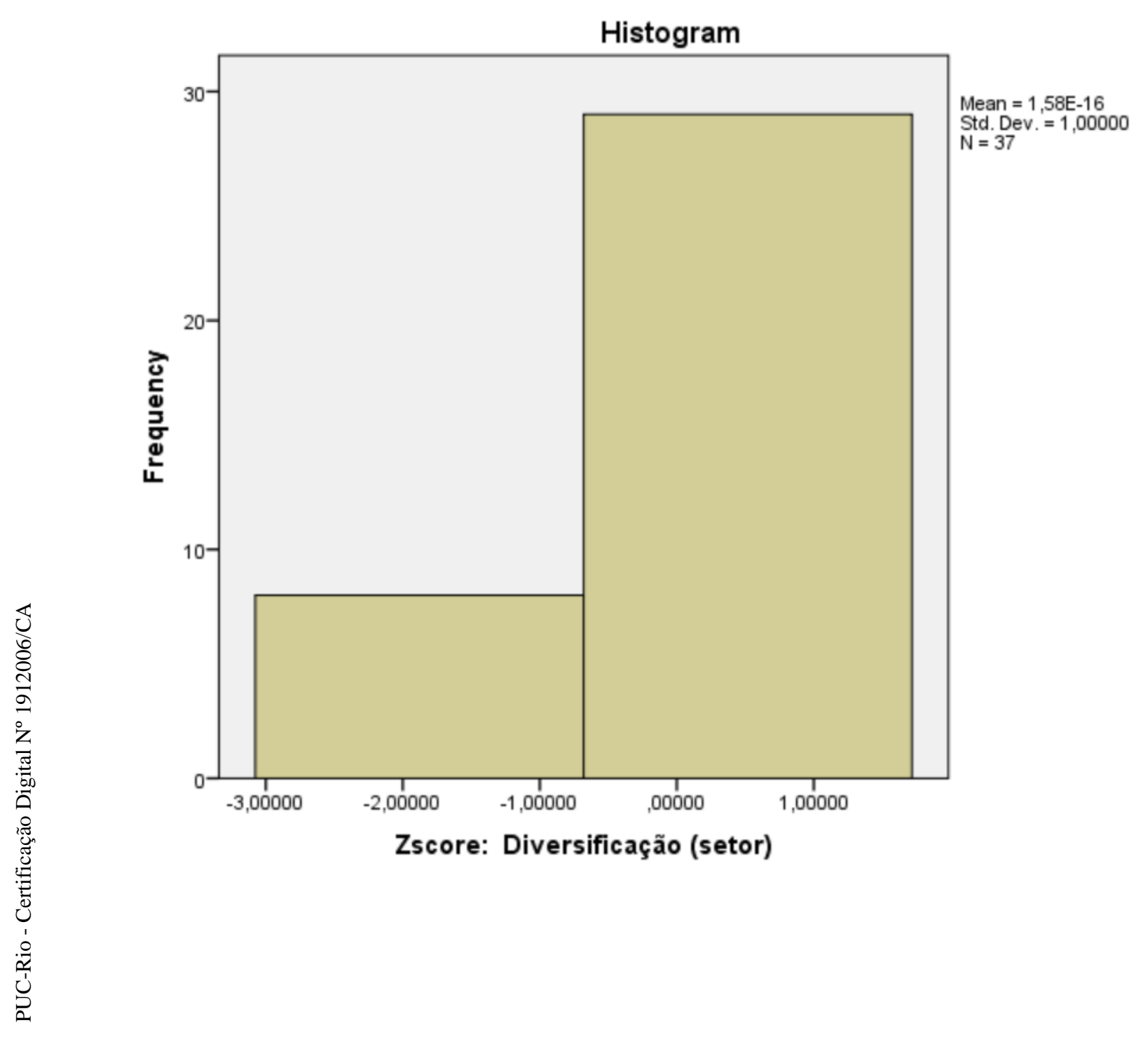


Diversificação do Modelo

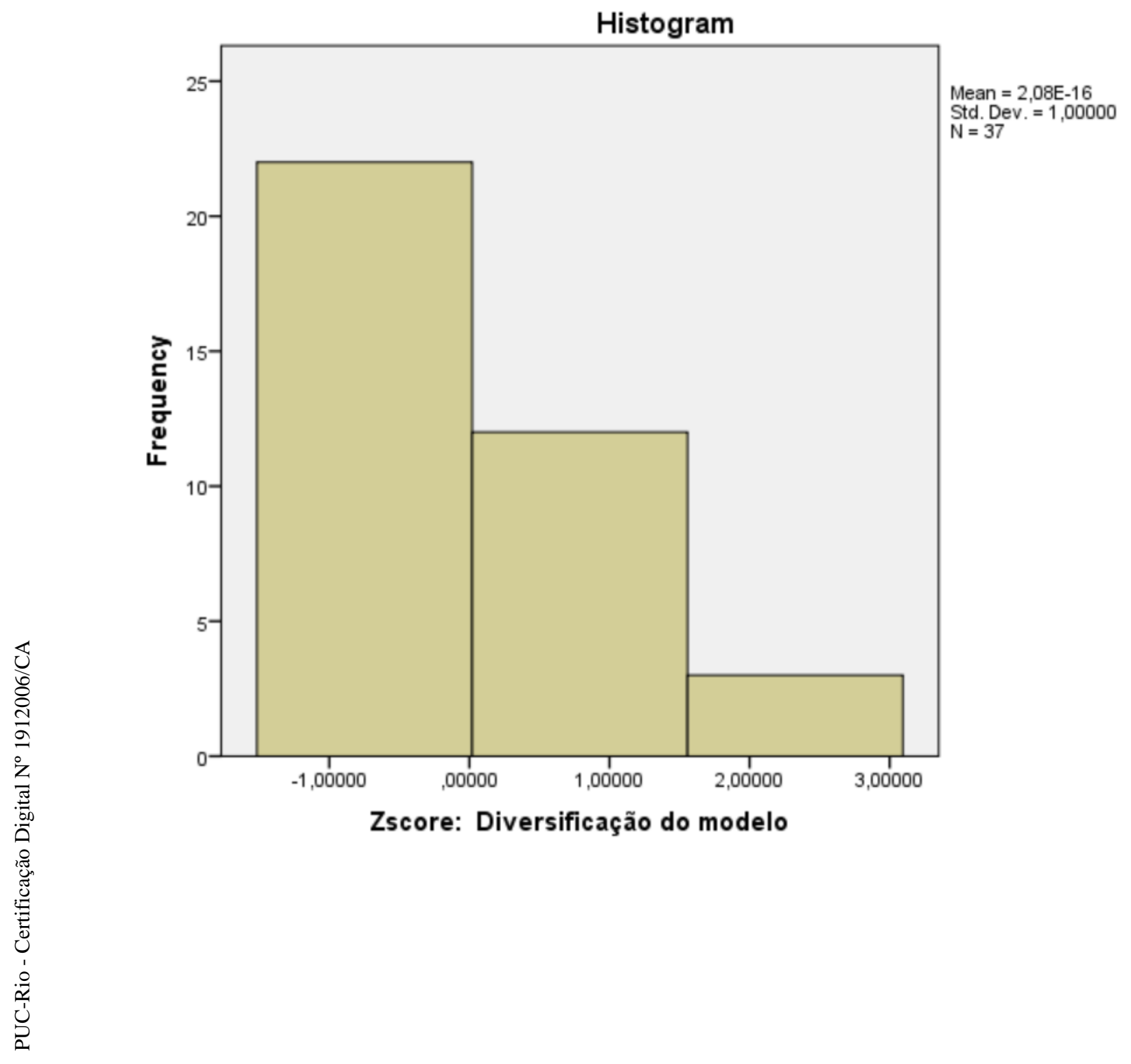


Marca

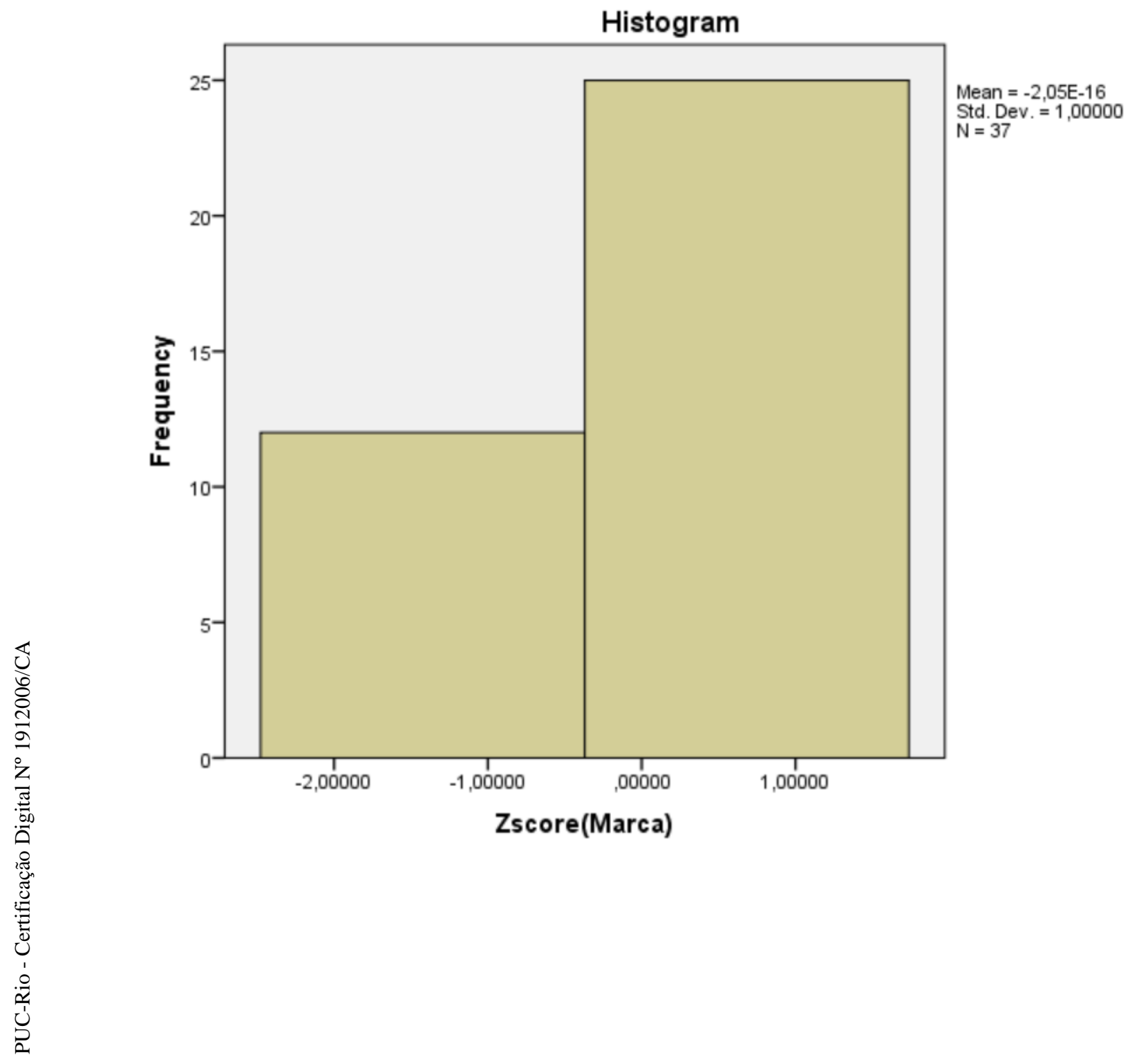


Geografia

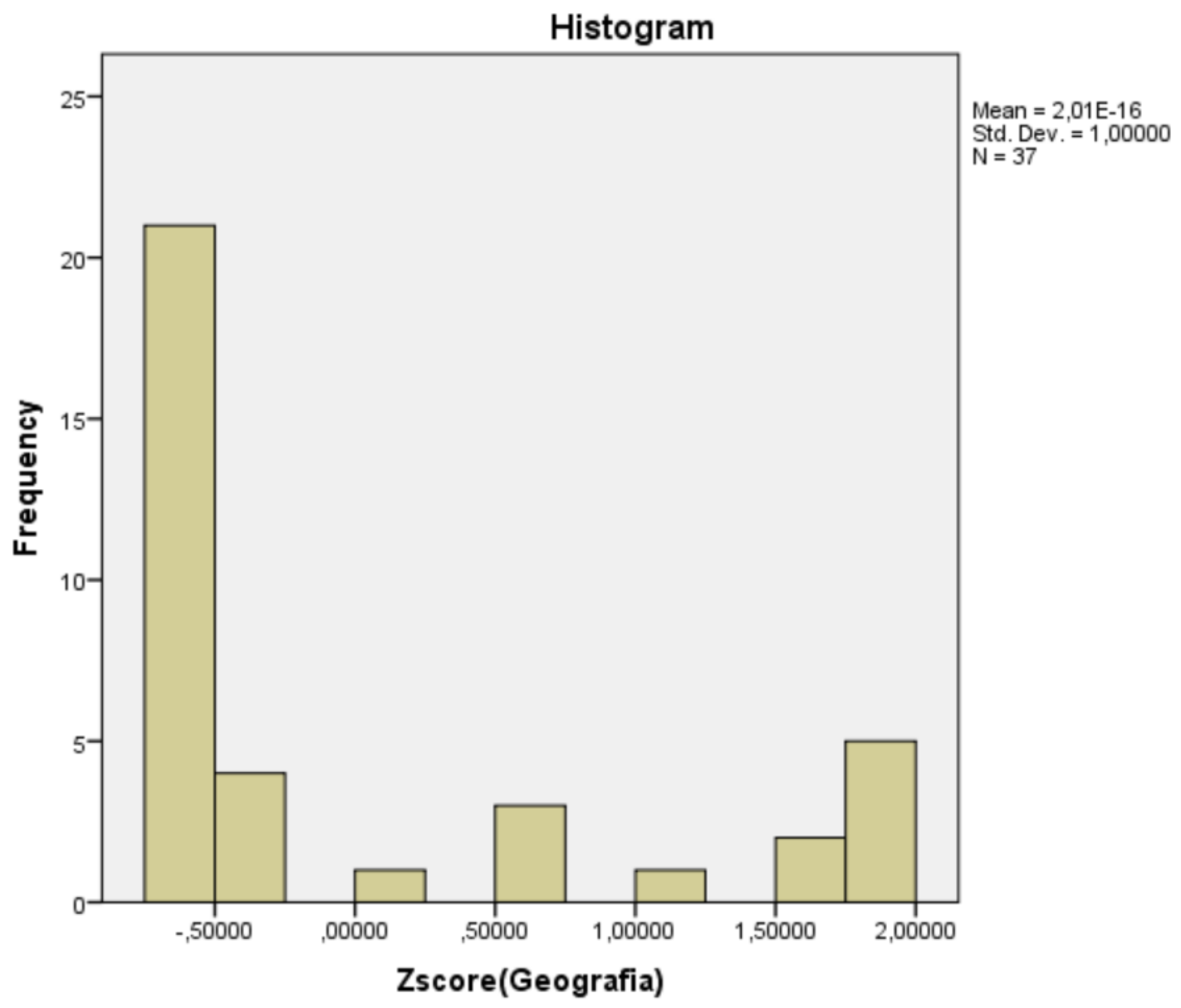


Trial

Histogram

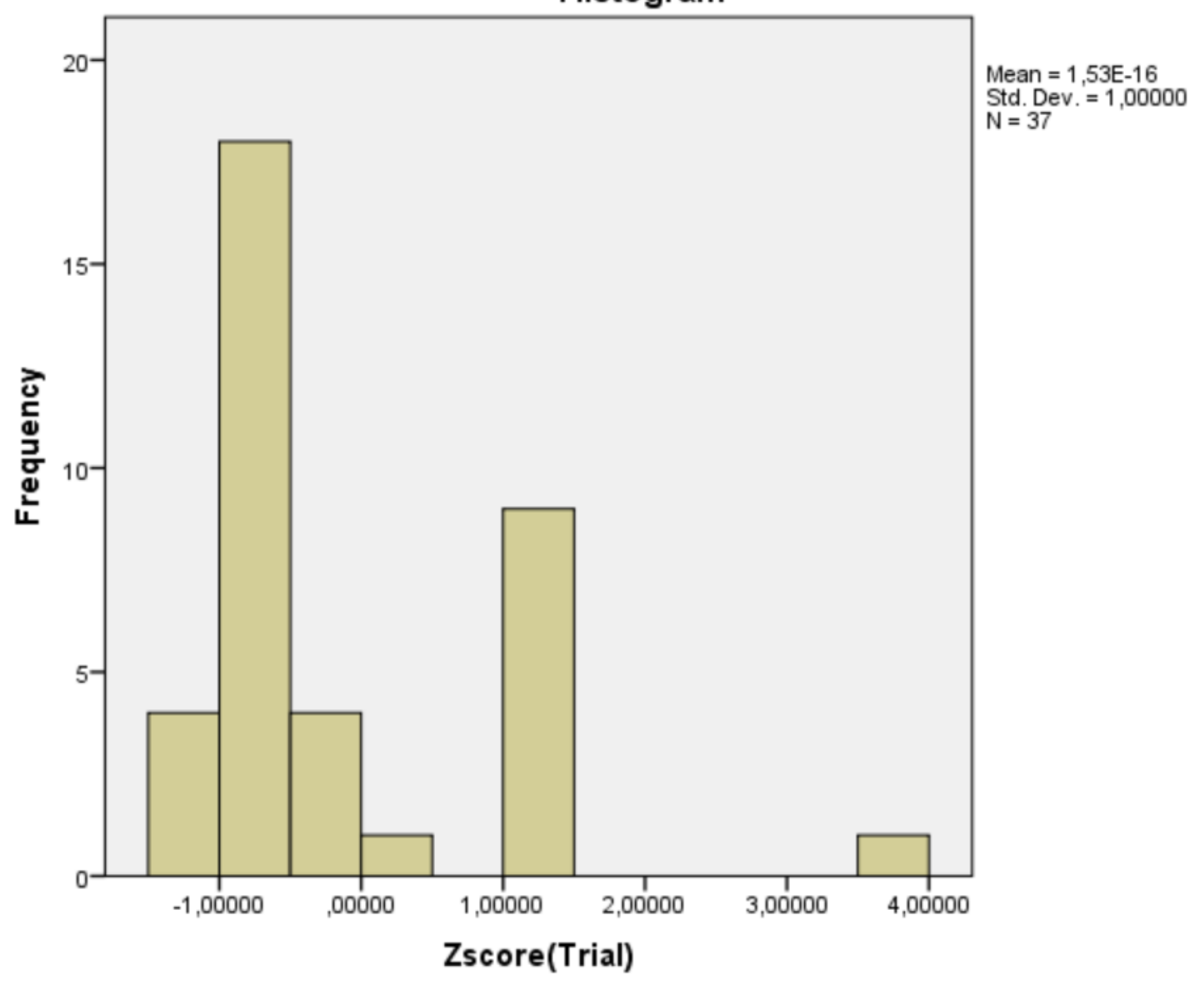




\section{Base}

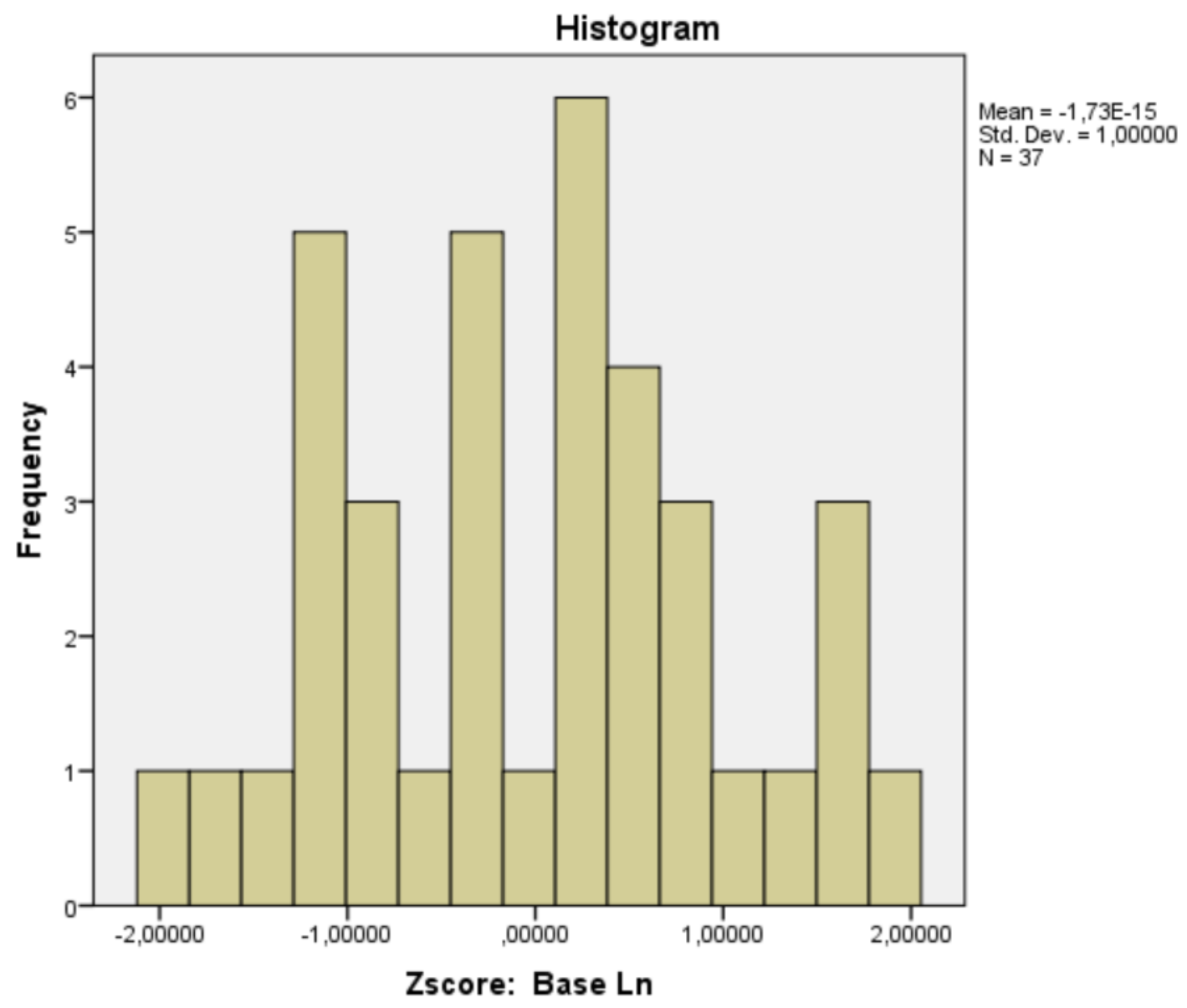




\section{Receita Estimada}

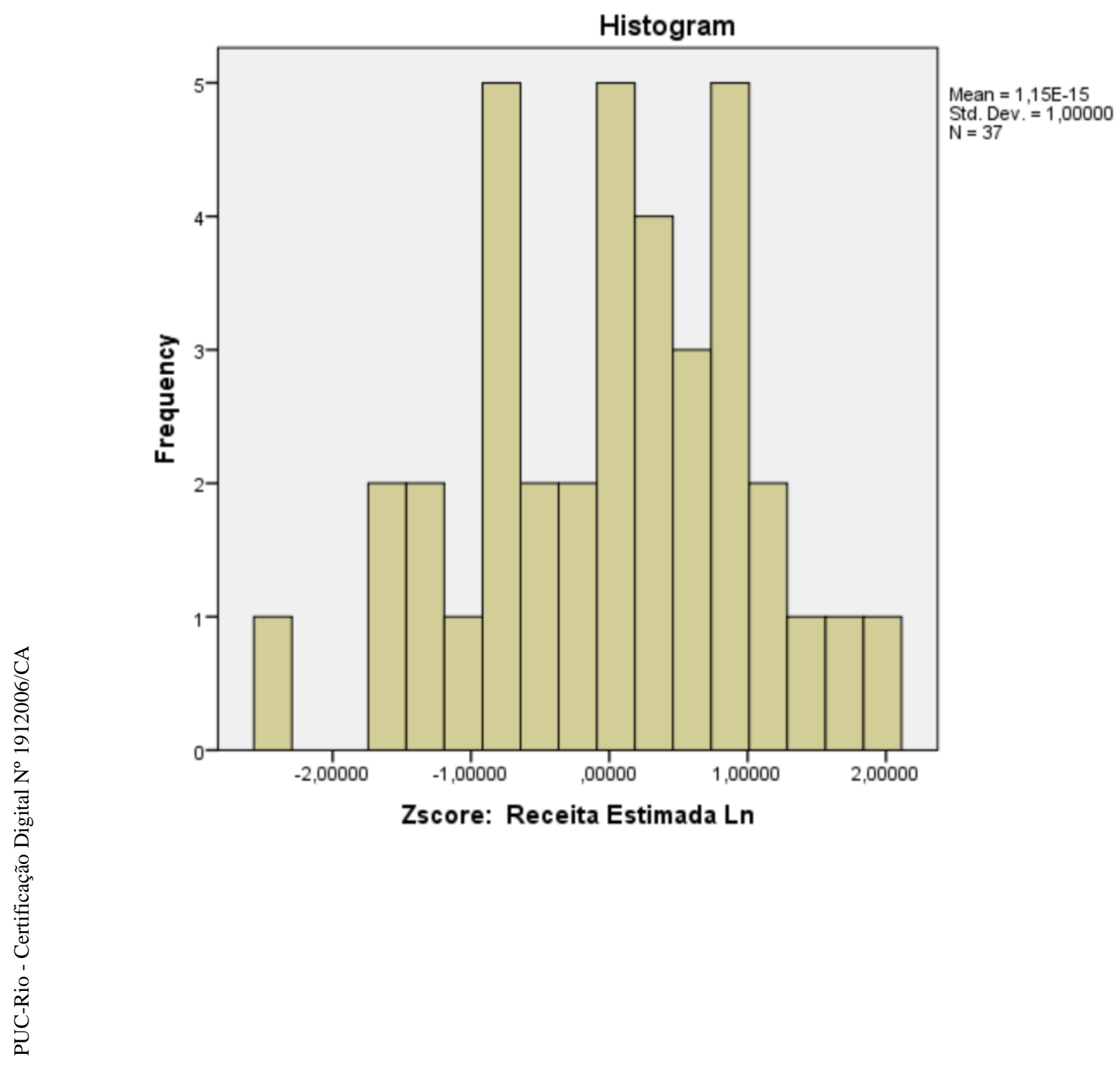




\section{Crescimento}

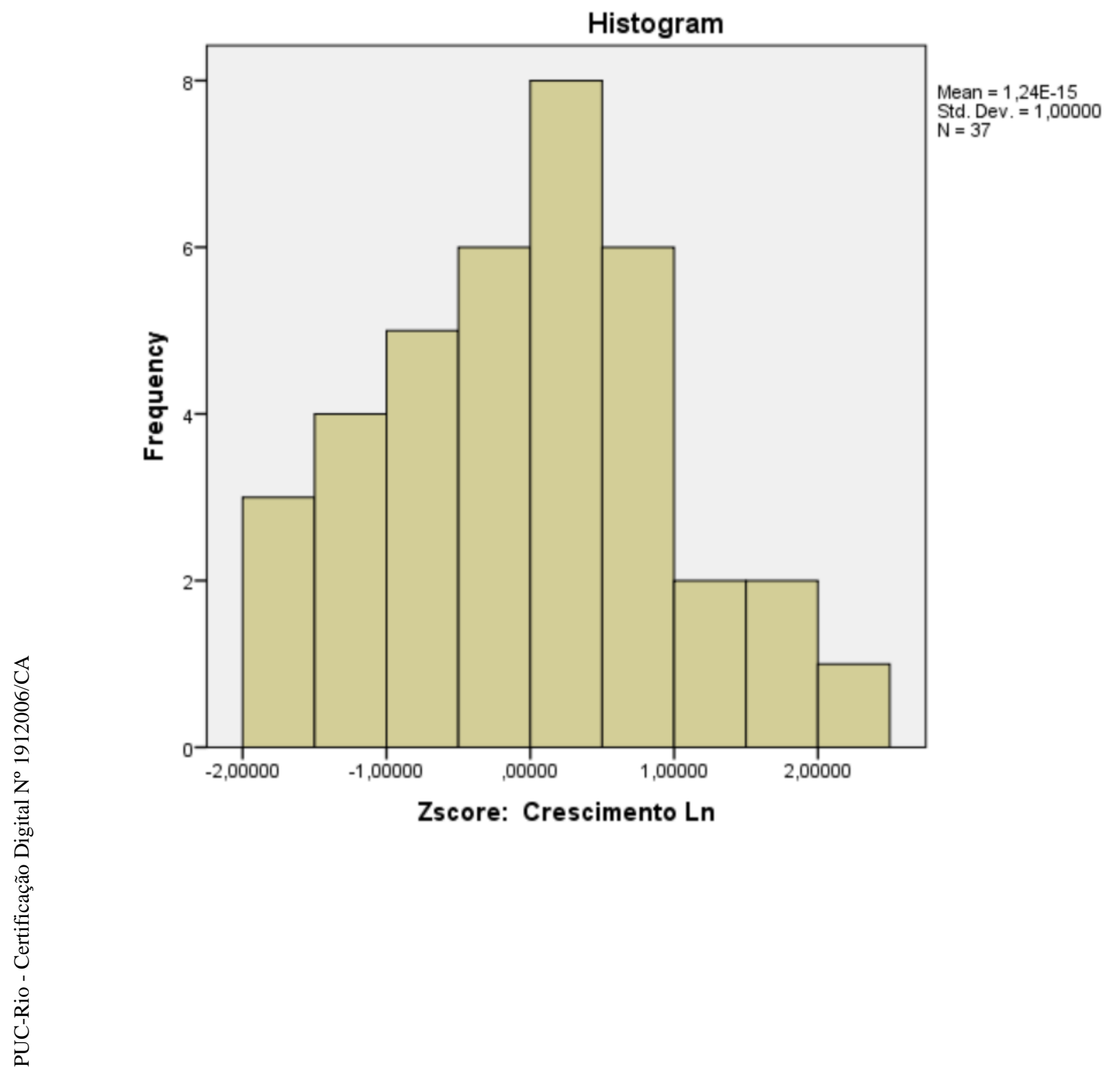




\section{Anexo III - Normal Q-Q Plot por variável}

\section{Preço}

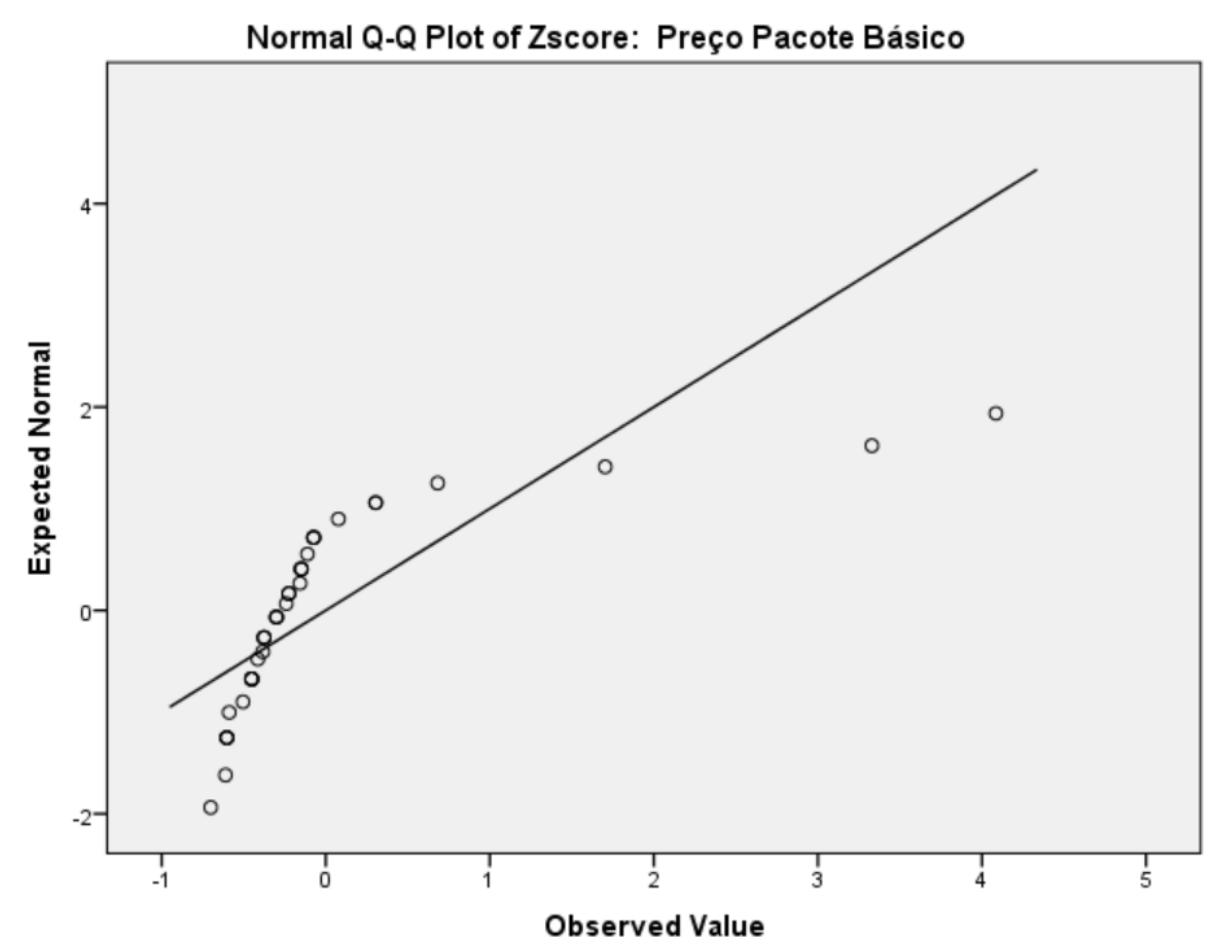

Amplitude da Oferta

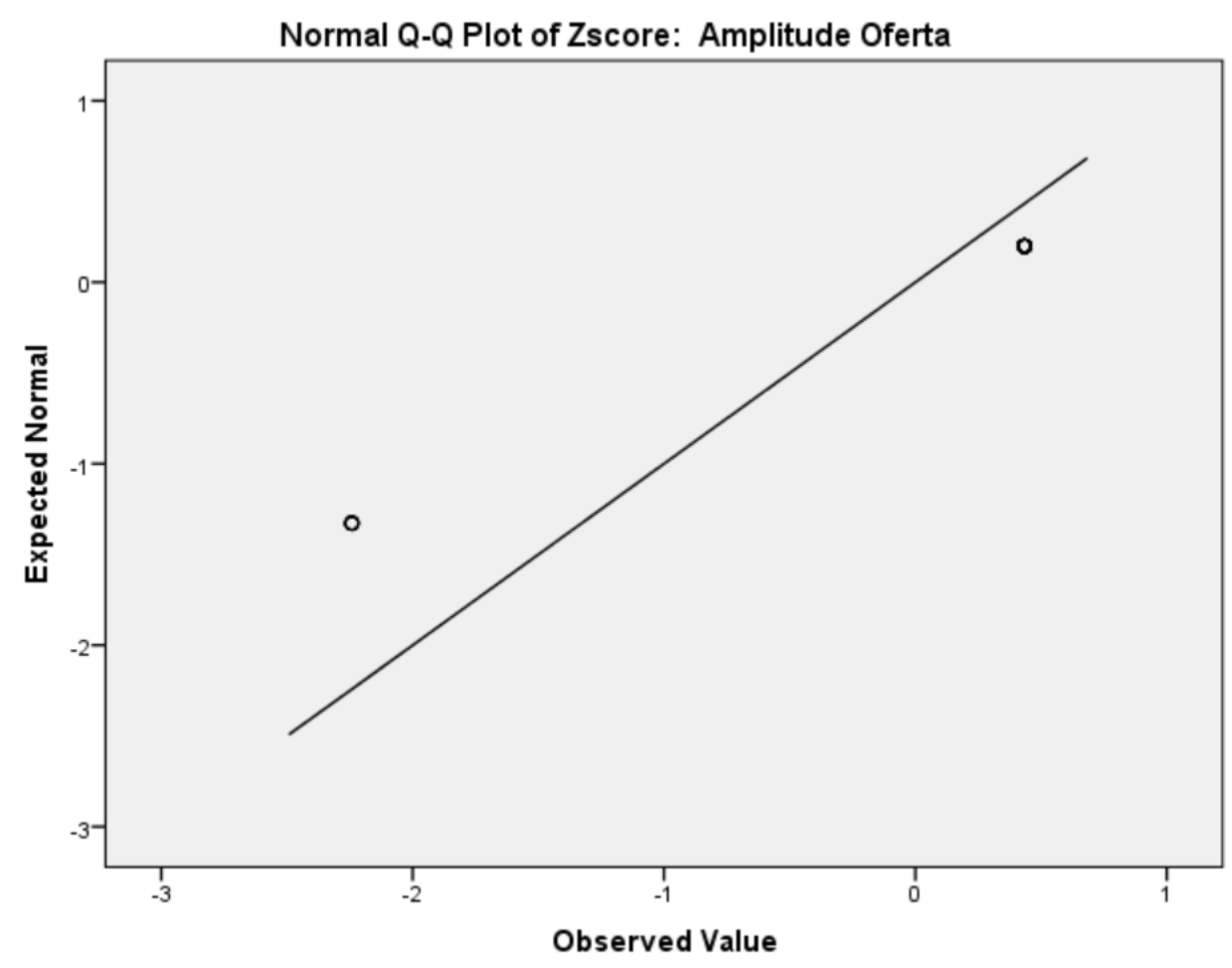




\section{Diversificação de Setor}

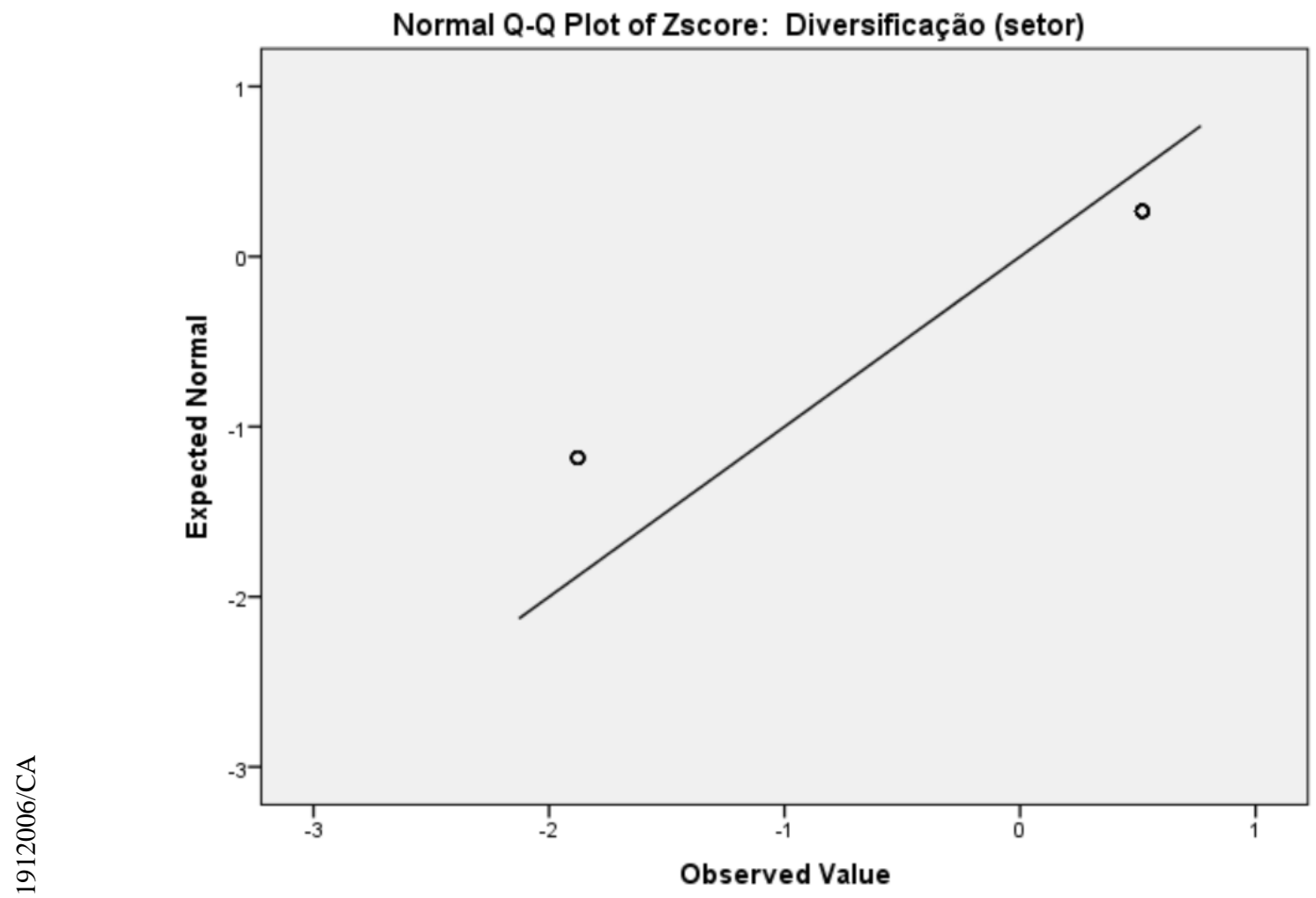

Diversificação do Modelo

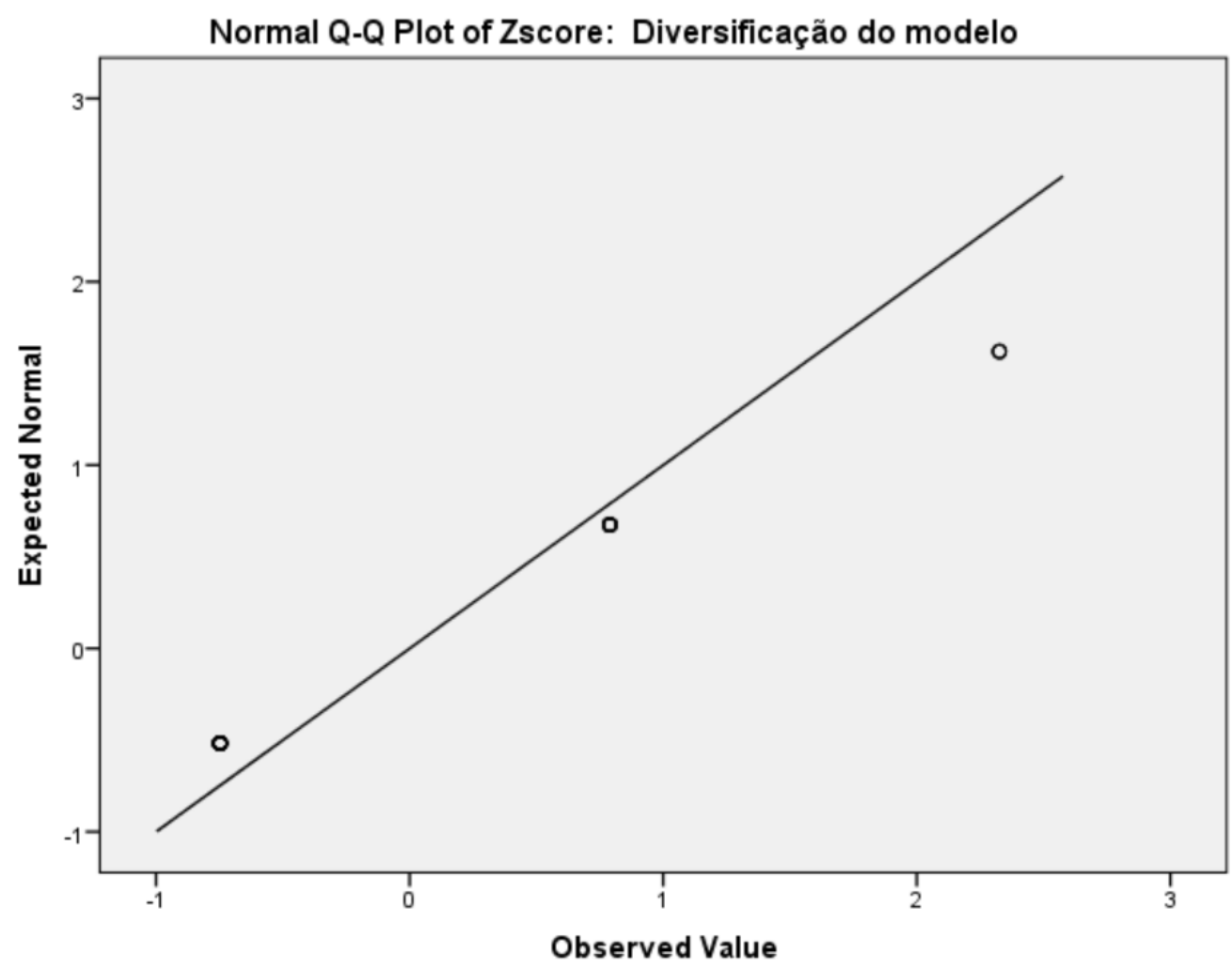




\section{Marca}

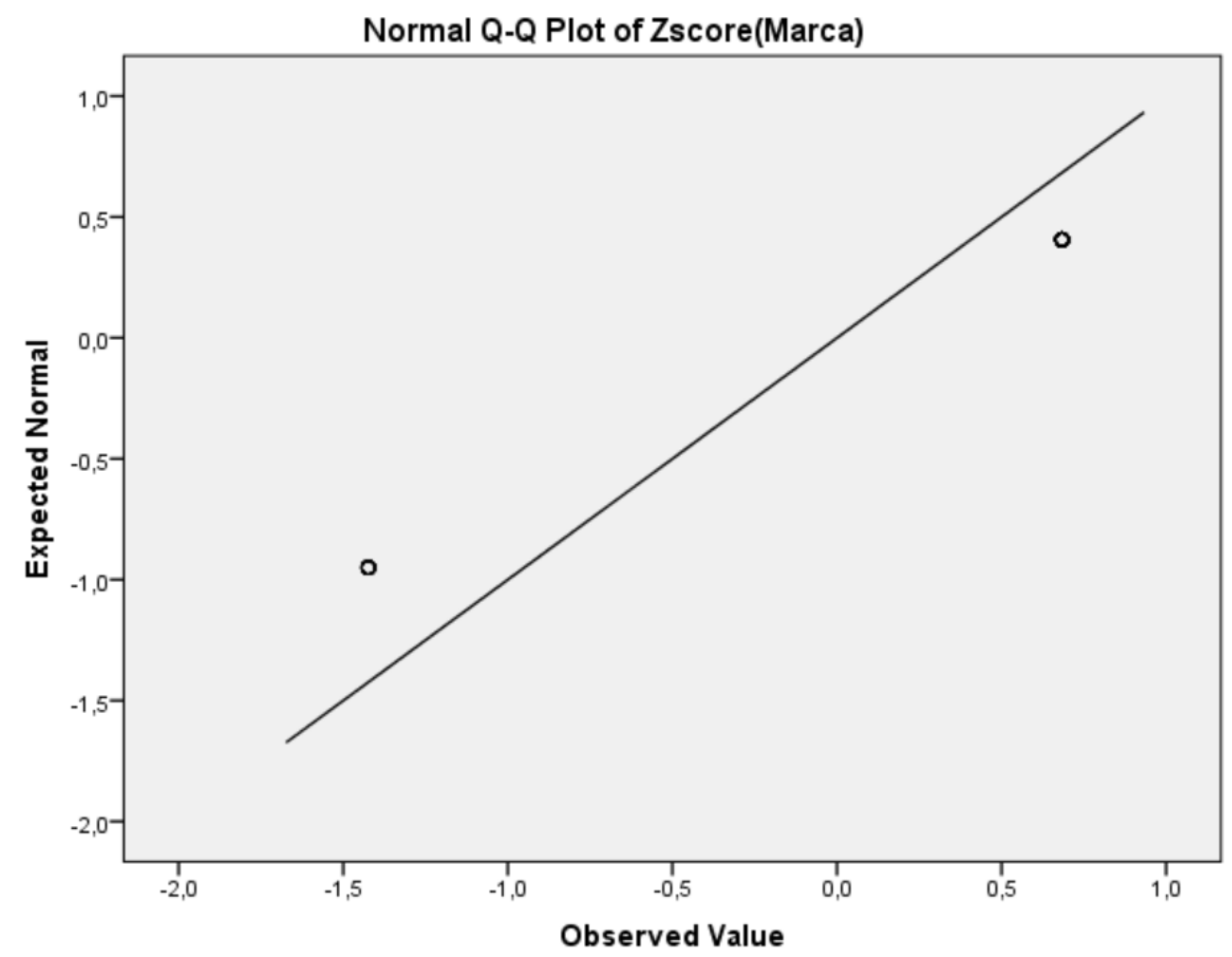

\section{Geografia}

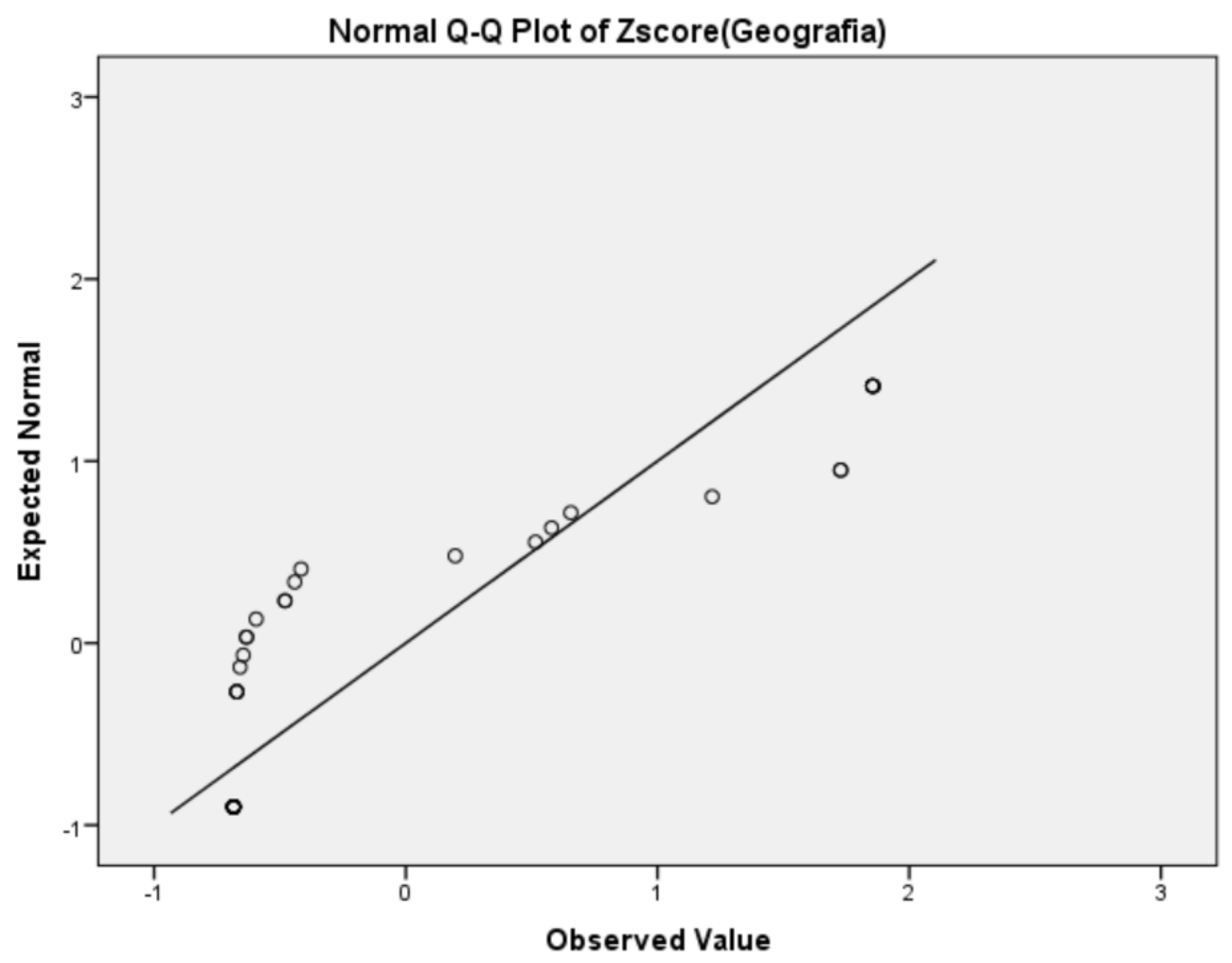




\section{Trial}

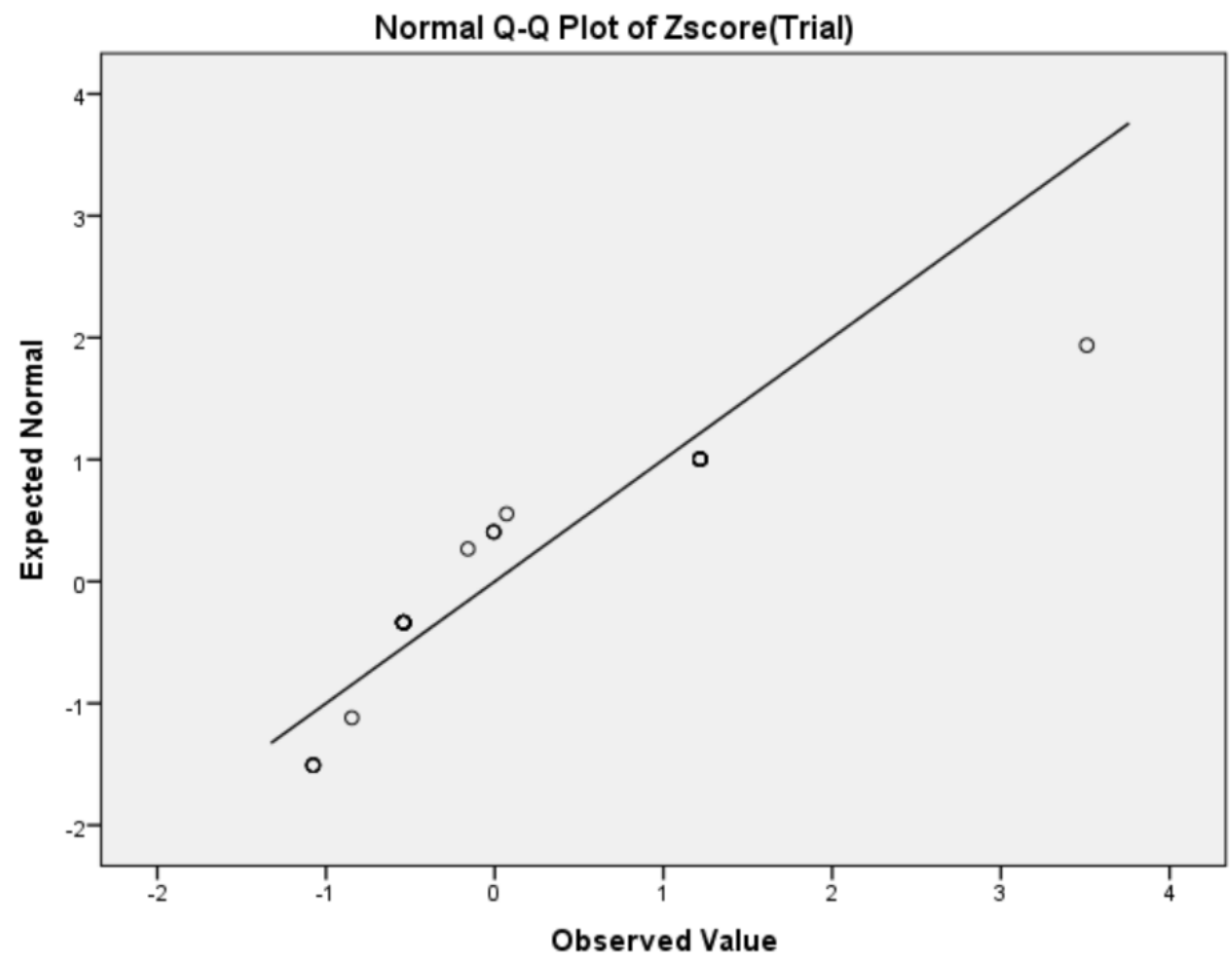

\section{Base}

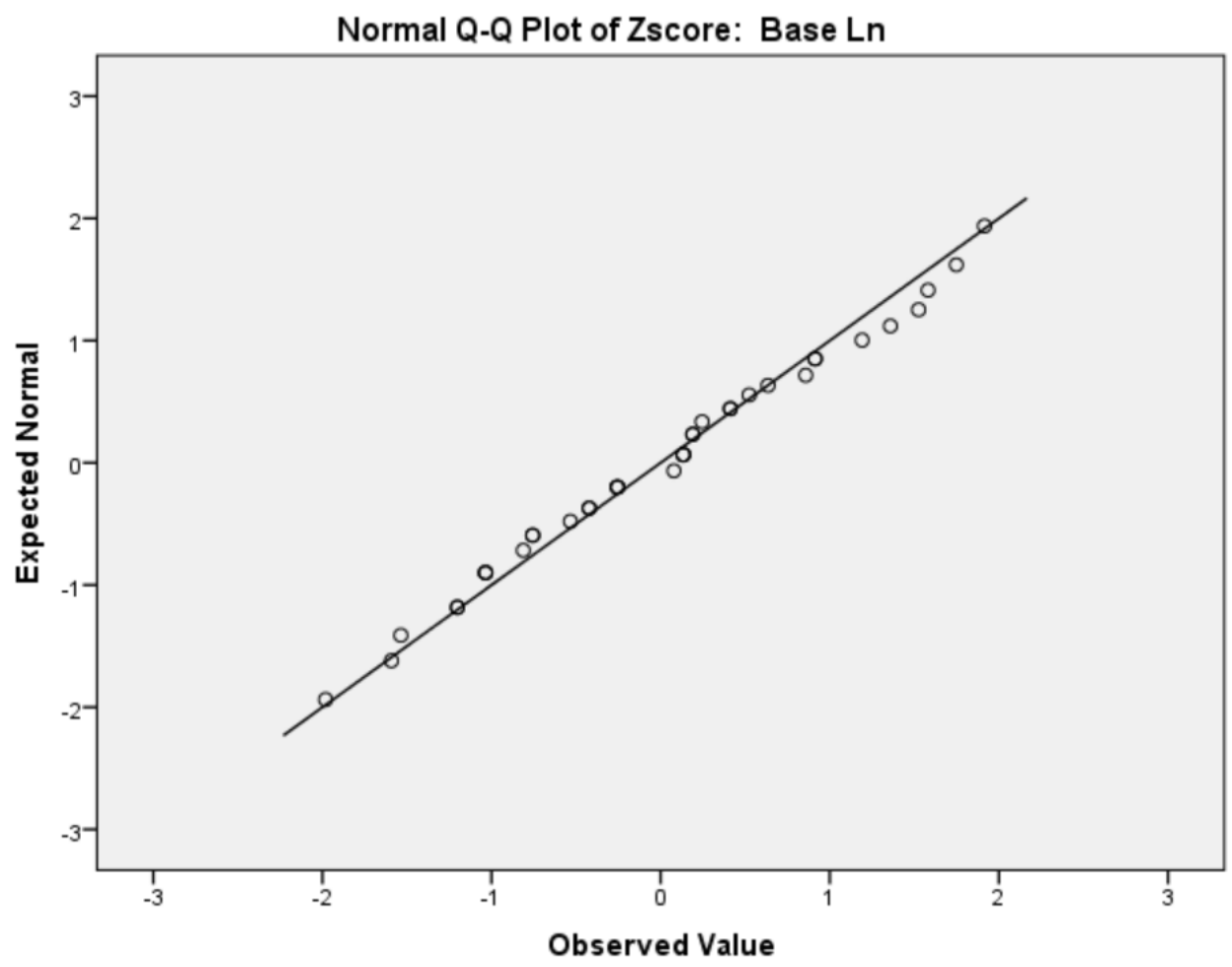




\section{Receita Estimada}

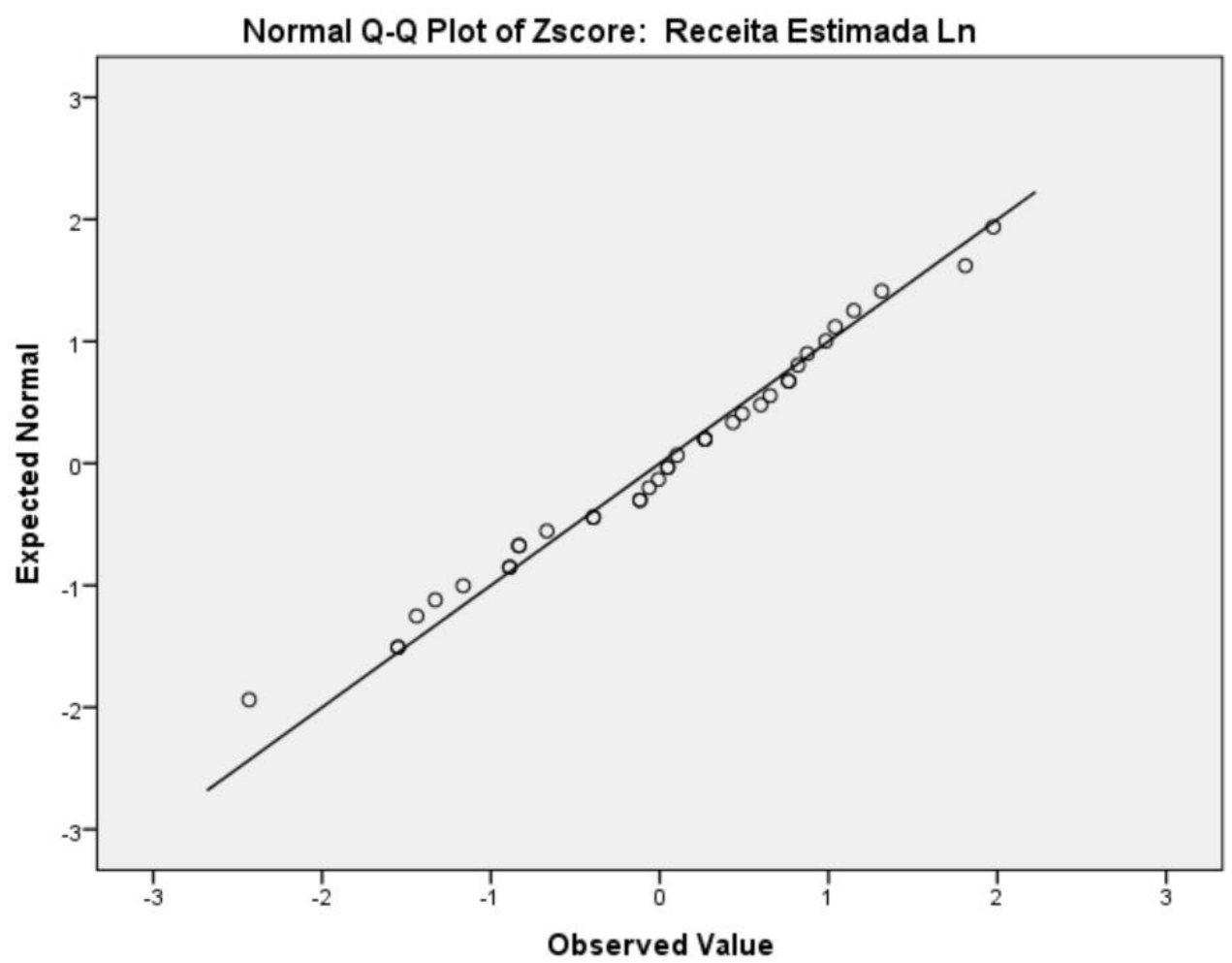

\section{Crescimento}

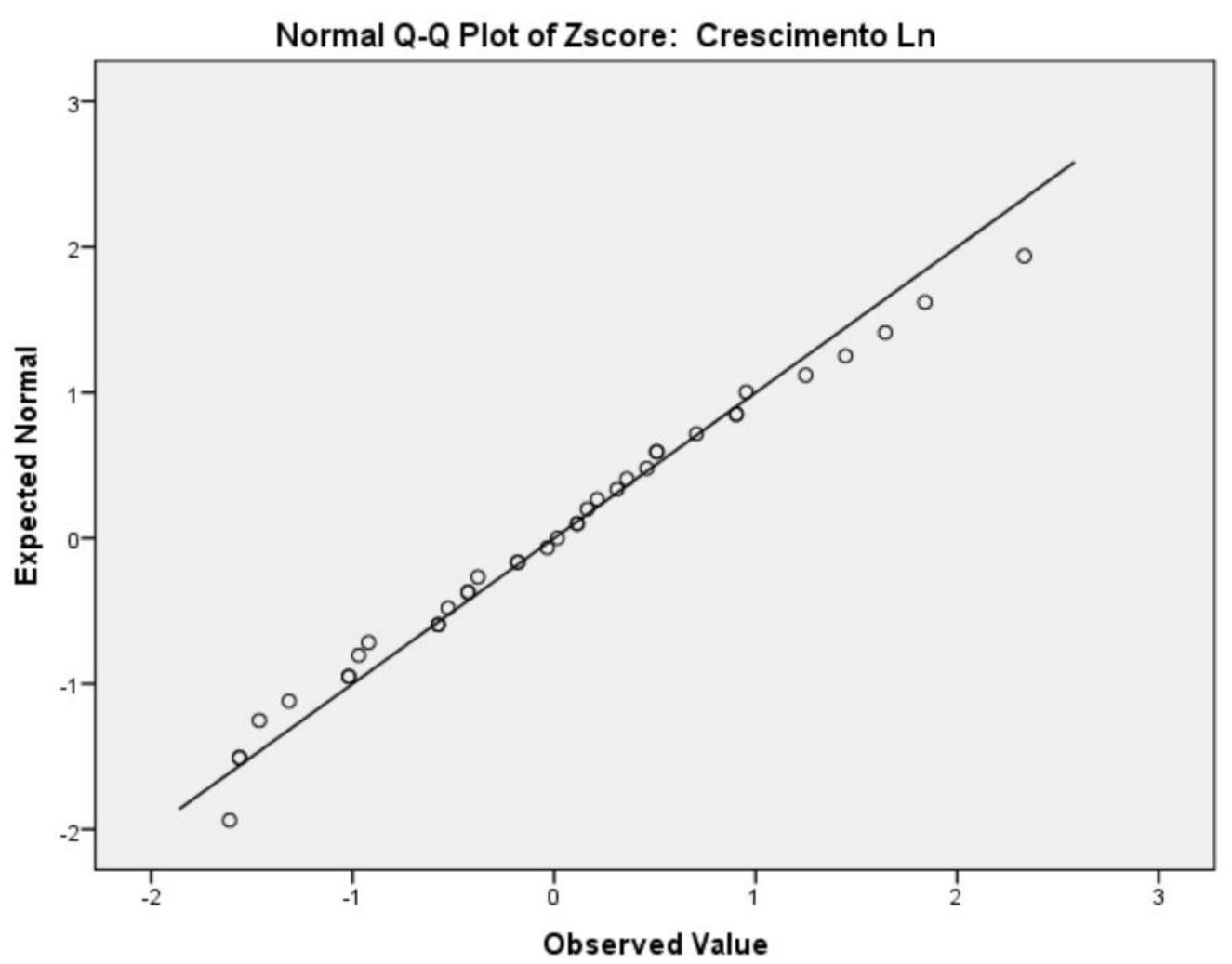

